\title{
UICN
}

\section{Directrices para la aplicación de las Categorías y Criterios de la Lista Roja de Ecosistemas de UICN}

Editado por Lucie M. Bland, David A. Keith, Rebecca M. Miller, Nicholas J. Murray y Jon Paul Rodríguez

Versión 1.0
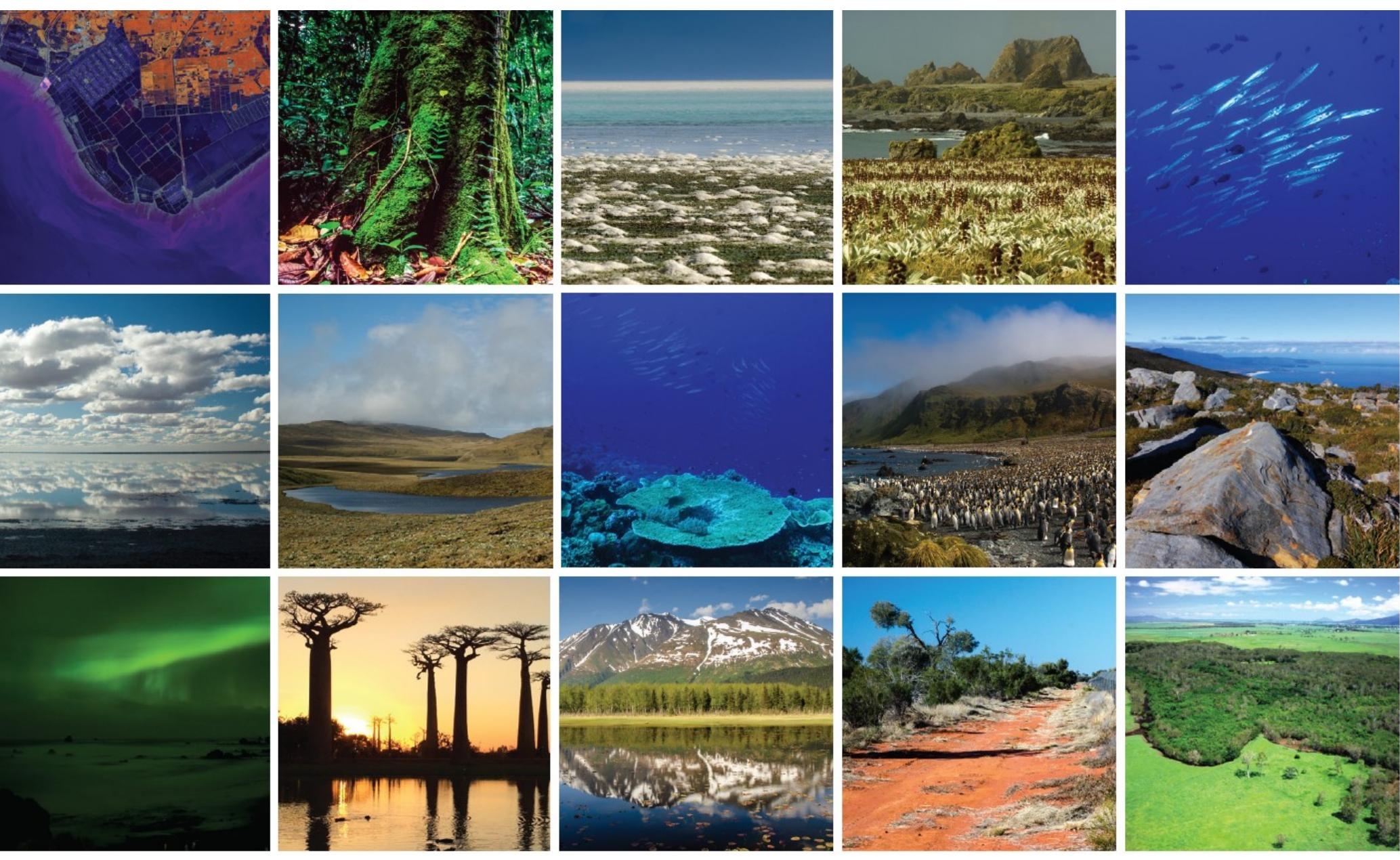

UNION INTERNACIONAL PARA LA CONSERVACIÓN DE LA NATURALEZA 
La designación de las entidades geográficas en este libro, y la presentación del material, no implican la expresión de opinión alguna por parte de UICN concerniente al estado legal de cualquier país, territorio, o área, o de sus autoridades, o concerniente a la delimitación de sus fronteras o bordes.

Las opiniones expresadas en esta publicación no reflejan necesariamente las de UICN.

Publicado por: UICN, Gland, Suiza

Derechos de autor: @ 2016 UICN, Unión Internacional para la Conservación de la Naturaleza

Las Directrices para la aplicación de las Categorías y Criterios de la Lista Roja de Ecosistemas de UICN es una publicación de acceso abierto bajo una licencia de Reconocimiento de Bien Común Creativo -No comercial-No Derivado 4.0 Internacional (CC BY-NC-ND 4.0).

La reproducción de esta publicación para usos educacionales u otro tipo no comercial está autorizada sin el permiso previo y por escrito del titular de los derechos de autor siempre y cuando la fuente bibliográfica sea reconocida.

Se prohíbe la reproducción de esta publicación para su venta u otros propósitos comerciales sin el permiso previo y por escrito del titular de los derechos de autor.

Cita: $\quad$ Bland, L.M., Keith, D.A., Miller, R.M., Murray, N.J. and Rodríguez, J.P. (eds.) (2016). Directrices para la aplicación de las Categorías y Criterios de la Lista Roja de Ecosistemas de UICN, Versión 1.0. Gland, Suiza: UICN. ix + 96pp.

ISBN:

978-2-8317-1769-2

DOI:

https://dx.doi.org/10.2305/IUCN.CH.2016.RLE.1.es

Fotos de portada: $\quad$ (c) R Ferrari Legorreta, (c) RM Miller, ( ) NJ Murray

Traducción: Ingrid Zager

Revisión traducción: Irene Zager

Todas las fotografías utilizadas en esta publicación son propiedad del titular de los derechos de autor. Las fotografías no deben ser reproducidas o utilizadas en otros contextos sin el permiso por escrito del titular de los derechos de autor.

Disponible desde: $\quad$ UICN (Unión Internacional para la Conservación de la Naturaleza)

Programa Global de Gestión de Ecosistemas

Comisión de Gestión de Ecosistemas

Rue Mauverney 28

1196 Gland

Suiza

Tel +41229990000

Fax +41229990002

www.iucn.org/publications

Estas directrices también se encuentran disponibles en: https://portals.iucn.org/library/node/45794 y en el sitio web de la Lista Roja de Ecosistemas de UICN (www.iucnrle.org). Las directrices son concebidas como un "documento viviente" y serán actualizadas periódicamente. Por favor envíe sus comentarios y sugerencias a http://iucnrle.org/work-with-us/contact-us/.

Numerosos expertos de todo el mundo participaron en el desarrollo de estas directrices. La lista completa de los contribuyentes se encuentra en el Apéndice 1. 


\section{Tabla de Contenido}

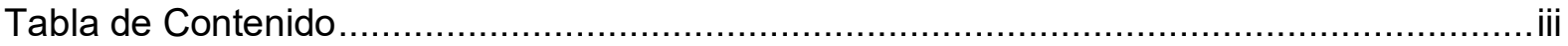

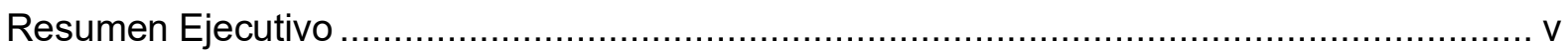

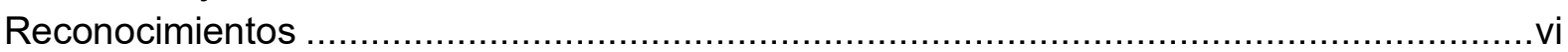

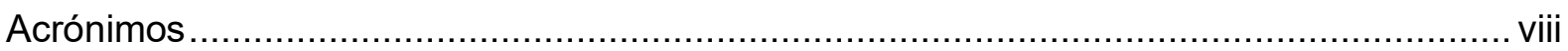

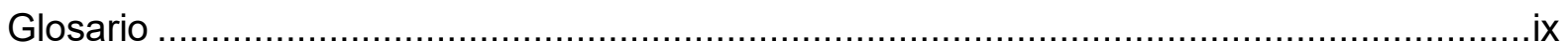

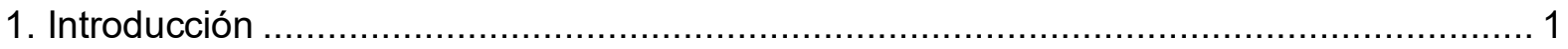

1.1 Objetivos de la Lista Roja de Ecosistemas de UICN .......................................... 1

1.2 Desarrollo de la Lista Roja de Ecosistemas de UICN ................................................. 2

1.3 Gobernanza de la Lista Roja de Ecosistemas de UICN ............................................ 3

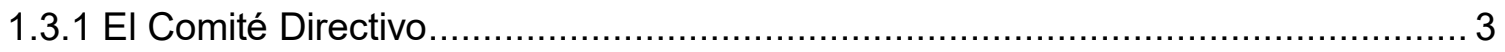

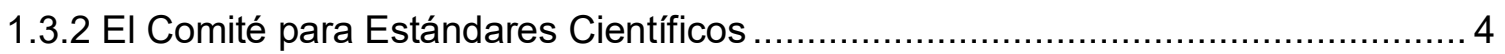

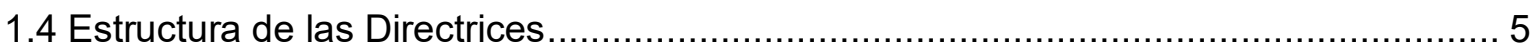

2. Categorías de la Lista Roja de Ecosistemas de UICN .......................................... 6

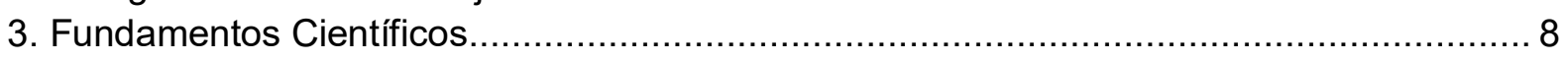

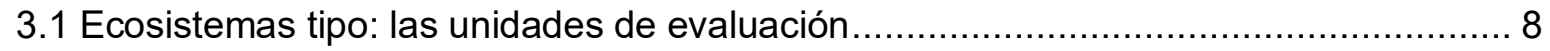

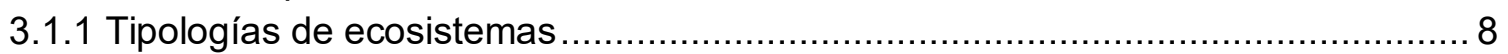

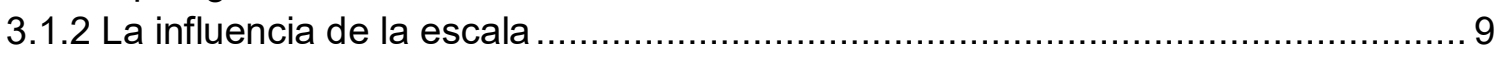

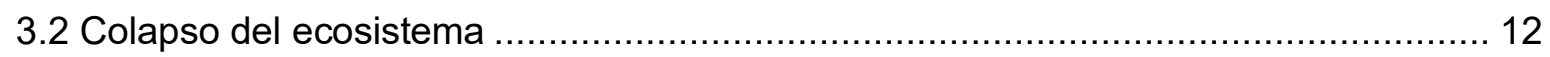

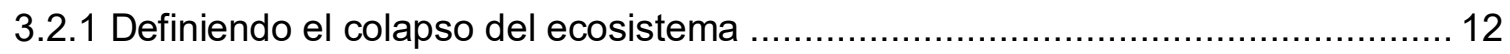

3.2.2 Incertidumbres en los puntos finales para la evaluación de riesgo ...................... 15

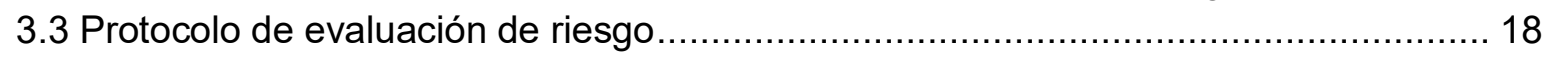

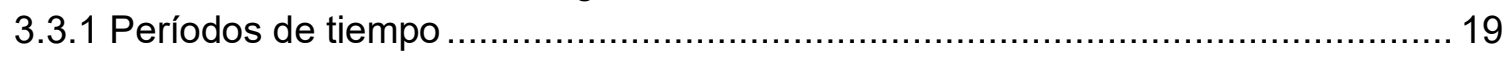

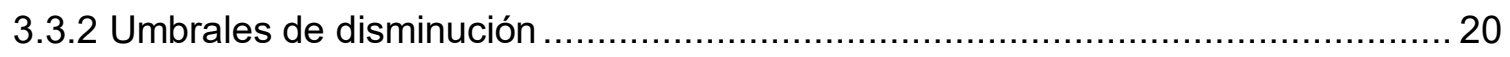

3.3.3 Estándares de evidencia y el tratamiento de la incertidumbre ............................. 21

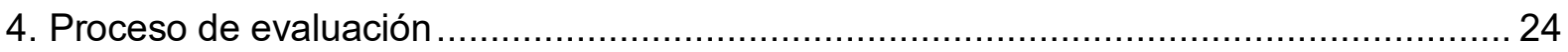

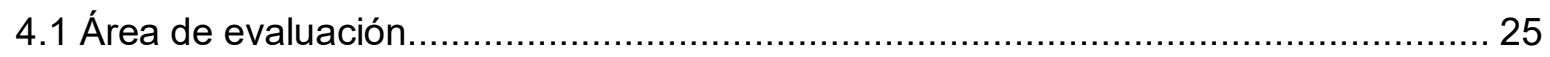

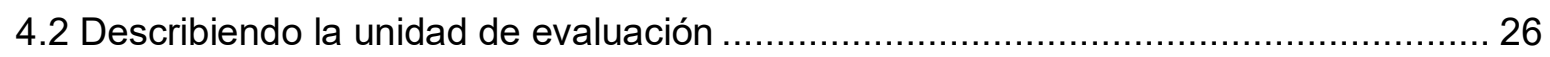

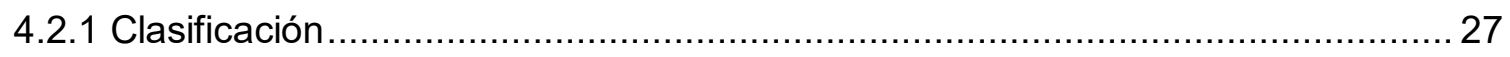

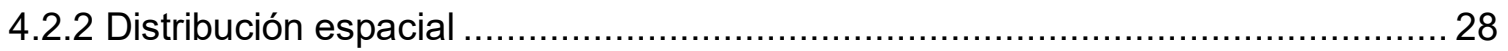

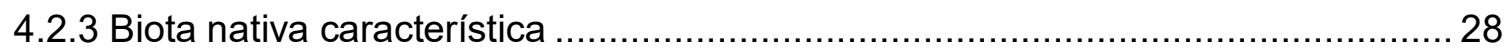

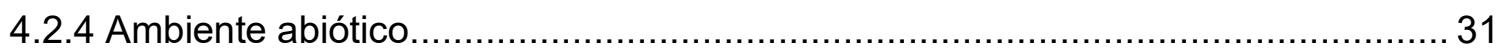

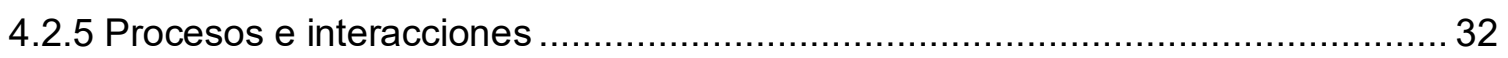

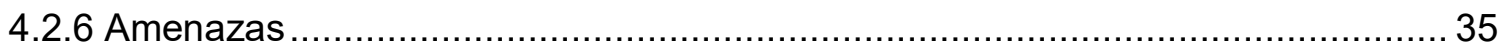

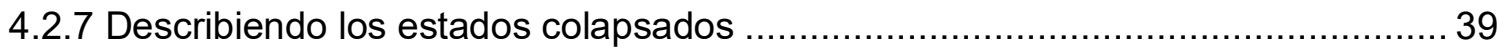

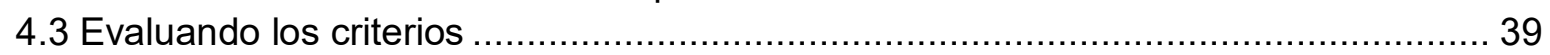

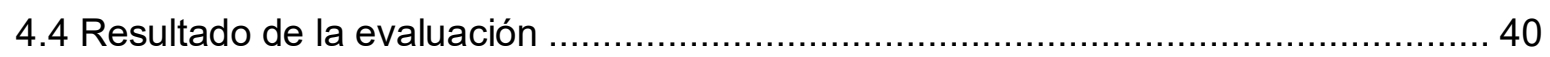

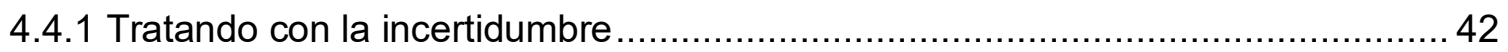

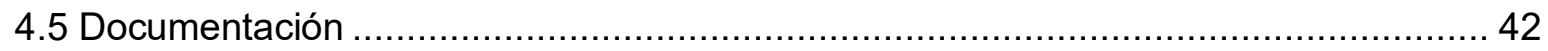

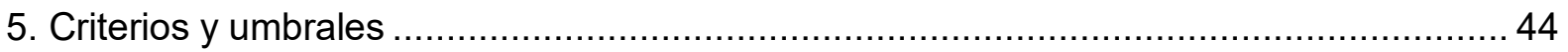

5.1 Criterio A. Disminución en la distribución geográfica ............................................. 45

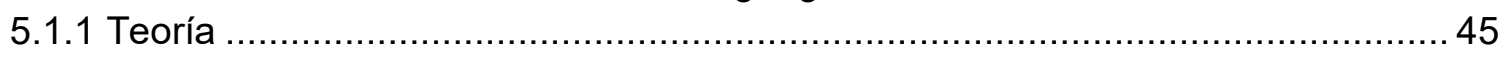

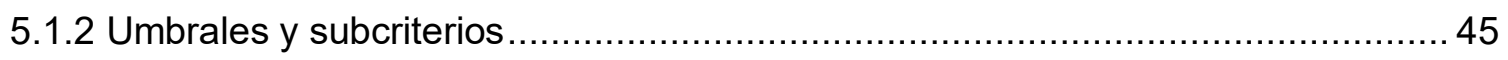




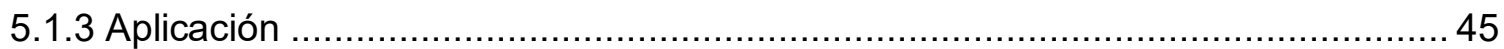

5.2 Criterio B. Distribución geográfica restringida .............................................. 51

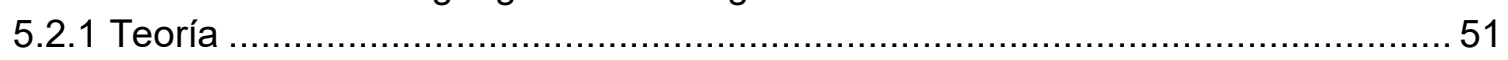

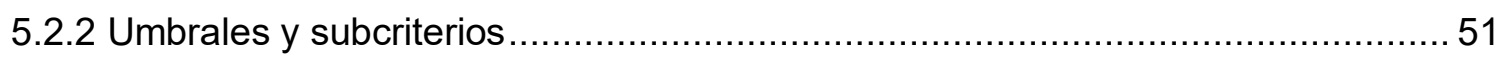

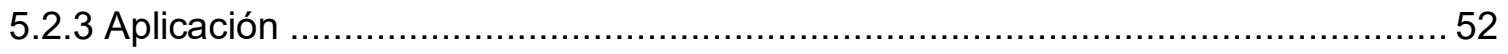

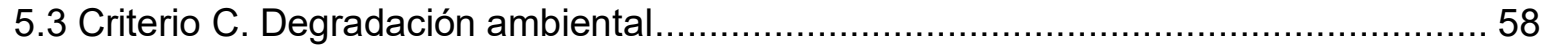

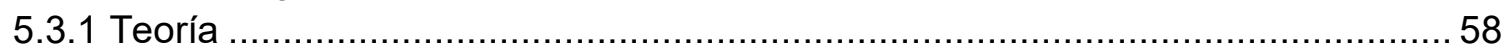

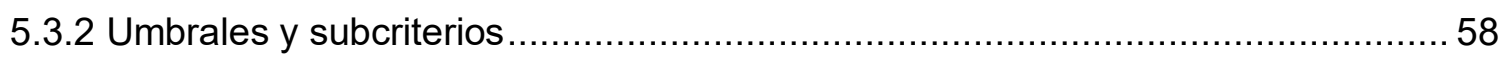

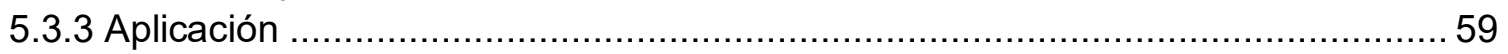

5.4 Criterio D. Interrupción de los procesos e interacciones bióticas ................................ 66

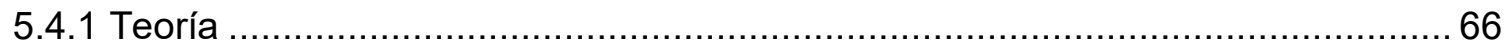

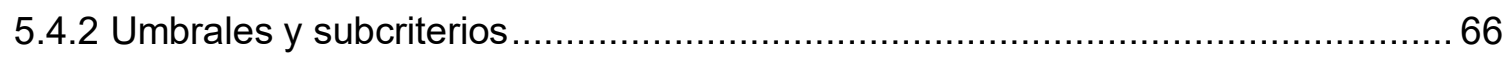

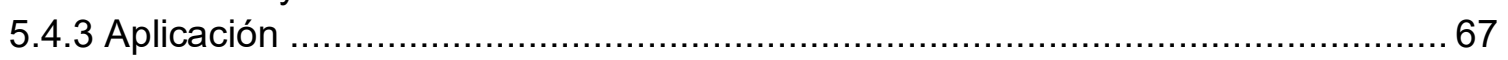

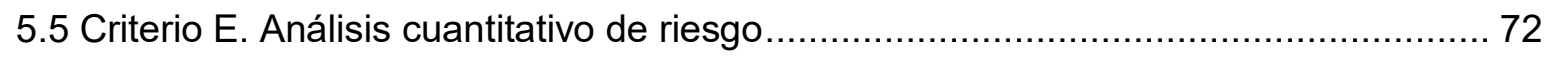

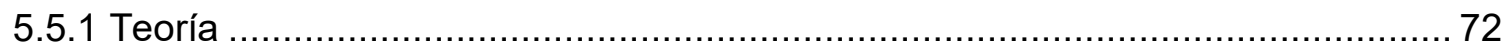

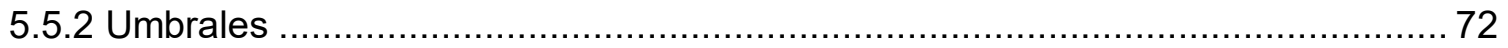

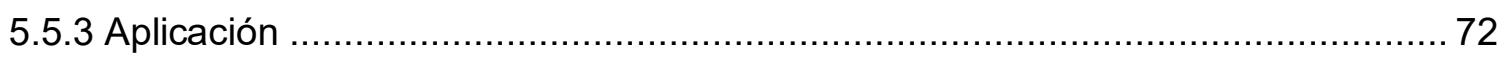

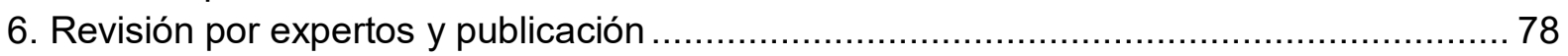

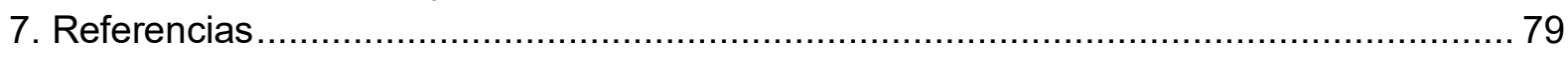

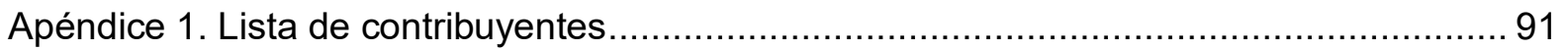

Apéndice 2. Criterios de la Lista Roja de Ecosistemas de UICN, Versión 2.1 ....................93

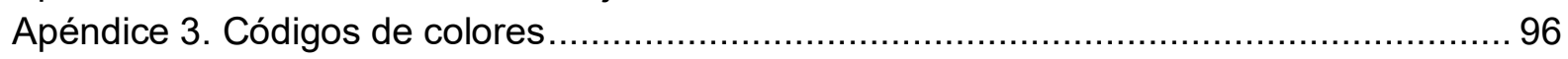




\section{Resumen Ejecutivo}

La Lista Roja de Ecosistemas de UICN es un nuevo marco global para monitorear el estatus de los ecosistemas. Es parte de la creciente caja de herramientas para la evaluación de riesgos para la biodiversidad y su objetivo es apoyar la conservación, el uso de recursos, y las decisiones de gestión mediante la identificación de los ecosistemas en mayor riesgo de pérdida de biodiversidad. Al enfocarse en un nivel de organización biológica por encima de las especies, la Lista Roja de Ecosistemas de UICN complementa a la Lista Roja de Especies Amenazadas de UICN ${ }^{\mathrm{TM}}$. Las Categorías y Criterios de la Lista Roja de Ecosistemas de UICN están diseñados para ser: ampliamente aplicables a través de los ecosistemas tipo y áreas geográficas; transparentes y científicamente rigurosos; y de fácil comprensión por los tomadores de decisiones y el público.

\section{Las Categorías y Criterios de la Lista Roja Ecosistemas de UICN}

La base de la Lista Roja de Ecosistemas de UICN son las Categorías y Criterios de la Lista Roja Ecosistemas de UICN, un conjunto de ocho categorías y cinco criterios que proporcionan un método consistente para la evaluación del riesgo de colapso de un ecosistema. Las ocho categorías de riesgo de ecosistemas son: Colapsado (CO), En Peligro Crítico (CR), En Peligro (EN), Vulnerable (VU), Casi Amenazado (NT), Preocupación Menor (LC), Datos Insuficientes (DD), y No Evaluado (NE).

El protocolo de la Lista Roja de Ecosistemas de UICN comprende cinco criterios basados en reglas (A-E) para asignar los ecosistemas a una categoría de riesgo. Dos de estos criterios evalúan los síntomas espaciales del colapso del ecosistema: disminución de la distribución (A) y distribución restringida (B). Dos criterios evalúan los síntomas funcionales del colapso del ecosistema: degradación ambiental (C) e interrupción de los procesos e interacciones bióticos (D). Múltiples amenazas y síntomas pueden ser integrados en un modelo de dinámica del ecosistema para producir estimados cuantitativos del riesgo de colapso $(E)$. Las directrices incluyen secciones detalladas para apoyar la aplicación de cada uno de los cinco criterios, incluyendo información sobre la teoría relevante, los umbrales y ejemplos.

\section{Estándares de aplicación y documentación}

Las directrices ayudan a la correcta aplicación de las Categorías y Criterios de la Lista Roja de Ecosistemas de UICN proporcionando información sobre el desarrollo del protocolo y una descripción detallada de los fundamentos científicos que soportan las categorías y criterios. Ellas definen las unidades de evaluación (ecosistemas tipo); definen el colapso del ecosistema; discuten la influencia de la escala; y explican la estructura del protocolo de evaluación de riesgo. Las directrices también proporcionan definiciones detalladas sobre los términos usados en las Categorías y Criterios de la Lista Roja de Ecosistemas de UICN.

Las directrices tienen como objetivo apoyar la aplicación práctica de las Categorías y Criterios de la Lista Roja de Ecosistemas de UICN desde áreas de evaluación sub-nacionales hasta globales. Por lo tanto, las directrices esbozan los pasos necesarios para: definir el área de evaluación; definir la unidad bajo evaluación; aplicar los criterios; y preparar la documentación de la evaluación para la revisión por expertos y su publicación. Todos los pasos son ilustrados con ejemplos que abarcan un amplio rango de ecosistemas tipo, localidades geográficas y niveles de disponibilidad de datos.

\section{El futuro de la Lista Roja de Ecosistemas de UICN}

El programa de la Lista Roja de Ecosistemas de UICN evaluará el estatus global de los ecosistemas terrestres, marinos, dulceacuícolas y subterráneos del mundo. Adicionalmente, el programa tiene como objetivo apoyar el desarrollo de las Listas Rojas nacionales y regionales para informar en la planificación de la conservación y el desarrollo sustentable. Para más información sobre la Lista Roja de Ecosistemas de UICN, por favor consulte el sitio web: www.iucnrle.org. 


\section{Reconocimientos}

UICN reconoce y agradece la dedicación y el esfuerzo de los cientos de científicos y profesionales que han contribuido al desarrollo científico y puesta a prueba de las Categorías y Criterios de la Lista Roja de Ecosistemas de UICN desde el año 2008. En conjunto, estos expertos han participado en cerca de 50 reuniones y talleres en más de 20 países alrededor del mundo, así como también han presentado comentarios y sugerencias de forma remota. Estamos en deuda con todos ellos. Los contribuyentes clave de este proceso se encuentran listados en el Apéndice 1.

El proceso de desarrollo de los criterios de la Lista Roja de Ecosistemas fue impulsado con la Resolución 4.020 de Cuarto Congreso Mundial de la Naturaleza de UICN en el 2008, y consolidado con la Resolución 5.055 adoptada por el Quinto Congreso Mundial de la Naturaleza de UICN en el 2012. Este proceso culminó con la adopción de las Categorías y Criterios de la Lista Roja de Ecosistemas de UICN por el Consejo de UICN en mayo de 2014. Más información sobre el desarrollo de la Lista Roja de Ecosistemas de UICN se encuentra disponible en la Sección 1.2.

El trabajo en la Lista Roja de Ecosistemas de UICN ha sido posible gracias al generoso apoyo de: la Agencia Francesa de Desarrollo; el Consejo de Investigación de Australia; Conoco-Philips; la Embajada de Holanda en Brasil; la Comisión Europea; la Fundación Gordon and Betty Moore; el Comité Nacional de Holanda de UICN; la Secretaría de UICN; la Comisión de Gestión de Ecosistemas de UICN; la Fundación MAVA; la Oficina de Medio Ambiente y Patrimonio de Nueva Gales del Sur; y el Departamento del Medio Ambiente, Agua y Recursos Naturales del Sur de Australia. 


\section{Lista Roja de Ecosistemas de UICN}

Sitio web www.iucnrle.org

Comité Directivo

Jon Paul Rodríguez, Presidente, Comité Directivo

David A. Keith, Presidente, Comité para Estándares Científicos

Edmund G. Barrow

Thomas M. Brooks

Rebecca M. Miller

Emily Nicholson

María A. (Tina) Oliveira-Miranda

Piet Wiet

Equipo

Cambridge, UK Rebecca M. Miller, Coordinador superior del Programa Lista Roja de Ecosistemas

Caracas

María A. (Tina) Oliveira-Miranda, Responsable Científico

Gland

Kaia Boe, Responsable del Programa de Ciencias Sociales y Ecosistemas

Nairobi

Edmund G. Barrow, Director, Programa Global de Gestión de Ecosistemas

\section{Comisión de Gestión de Ecosistemas de UICN (2013-2016)}

Sitio web $\quad$ www.iucn.org/about/union/commissions/cem/

Comité Directivo

Piet Wit, Presidente

Dominique Noome, Asistente a la Presidencia

Angela Andrade, Presidente Adjunto

Birguy Lamizana, Vicepresidente Tierras Áridas y Creación de Capacidad

Said Damhoureyeh, Vice Presidente

Kelvin Passfield, Vicepresidente Ecosistemas Marinos y Costeros

Steve Edwards, Vicepresidente Resiliencia y Aprendizaje Social

Grupo Temático de la Lista Roja de Ecosistemas

Jon Paul Rodríguez, Líder

David A. Keith, Co-líder

\section{Acerca de UICN}

UICN es una Unión de miembros compuesta únicamente tanto por organizaciones gubernamentales como por la sociedad civil. Proporciona a las organizaciones públicas, privadas y no gubernamentales el conocimiento y las herramientas que permitan en conjunto el progreso humano, el desarrollo económico y la conservación de la naturaleza.

Creada en 1948, la UICN es ahora la más grande y diversa red ambiental del mundo, aprovechando los conocimientos, recursos y alcance de 1.300 organizaciones miembros y unos 15.000 expertos.

Es un proveedor líder de datos, evaluaciones y análisis relacionados con la conservación. Su amplia membresía le permite a UICN llenar el papel de incubadora y repositorio de confianza de las mejores prácticas, herramientas y estándares internacionales.

UICN provee un espacio neutral en el cual diversos actores, incluyendo gobiernos, ONG, científicos, empresas, comunidades locales, organizaciones de pueblos indígenas y otros pueden trabajar en conjunto para forjar e implementar soluciones a los retos ambientales y lograr un desarrollo sustentable.

Trabajando con muchos socios y simpatizantes, UICN implementa un amplio y diverso portafolio de proyectos de conservación en todo el mundo. Combinando los últimos avances científicos con los conocimientos tradicionales de las comunidades locales, estos proyectos trabajan para revertir la pérdida de hábitat, restaurar los ecosistemas y mejorar el bienestar de las personas. www.iucn.org 


\section{Acrónimos}

\begin{tabular}{|ll|}
\hline Acrónimo & Definición \\
\hline AOO & Área de ocupación \\
\hline ARD & Tasa de disminución absoluta \\
\hline CGE & Comisión de Gestión de Ecosistemas de UICN \\
\hline CO & Colapsado \\
\hline CR & En Peligro Crítico \\
\hline DD & Datos Insuficientes \\
\hline EN & En Peligro \\
\hline EOO & Extensión de la presencia \\
\hline GEMP & Programa Global de Gestión de Ecosistemas de \\
\hline PGE & UICN \\
\hline UICN & Unión Internacional para la Conservación de la \\
\hline LC & Paturaleza \\
\hline NE & No Evaluadoción Menor \\
\hline NT & Casi Amenazado \\
\hline PRD & Tasa de disminución proporcional \\
\hline LRE & Lista Roja de Ecosistemas de UICN \\
\hline RLTS & Lista Roja de Especies Amenazadas de UICN ${ }^{\mathrm{TM}}$ \\
\hline CSE & Comisión de Supervivencia de Especies de UICN \\
\hline VU & Vulnerable \\
\hline
\end{tabular}




\section{Glosario}

\begin{tabular}{|c|c|}
\hline Término & Definición \\
\hline Área de evaluación & Define los límites de aplicación de la evaluación. \\
\hline Área de ocupación & $\begin{array}{l}\text { El área de ocupación (AOO) es una medida estandarizada del } \\
\text { área que es ocupada por un ecosistema tipo. }\end{array}$ \\
\hline Biota nativa característica & $\begin{array}{l}\text { Características biológicas que definen la identidad de un } \\
\text { ecosistema tipo y lo distinguen de otro ecosistema tipo y/o que } \\
\text { conducen la dinámica y funciones de los ecosistemas, p. ej., los } \\
\text { procesos ecológicos, los ingenieros de ecosistemas, especies } \\
\text { tróficas o estructurales dominantes, elementos de funcionalidad } \\
\text { única, las interacciones entre especies. }\end{array}$ \\
\hline Disminución continua & $\begin{array}{l}\text { Una disminución gradual o episódica en la distribución o } \\
\text { proceso ecológico que es probable que continúe en el futuro, y } \\
\text { no es trivial en magnitud y en su efecto sobre la sostenibilidad } \\
\text { de la biota nativa característica. }\end{array}$ \\
\hline colapso del ecosistema & $\begin{array}{l}\text { El colapso es una transformación de la identidad, una pérdida } \\
\text { de las características que lo definen y el reemplazo por un } \\
\text { ecosistema tipo diferente. }\end{array}$ \\
\hline Extensión de la presencia & $\begin{array}{l}\text { Extensión de la presencia (EOO) es una medida estandarizada } \\
\text { del área dentro del cual existen todas las ocurrencias de un } \\
\text { ecosistema tipo. }\end{array}$ \\
\hline Ecosistema tipo & La unidad de evaluación. \\
\hline Distribución geográfica & $\begin{array}{l}\text { La distribución geográfica de un ecosistema tipo representa } \\
\text { todas las ocurrencias espaciales de un ecosistema tipo. }\end{array}$ \\
\hline Tamaño de grano & $\begin{array}{l}\text { El tamaño de la unidad espacial (p. ej. celda de la cuadrícula, } \\
\text { segmento de polígono) usada para medir una distribución. }\end{array}$ \\
\hline Localidad & $\begin{array}{l}\text { Un área distinguible geográfica o ecológicamente en la que un } \\
\text { único evento de amenaza puede rápidamente afectar todas las } \\
\text { ocurrencias de un ecosistema tipo. }\end{array}$ \\
\hline Severidad relativa & $\begin{array}{l}\text { La magnitud estimada de degradación ambiental pasada o } \\
\text { futura o de interrupción de procesos bióticos, expresada como } \\
\text { un porcentaje relativo de un cambio lo suficientemente grande } \\
\text { para causar el colapso de un ecosistema. }\end{array}$ \\
\hline Extensión espacial & $\begin{array}{l}\text { El área total de la distribución geográfica de un ecosistema tipo } \\
\text { estimado con una métrica específica. }\end{array}$ \\
\hline Resolución temporal & $\begin{array}{l}\text { Las unidades de tiempo durante las cuales se miden las } \\
\text { tendencias. }\end{array}$ \\
\hline Escala temática & $\begin{array}{l}\text { Una medida de la similitud de características dentro y entre } \\
\text { ecosistemas tipo. Puede ser representada por los niveles de } \\
\text { clasificación jerárquica. }\end{array}$ \\
\hline Período de tiempo & $\begin{array}{l}\text { El período total dentro del cual el cambio de un ecosistema es } \\
\text { evaluado. }\end{array}$ \\
\hline
\end{tabular}




\section{Introducción}

La Lista Roja de Ecosistemas de UICN fue desarrollada para promover un marco global coherente para monitorear el estatus de los ecosistemas (Keith et al., 2015). Es parte de una creciente caja de herramientas para evaluar los riesgos a la biodiversidad y tiene como objetivo apoyar la conservación, el uso de recursos y las decisiones de gestión mediante la identificación de los ecosistemas con mayor riesgo de pérdida de biodiversidad. Al enfocarse en un nivel de organización biológica por encima de las especies, la Lista Roja de Ecosistemas de UICN complementa la Lista Roja de Especies Amenazadas de UICN ${ }^{\mathrm{TM}}$ (UICN, 2015), proporcionando en conjunto una evaluación simultánea a una escala gruesa y fina de la biodiversidad. Es más probable que un enfoque combinado logre el objetivo de resultados de conservación integrales, eficaces y representativos y mejorará la capacidad de monitorear el estatus de la biodiversidad en la Tierra

Las bases de la Lista Roja de Ecosistemas de UICN son las Categorías y Criterios de la Lista Roja de Ecosistemas de UICN (Apéndice 2), un conjunto de cinco criterios y umbrales asociados que proporcionan un método repetible y consistente a nivel mundial para la clasificación del riesgo de colapso de los ecosistemas (Rodríguez et al., 2015; Keith et al., 2013). Garantizar evaluaciones precisas y comparables para todos los ecosistemas tipo incluidos en la Lista Roja de Ecosistemas de UICN es un desafío clave para el programa de la Lista Roja de Ecosistemas de UICN. Estas directrices proporcionan la información necesaria para responder a este desafío.

Las directrices brindan apoyo a los usuarios para aplicar correctamente las Categorías y Criterios de la Lista Roja de Ecosistemas de UICN, acompañando al evaluador a través de todo el proceso de evaluación de la Lista Roja de Ecosistemas de UICN, desde la comprensión de los fundamentos científicos hasta la culminación de las evaluaciones para su publicación. Proporcionan información sobre el desarrollo del protocolo (Sección 1) y una descripción detallada de los fundamentos científicos que soportan el desarrollo de las categorías y criterios (Secciones 2 y 3). Las directrices describen los pasos requeridos para la definición del área y las unidades de evaluación, y los procesos clave del ecosistema que permitirán la aplicación precisa de los cinco criterios (Sección 4). Adicionalmente, las directrices contienen secciones completas sobre cada uno de los cinco criterios, incluyendo información relevante sobre la teoría, los umbrales y las aplicaciones de cada criterio (Sección 5). Finalmente, se describe el proceso de preparación de las evaluaciones para su revisión por expertos y su publicación (Sección 6).

\subsection{Objetivos de la Lista Roja de Ecosistemas de UICN}

El objetivo principal de la Lista Roja de Ecosistemas de UICN (LRE) es el apoyar la conservación en el uso de recursos y toma de decisiones mediante la identificación de los ecosistemas que se encuentran en mayor riesgo de pérdida de biodiversidad (Keith et al., 2013; Keith et al., 2015). Mediante la evaluación relativa de los riesgos de pérdida de biodiversidad a nivel del ecosistema, la LRE considera procesos ecológicos de escala gruesa así como dependencias importantes y las interacciones entre especies (Keith et al., 
2015). La Lista Roja de Ecosistemas de UICN también proporciona una luz sobre las especies comunes, las cuales definen la identidad de muchos ecosistemas, están involucradas en interacciones clave con un gran número de las especies coexistentes, y puede tener una gran influencia en la forma y función de los ecosistemas (Gaston \& Fuller, 2008). Para alcanzar el objetivo principal de la LRE, el listado de categorías y criterios fue diseñado para ser:

1. Un método estándar para la evaluación y comparación de los riesgos de colapso de los ecosistemas.

2. Fácil de entender por los tomadores de decisiones y el público.

3. Transparente, objetivo y científicamente riguroso.

4. Aplicable a sistemas terrestres, marinos, dulceacuícolas y subterráneos.

5. Aplicable a evaluaciones de riesgo de áreas locales hasta globales.

6. Flexible en el uso de datos de diversa calidad y cobertura.

7. Consistente con y complementario de la Lista Roja de Especies Amenazadas de UICN.

Aunque el objetivo principal de la LRE se enfoca en la conservación de la biodiversidad, los datos asociados con la LRE pueden informar a una amplia gama de otras actividades, incluyendo el manejo sustentable de los servicios ecosistémicos. Este tipo de aplicaciones por lo general requerirán de herramientas adicionales para lograr resultados de planificación efectivos (Keith et al., 2015).

\subsection{Desarrollo de la Lista Roja de Ecosistemas de UICN}

Aunque el deseo de crear una Lista Roja de Ecosistemas (LRE) mundial no es nuevo dentro de UICN (Rodríguez et al., 2012a), la adopción de la Resolución 4.020 sobre los Umbrales cuantitativos para las categorías y criterios de ecosistemas amenazados (Cuarto Congreso Mundial de la Naturaleza, Barcelona, 2008) promovió activamente el desarrollo formal de las categorías y criterios. La resolución solicitaba a UICN el "iniciar un proceso de consulta para el desarrollo, implementación y monitoreo de un estándar mundial para la evaluación del estatus de los ecosistemas, aplicable a niveles local, regional y global". Durante los siguientes cuatro años, con contribuciones significativas de los sectores científicos, gubernamentales y de conservación, el Grupo Temático de la Lista Roja de Ecosistemas de UICN de la Comisión de Gestión de Ecosistemas (CGE) redactó un conjunto inicial de criterios (Versión 1.0; Rodríguez et al., 2011). En los años siguientes, los criterios fueron difundidos y puestos a prueba a nivel mundial para un conjunto de ecosistemas tipo por una serie de socios externos y en colaboración con el Programa Global de Gestión de Ecosistemas de UICN (GEMP).

Uno de los principales resultados de la consulta mundial dirigida por la CGE fue un avance sustancial en el conocimiento científico que sustenta la LRE. El proceso resultó en una revisión exhaustiva de la literatura relevante sobre la estructura y funcionamiento de los ecosistemas, documentación de la base teórica de los criterios de la LRE, el desarrollo de un modelo para la evaluación de riesgo de los ecosistemas, y la aplicación de este nuevo modelo a 20 ecosistemas de todo el mundo (Keith et al., 2013). Este conjunto revisado de Categorías y Criterios de la Lista Roja de Ecosistemas de UICN (Keith et al., 2013) ha sido 
refinado aún más después de la aplicación de los criterios a los estudios de caso, los cuales actualmente abarcan muchos ecosistemas tipo en todos los continentes (Keith et al., 2015; Keith, 2015).

El Quinto Congreso Mundial de la Naturaleza (Jeju, 2012) adoptó la Resolución 5.055 sobre la Consolidación de la Lista Roja de Ecosistemas de UICN, la cual reconoce el progreso del desarrollo de la LRE y solicita al Consejo de UICN el "tomar las medidas necesarias para la aprobación formal de las categorías y criterios como un protocolo de análisis de datos oficial de UICN para ser usado por los miembros y cualquier otra parte interesada en la evaluación de riesgo de los ecosistemas". El Consejo examinó la documentación de las Categorías y Criterios de la Lista Roja de Ecosistemas de UICN y el 21 de Mayo del 2014 las adoptó como el estándar mundial oficial para la evaluación de riesgo de los ecosistemas.

\subsection{Gobernanza de la Lista Roja de Ecosistemas de UICN}

La Lista Roja de Ecosistemas es conjuntamente coordinada por dos cuerpos de UICN, la Comisión de Gestión de Ecosistemas (CGE) y el Programa Global de Gestión de Ecosistemas (GEMP). Se rige por dos comités que interactúan con funciones específicas: (i) el Comité Directivo, y (ii) el Comité para Estándares Científicos. Es apoyada por el Grupo Temático de la Lista Roja de Ecosistemas de la CGE, el cual es un grupo de expertos voluntarios que asumen diversos deberes en apoyo a los objetivos de la LRE. La Unidad del Programa de la LRE—con base en Cambridge, Reino Unido; Gland, Suiza; y Nairobi, Kenia-administra la LRE y asegura la coordinación a nivel mundial de los expertos involucrados en la investigación, aplicación y actividades de revisión por expertos.

\subsubsection{El Comité Directivo}

El Comité Directivo de la LRE supervisa la aplicación de las Categorías y Criterios de la Lista Roja de Ecosistemas de UICN a nivel global y sub-global. El Comité Directivo está compuesto por el Líder (y si aplica, el Co-líder) del Grupo Temático de la Lista Roja de Ecosistemas de la CGE (designado por el Presidente de la CGE), el Presidente del Comité para Estándares Científicos de la LRE, el Presidente de la CGE, el Director del GEMP, el Jefe de la Unidad de Ciencia y Conocimiento de UICN, así como también miembros adicionales representantes de la CGE, la Secretaría de UICN, y/o socios claves de la LRE designados por el Presidente de la CGE debido a su experticia técnica u organizacional específica. EI Director del GEMP y el Jefe de la Unidad de Ciencia y Conocimiento de UICN representan la Secretaría de UICN.

El Comité Directivo tiene las siguientes funciones:

1. Desarrollar y gestionar la estrategia y plan de trabajo para la aplicación de la LRE en todo el mundo, para alcanzar la meta de evaluar todos los ecosistemas a nivel mundial para el 2025.

2. Establecer un mecanismo para la actualización periódica de las evaluaciones mundiales.

3. Identificar y abordar potenciales fuentes de financiamiento para las evaluaciones y su difusión. 
4. Supervisar un equipo de personal profesional dentro de la Unidad del Programa de la LRE, y construir una red de voluntarios para la aplicación del plan de trabajo de la LRE tanto dentro de la CGE como de la Secretaría de UICN.

5. Conseguir la participación activa de la CGE en el desarrollo y revisión por parte de expertos de las evaluaciones a nivel global y sub-global.

6. Desarrollar materiales de entrenamiento y directrices en los tres idiomas oficiales de UICN para apoyar las evaluaciones.

7. Recomendar nombramientos al Comité para Estándares Científicos de la LRE.

8. Garantizar que el progreso de la LRE es reportado de vuelta al Consejo de UICN y a la alta dirección de la Secretaría.

9. Asegurar que el progreso y los resultados de la LRE sean comunicados adecuadamente en la literatura científica y los medios.

10. Garantizar la ejecución del plan de trabajo de la LRE y mantener la cooperación entre las diferentes organizaciones colaboradoras.

11. Participar activamente con otras personas involucradas en el desarrollo, prueba y aplicación de los Productos del Conocimiento movilizados por UICN.

\subsubsection{El Comité para Estándares Científicos}

El Comité para Estándares Científicos de la LRE (CES) es el organismo científico principal que proporciona la experticia en el desarrollo, aplicación y revisión de todos los aspectos relacionados con la LRE. El Comité está integrado por expertos científicos con experiencia equilibrada que abarca una amplia gama de habilidades, incluyendo la evaluación de riesgos, los modelos ecológicos, los sensores remotos, la clasificación y mapeo de ecosistemas, teoría de decisión, y la ecología de los ecosistemas terrestres, dulceacuícolas, marinos y subterráneos. La experticia combinada de los miembros del Comité para Estándares Científicos abarca toda la diversidad de ecosistemas tipo y regiones geográficas.

Los miembros del Comité para Estándares Científicos de la LRE, incluyendo el Presidente y el Presidente Adjunto, son propuestos por el Comité Directivo de la LRE. El Presidente de la CGE es el responsable final de designar los miembros por un período máximo de cuatro años, el cual expira en la siguiente sesión del Congreso Mundial de la Naturaleza. Un puesto del Comité para Estándares Científicos está reservado para un representante de la Lista Roja de Especies Amenazadas de UICN designado por la Comisión de Supervivencia de Especies (CSE) y el Programa Global de Especies (PGE).

El Comité para Estándares Científicos promueve la aplicación de altos estándares científicos en la implementación de las Categorías y Criterios de la Lista Roja de Ecosistemas de UICN, y se asegura que la intención de las categorías y criterios no se vea comprometida. Las funciones específicas del Comité para Estándares Científicos son:

1. Desarrollar y mantener las directrices técnicas en los tres idiomas oficiales de UICN para apoyar la aplicación de las Categorías y Criterios de la Lista Roja de Ecosistemas de UICN, incluyendo detalles sobre los estándares de implementación y calidad de los datos.

2. Proporcionar asesoría científica sobre las categorías y criterios al Comité Directivo de la LRE y a la Unidad del Programa. 
3. Proporcionar asesoramiento científico a la Unidad del Programa en el desarrollo de bases de datos, materiales de entrenamiento y otros recursos.

4. Prestar asesoramiento científico en el diseño e implementación de proyectos de evaluaciones de riesgo de los ecosistemas sistemáticas que puedan contribuir a la LRE global.

5. Gestionar el proceso de revisión por expertos de todas las clasificaciones y mapas de los ecosistemas tipo propuestos para su uso en la LRE global.

6. Gestionar el proceso de revisión por expertos de todas las evaluaciones propuestas para su inclusión en la LRE global y, sujeto a los resultados del proceso de revisión, presentar recomendaciones al Comité Directivo sobre la inclusión o rechazo de estas evaluaciones.

7. Revisar críticamente todas las aplicaciones del criterio E.

8. Proporcionar apoyo científico y entrenamiento para las evaluaciones sub-globales de los ecosistemas tipo a través de la Unidad del Programa de la LRE y otros socios de la LRE.

9. Promover y realizar investigaciones para mejorar las metodologías de evaluación de riesgo de los ecosistemas que sustentan las Categorías y Criterios de la Lista Roja de Ecosistemas de UICN.

10. Todas las decisiones formales y recomendaciones del Comité para Estándares Científicos de la LRE son sometidas al Comité Directivo para su revisión y adopción formal.

\subsection{Estructura de las Directrices}

Las Directrices para la aplicación de las Categorías y Criterios de la Lista Roja de Ecosistemas de UICN proporcionan la información necesaria para conducir una evaluación de riesgo de un ecosistema robusta y repetible, adecuada para su inclusión en la LRE. La sección 1 (Introducción) ofrece una visión general sobre la motivación e historia de la LRE, describiendo sus objetivos generales y su estructura de gobierno. La sección 2 (Categorías de la Lista Roja de Ecosistemas de UICN) presenta las categorías. La sección 3 (Fundamentos Científicos) resume la ciencia que sustenta las categorías y criterios, y presenta el modelo de evaluación de riesgo de la LRE. La sección 4 (Proceso de Evaluación) guía a los evaluadores a través de una evaluación completa adecuada para presentación. La sección de los Criterios y Umbrales (Sección 5) esboza la teoría científica que sustenta cada criterio, la estimación de las variables para la evaluación, y los valores de los umbrales para cada categoría. La sección 6 (Revisión por expertos y Publicación) describe los estándares para evaluar la calidad de la evaluación de riesgo. En todo momento, se proporcionan una serie de ejemplos resueltos y estudios de caso para ayudar a los evaluadores en la aplicación de las categorías y criterios.

Una tabla resumen de la versión actual de las Categorías y Criterios de la Lista Roja de Ecosistemas de UICN está incluida en el Apéndice 2. Más información sobre la Lista Roja de Ecosistemas de UICN, enlaces a documentos relevantes, y resúmenes de los estudios de caso se encuentran disponibles en varios idiomas en el sitio web de la Lista Roja de Ecosistemas de UICN (www.iucnrle.org). 


\section{Categorías de la Lista Roja de Ecosistemas de UICN}

La Lista Roja de Ecosistemas de UICN incluye ocho categorías: Colapsado (CO), En Peligro Crítico (CR), En Peligro (EN), Vulnerable (VU), Casi Amenazado (NT), Preocupación Menor (LC), Datos Insuficientes (DD), y No Evaluado (NE; Fig. 1). Las primeras seis categorías (CO, CR, EN, VU, NT y LC) están ordenadas en orden decreciente del riesgo de colapso. Las categorías Datos Insuficientes y No Evaluado no indican un nivel de riesgo.

Las categorías En Peligro Crítico, En Peligro y Vulnerable indican ecosistemas amenazados y son definidas por criterios cuantitativos y cualitativos descritos en la Sección 5 y el Apéndice 2. Estas categorías están anidadas, de forma tal que un ecosistema tipo que cumpla los criterios para En Peligro Crítico también cumplirá los criterios para las categorías En Peligro y Vulnerable. Las tres categorías de ecosistemas amenazados son complementadas por varias categorías cualitativas que acomodan: (i) ecosistemas tipo que casi cumplen los criterios cuantitativos para Vulnerable (Casi Amenazado); (ii) ecosistemas que de forma inequívoca no cumplen ninguno de los criterios cuantitativos (Preocupación Menor); (iii) ecosistemas para los cuales existe muy poca data como para aplicar algún criterio (Datos Insuficientes); (iv) ecosistemas que todavía no han sido evaluados (No Evaluado). Siguiendo el principio de precaución (Precautionary Principle Project, 2005), el estatus general de un ecosistema tipo es la categoría de riesgo más alta obtenida a través de cualquier criterio.

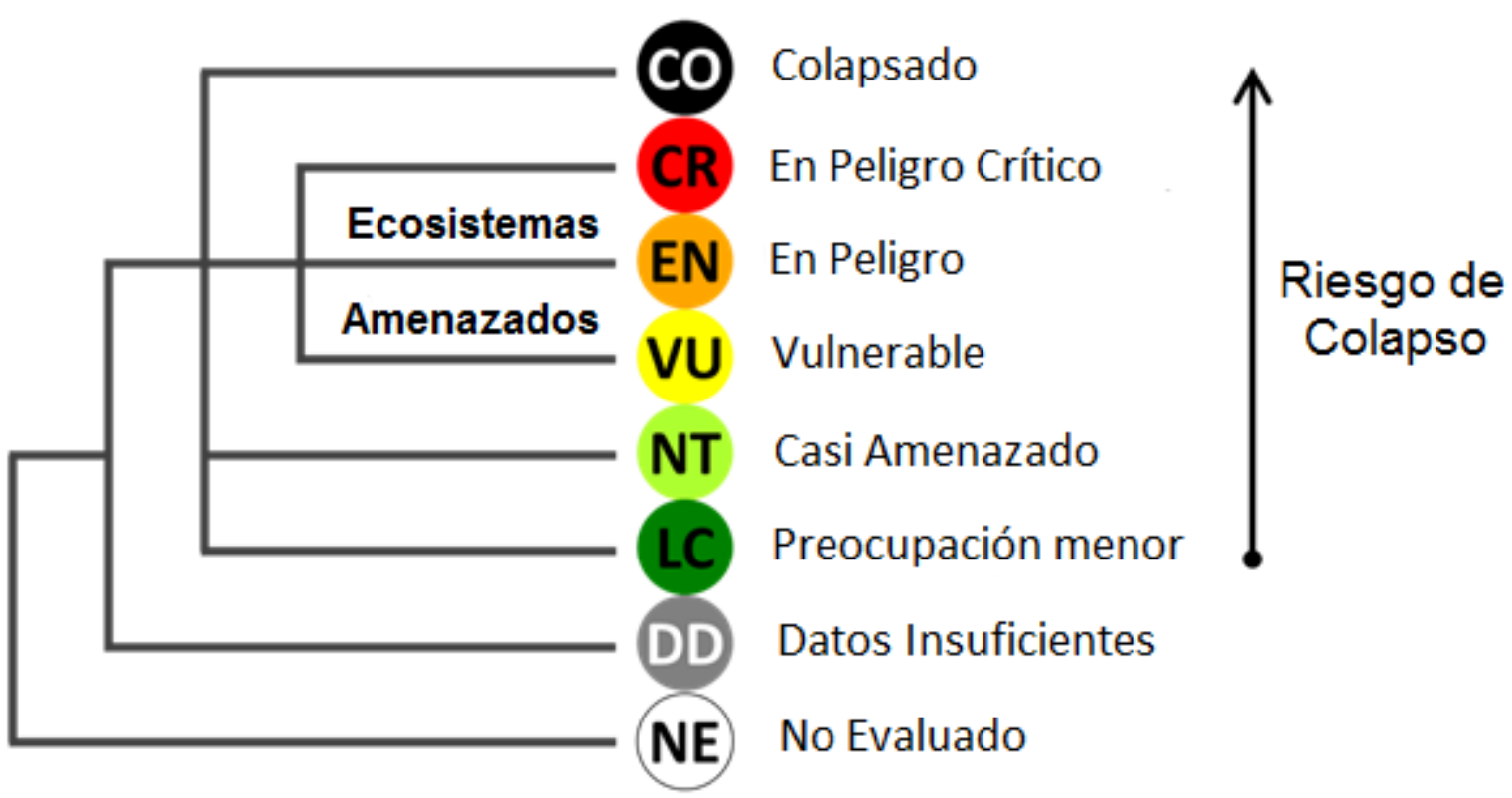

Figura 1. Estructura de las categorías de la Lista Roja de Ecosistemas de UICN. 
Colapsado (CO)

Un ecosistema está Colapsado cuando es prácticamente seguro (Tabla 3) que las características bióticas o abióticas que lo definen han desaparecido de todas las ocurrencias, y la biota nativa característica ya no es sostenida. El colapso puede ocurrir cuando la mayoría de los componentes diagnósticos de la biota nativa característica han desaparecido del sistema, o cuando los componentes funcionales (la biota que desempeña las funciones principales en la organización del ecosistema) se reducen considerablemente en abundancia y pierden la capacidad de reclutar.

\section{En Peligro Crítico (CR)}

Un ecosistema está En Peligro Crítico cuando la mejor evidencia disponible indica que cumple con cualquiera de los criterios desde A hasta E para la condición En Peligro Crítico. Por lo tanto, se considera que tiene un riesgo extremadamente alto de colapso.

\section{En Peligro (EN)}

Un ecosistema está En Peligro cuando la mejor evidencia disponible indica que cumple con cualquiera de los criterios desde A hasta E para la condición En Peligro. Por tanto, se considera como que está en un muy alto riesgo de colapso.

\section{Vulnerable (VU)}

Un ecosistema es Vulnerable cuando la mejor evidencia disponible indica que cumple con cualquiera de los criterios desde A hasta E para la condición Vulnerable. Por tanto, se considera que está en un alto riesgo de colapso.

\section{Casi Amenazado (NT)}

Un ecosistema está Casi Amenazado cuando ha sido evaluado contra los criterios y no califica de momento para las categorías En Peligro Crítico, En Peligro o Vulnerable, pero está cercano a calificar o es probable que califique en una categoría de amenaza en un futuro cercano.

\section{Preocupación Menor (LC)}

Un ecosistema es considerado Preocupación Menor cuando ha sido evaluado contra los criterios y no califica para las categorías En Peligro Crítico, En Peligro, Vulnerable o Casi Amenazado. Ecosistemas ampliamente distribuidos y relativamente no degradados son incluidos en esta categoría.

Datos Insuficientes (DD)

Un ecosistema se considera como Datos Insuficientes cuando la información disponible no es adecuada para realizar una evaluación directa, o indirecta, de su riesgo de colapso basado en la disminución de la distribución, alteración de las funciones ecológicas o degradación del ambiente físico. Datos Insuficientes no es una categoría de amenaza, y no implica ningún nivel de riesgo de colapso. El listar ecosistemas en esta categoría indica que su situación ha sido revisada, pero que se requiere más información para determinar su estatus de riesgo.

No Evaluado (NE)

Un ecosistema se considera No Evaluado cuando todavía no ha sido evaluado contra los criterios. 


\section{Fundamentos Científicos}

\subsection{Ecosistemas tipo: las unidades de evaluación}

El protocolo de la Lista Roja de Ecosistemas de UICN (LRE) es un marco de evaluación de riesgos robusto y genérico que se puede aplicar a clasificaciones internamente consistentes de ecosistemas tipo. Tiene flexibilidad para evaluar los riesgos a ecosistemas que varían ampliamente en las características biológicas y ambientales, escalas de organización y cantidades de datos disponibles. Por tanto, desarrollar una definición y descripción claras de los ecosistemas tipo es un primer paso esencial para una evaluación de la LRE.

Los ecosistemas son complejos de organismos y el ambiente físico al que están asociados dentro de un área específica (Tansley, 1935). Tienen cuatro elementos esenciales: un complejo biótico, un ambiente abiótico, las interacciones dentro y entre ellos, y un espacio físico en el cual estas operan (Pickett y Cadenasso, 1995). En la sección 4.2 Describiendo la unidad de evaluación se brinda orientación sobre cómo aplicar estos conceptos para definir y describir las unidades adecuadas para la evaluación de la LRE.

\subsubsection{Tipologías de ecosistemas}

Las Categorías y Criterios de la Lista Roja de Ecosistemas de UICN pueden ser aplicadas sistemáticamente a un conjunto de ecosistemas tipo dentro de un área de evaluación especifica (global o sub-global) o a un solo ecosistema tipo. Las evaluaciones independientes de un solo ecosistema tipo pueden ser herramientas de diagnóstico útiles para la gestión de los ecosistemas (Keith et al., 2015). En tanto que la unidad de evaluación esté claramente definida y delimitada, las evaluaciones autónomas son menos dependientes de una clasificación (tipología) de ecosistemas tipo que las evaluaciones sistemáticas de múltiples ecosistemas. Estas evaluaciones sistemáticas requieren una tipología para garantizar que las evaluaciones de riesgos de los ecosistemas sean coherentes y comparables dentro del área de evaluación. La clasificación puede simplemente delimitar unidades a una escala temática particular, o puede describir sus relaciones utilizando jerarquías o arreglos anidados que abarquen una gama de escalas temáticas (Rodríguez et al., 2011).

Un número de jurisdicciones han desarrollado tipologías adecuadas para apoyar las evaluaciones de la LRE de jurisdicciones nacionales (Kontula \& Raunio, 2009; Lindgaard \& Henriksen, 2011; Driver et al., 2012). A nivel continental, una evaluación de la LRE de varios cientos de ecosistemas tipo terrestres para las Américas está basado en un marco de clasificación internacional para la vegetación terrestre (Faber-Langendoen et al., 2014; Rodríguez et al., 2012b). La escala temática de los ecosistemas tipo en esta evaluación corresponde a niveles de grupo y macro grupo en el sistema de clasificación internacional de vegetación (Faber-Langendoen et al., 2014), y es apropiado para las evaluaciones globales de la LRE. 
Las evaluaciones sub-globales pueden estar basadas en clasificaciones de ecosistemas nacionales o regionales ya establecidas, proporcionando las unidades de evaluación conforme a la definición de ecosistemas tipo (ver 3.1 Ecosistemas tipo: unidades de evaluación, arriba). Estas unidades deben ser justificadas como indicadores adecuados para las agrupaciones ecológicas y deben tener referencias cruzadas con los sistemas de clasificación nacionales, regionales o globales.

El desarrollo de una tipología global de ecosistemas está actualmente en curso (liderado por el Comité de Estándares Científicos de la LRE, y el Grupo Temático de la LRE de la CGE). Este trabajo está guiado por investigaciones recientes en clasificaciones de vegetaciones terrestres (Faber-Langendoen et al., 2014) y ambientes marinos (Gregr et al., 2012), y trata de promover cruces transparentes y repetibles entre tipologías sub-globales cumpliendo ciertas especificaciones (Sección 4.1). Mientras tanto, el Esquema de Clasificación de Hábitats de UICN (www.iucnredlist.org/technical-documents/classificationschemes/habitats-classification-scheme-ver3) proporciona un marco comparativo útil para las evaluaciones de ecosistemas tipo contrastantes en un rango de escalas temáticas.

Los ecosistemas tipo globalmente reconocibles no deben ser confundidos con las ecoregiones biogeográficas o biofísicas (Spalding et al., 2007), o biomas (Allen \& Hoekstra, 1990). Las eco-regiones y biomas son áreas con características macro-ambientales y biogeográficas comunes y contienen complejos de ecosistemas tipo contrastantes, pero coexistentes (Spalding et al., 2007). La potencial heterogeneidad de las ecorregiones y biomas los hace inadecuados para la mayoría de las aplicaciones de la LRE (Rodríguez et al., 2015; Keith et al., 2015; Keith et al., 2013). Otros términos aplicados en evaluaciones de conservación - tales como comunidades ecológicas, hábitats, biotopos, y (en gran medida en contextos terrestres) tipos de vegetación - son considerados como sinónimos operativos de ecosistemas tipo (Nicholson et al., 2009) siempre que estén adecuadamente definidos de acuerdo con los procedimientos descritos en el proceso de evaluación (Sección 4.2).

\subsubsection{La influencia de la escala}

El protocolo de evaluación de riesgo de la LRE fue diseñado para ser flexible para la aplicación a múltiples escalas espaciales y con un amplio rango de tipos de datos (Rodríguez et al., 2015; Keith et al., 2015; Keith et al., 2013). Sin embargo, hay límites prácticos a las escalas espaciales, temporales y temáticas de las unidades que pueden ser evaluadas, y dentro de estos límites los resultados de la evaluación son sensibles a la escala. La evaluación de unidades que son definidas de forma muy amplia o muy restringida, así como la falta de implementación de métodos o procedimientos de estandarización (Sección 5) pueden resultar en incongruencias de escala, evaluaciones que no son comparables entre escalas, o resultados de evaluaciones no válidos (Keith et al., 2013). Una serie de medidas en el protocolo de la LRE abordan la influencia de la escala:

1. Hay una investigación en marcha para apoyar la interpretación de los criterios de la LRE para evaluaciones de diferentes áreas geográficas. Las categorías y criterios fueron diseñadas principalmente para evaluaciones a nivel global, pero son aplicables a evaluaciones sub-globales (Sección 3.1.1). Muchas de estas evaluaciones sub-globales funcionarán dentro de límites ecológicos arbitrarios ( $p$. ej. 
fronteras nacionales), y por lo tanto, considerarán solamente partes de la distribución global de algunos ecosistemas tipo. Para tener en cuenta estos escenarios, actualmente están bajo investigación distintos métodos para la interpretación y escalamiento de las categorías de amenaza o sus umbrales.

2. Un creciente número de evaluaciones nacionales y sub-nacionales proporcionan orientación sobre las escalas temáticas apropiadas (nivel de clasificación o fuerza; Hermoso et al., 2013) para las evaluaciones de riesgo de los ecosistemas (Tabla 1). Las tipologías de ecosistemas proporcionan ejemplos de clasificaciones de ecosistemas diseñadas para apoyar los diferentes marcos regulatorios y las aplicaciones de planes de conservación entre las jurisdicciones. El desarrollo de una tipología global proporcionará mayor orientación sobre la escala temática de las evaluaciones de la LRE global.

3. Escalas estándar para evaluar la distribución geográfica: el tamaño de grano (p. ej. resolución de píxel) al cual se mapea la distribución de un ecosistema puede afectar considerablemente la estimación del tamaño de la distribución. Para mantener la consistencia con los umbrales establecidos para evaluar el tamaño de la distribución (criterio $B$ ), las distribuciones son medidas a un tamaño de grano estándar (cuadrículas de $10 \times 10 \mathrm{~km}$ ) para estimar el AOO y con un método geométrico estándar (polígono convexo mínimo) para estimar la EOO. Este proceso de generalización es lo suficientemente amplio como para dar cabida a los procesos relevantes a la persistencia en una amplia gama de ecosistemas tipo (Sección 5.2). Una gama de herramientas está disponible para apoyar con el re-escalamiento (hacia abajo o hacia arriba) de los datos de distribución, y completar las evaluaciones de acuerdo con los criterios A y B (Sección 5).

4. Períodos de tiempo estándar para las evaluaciones: temporalmente, los ecosistemas pueden desarrollarse, persistir o cambiar sobre períodos de tiempo que pueden variar desde horas hasta milenios. Ellos parecen estables a algunas escalas temporales, mientras experimentan tendencias y fluctuaciones en otras (Wiens, 1989; Carpenter \& Turner, 2001). Las categorías evalúan los cambios de los ecosistemas sobre períodos de tiempo estándar que representan tendencias sobre el presente, futuro y escalas de tiempo históricas. Los períodos de tiempo presente y futuro son fijados a 50 años para equilibrar la necesidad de diagnosticar las tendencias con una certeza razonable (lo cual requiere largos períodos de tiempo) con la necesidad de responder oportunamente a las tendencias adversas. Períodos de tiempo históricos son incluidos para acomodar los efectos de retrasos ecológicos en las evaluaciones (Sección 5). 
Tabla 1. Ejemplos de tipologías de ecosistemas y clasificaciones similares que apoyan evaluaciones nacionales de riesgo de ecosistemas para diversas aplicaciones de planes de conservación y de regulación (adaptado de Keith et al., 2015)

\begin{tabular}{|c|c|c|c|}
\hline Jurisdicción & Aplicación & Unidad de evaluación & Referencia \\
\hline $\begin{array}{l}\text { Unión } \\
\text { Europea }\end{array}$ & $\begin{array}{l}\text { Directiva de Hábitats } \\
\text { 92/43/EEC (Comisión } \\
\text { Europea) }\end{array}$ & $\begin{array}{l}\text { Hábitat tipo. 'Comunidades de } \\
\text { plantas y animales como los } \\
\text { elementos característicos del } \\
\text { medio biótico, que junto con los } \\
\text { factores abióticos funcionan } \\
\text { conjuntamente a una escala } \\
\text { particular'. }\end{array}$ & $\begin{array}{l}\text { Council of the } \\
\text { European } \\
\text { Commission } \\
(1992)\end{array}$ \\
\hline Alemania & $\begin{array}{l}\text { Lista Roja de biotopos } \\
\text { (Agencia Federal del Medio } \\
\text { Ambiente) }\end{array}$ & $\begin{array}{l}\text { Biotopo. 'Hábitat de una } \\
\text { comunidad de fauna y flora que } \\
\text { viven en estado salvaje'. }\end{array}$ & $\begin{array}{l}\text { Riecken et al. } \\
\text { (2009); Riecken } \\
\text { et al. (2006) }\end{array}$ \\
\hline Finlandia & $\begin{array}{l}\text { Lista Roja de los tipos de } \\
\text { hábitat (Instituto Finlandés } \\
\text { del Medio Ambiente) }\end{array}$ & $\begin{array}{l}\text { Hábitat tipo. 'Zonas terrestres o } \\
\text { acuáticas espacialmente } \\
\text { definibles con condiciones } \\
\text { ambientales características y biota } \\
\text { que son similares entre estas } \\
\text { áreas, pero que difieren de las } \\
\text { áreas de otros hábitat tipo'. }\end{array}$ & $\begin{array}{l}\text { Kontula \& } \\
\text { Raunio (2009) }\end{array}$ \\
\hline Noruega & $\begin{array}{l}\text { Lista Roja de ecosistemas } \\
\text { y los tipos de hábitat } \\
\text { (Centro de Información } \\
\text { sobre Biodiversidad de } \\
\text { Noruega) }\end{array}$ & $\begin{array}{l}\text { Hábitat tipo. 'Un entorno } \\
\text { homogéneo, incluyendo toda la } \\
\text { vida vegetal y animal y los } \\
\text { factores ambientales que allí } \\
\text { operan'. }\end{array}$ & $\begin{array}{l}\text { Lindgaard \& } \\
\text { Henriksen } \\
(2011)\end{array}$ \\
\hline Venezuela & $\begin{array}{l}\text { Lista Roja Nacional de } \\
\text { Ecosistemas (Provita) }\end{array}$ & $\begin{array}{l}\text { Principales tipos de vegetación } \\
\text { para la evaluación nacional; tipos } \\
\text { de cobertura derivados de } \\
\text { imágenes satelitales para las } \\
\text { evaluaciones sub-nacionales. }\end{array}$ & $\begin{array}{l}\text { Rodríguez et al. } \\
\text { (2010) }\end{array}$ \\
\hline Canadá & $\begin{array}{l}\text { Legislación estatal de } \\
\text { especies y ecosistemas } \\
\text { amenazados } \\
\text { (Departamento de } \\
\text { Conservación y } \\
\text { Administración del Agua de } \\
\text { Manitoba) }\end{array}$ & $\begin{array}{l}\text { Ecosistema. 'Un complejo } \\
\text { dinámico de comunidades de } \\
\text { animales, plantas y } \\
\text { microorganismos y su entorno } \\
\text { abiótico interactuando como una } \\
\text { unidad funcional'. }\end{array}$ & $\begin{array}{l}\text { Government of } \\
\text { Manitoba (2014) }\end{array}$ \\
\hline Australia & $\begin{array}{l}\text { Listas de comunidades } \\
\text { ecológicas amenazadas a } \\
\text { niveles nacional y estatal } \\
\text { (Departamento Federal del } \\
\text { Medio Ambiente, agencias } \\
\text { ambientales estatales) }\end{array}$ & $\begin{array}{l}\text { Comunidad ecológica. 'Un } \\
\text { ensamble de especies nativas que } \\
\text { habita en un área en particular en } \\
\text { la naturaleza'. }\end{array}$ & $\begin{array}{l}\text { Commonwealth } \\
\text { of Australia } \\
\text { (2000); Keith } \\
\text { (2009); } \\
\text { Nicholson et al. } \\
\text { (2015) }\end{array}$ \\
\hline Sudáfrica & $\begin{array}{l}\text { Legislación nacional de } \\
\text { biodiversidad (Instituto } \\
\text { Nacional de Biodiversidad } \\
\text { de Sudáfrica) }\end{array}$ & $\begin{array}{l}\text { Ecosistema. 'Un complejo } \\
\text { dinámico de comunidades } \\
\text { animales, vegetales y de } \\
\text { microorganismos y su entorno } \\
\text { abiótico interactuando como una } \\
\text { unidad funcional'. }\end{array}$ & $\begin{array}{l}\text { Republic of } \\
\text { South } \\
\text { Africa (2004); } \\
\text { Driver et al. } \\
(2012)\end{array}$ \\
\hline
\end{tabular}




\subsection{Colapso del ecosistema}

Para lograr una aplicación robusta de las Categorías y Criterios de la Lista Roja de Ecosistemas de UICN, los evaluadores deben sintetizar diversas causas, mecanismos y vías de degradación de los ecosistemas dentro del marco genérico de evaluación de riesgos. Para evaluar el riesgo -la probabilidad de un resultado adverso en un período de tiempo determinado - es necesario definir el punto final de degradación de los ecosistemas, el punto final en el cual el ecosistema se considera colapsado. La definición del punto final de la degradación del ecosistema debe ser los suficientemente discreta para permitir una evaluación de riesgo, pero lo suficientemente general para abarcar la amplia gama de contextos en los que se necesitan evaluaciones de riesgo. El protocolo de la LRE tiene dos elementos para hacer frente a esta disyuntiva: (i) una definición de colapso del ecosistema como el punto final de degradación del ecosistema; (ii) un modelo de evaluación de riesgo que identifica múltiples vías para el colapso del ecosistema y que constituye la base de los criterios.

Dentro de las Categorías y Criterios de la Lista Roja de Ecosistemas de UICN, "un ecosistema está Colapsado cuando es prácticamente seguro (Tabla 3) que las características bióticas o abióticas que lo definen han desaparecido de todas las ocurrencias, y la biota nativa característica ya no es sostenida. El colapso puede ocurrir cuando la mayoría de los componentes diagnósticos de la biota nativa característica han desaparecido del sistema, o cuando los componentes funcionales (la biota que desempeña las funciones principales en la organización del ecosistema) se reducen considerablemente en abundancia y pierden la capacidad de reclutar".

\subsubsection{Definiendo el colapso del ecosistema}

A diferencia de las especies, los ecosistemas no desaparecen; más bien se transforman en ecosistemas nóveles (emergentes), con biotas características y mecanismos de organización diferentes (Hobbs et al., 2006; Keith et al., 2015; Keith et al., 2013). Muchos rasgos característicos pueden desaparecer mucho antes de que la última especie característica desaparezca de la última ocurrencia del ecosistema (ensamble de extinción; Gaston \& Fuller, 2008). Los sistemas nóveles pueden retener parte de la biota características del sistema colapsado que reemplazan, pero la abundancia de esas especies, sus interacciones o funciones ecológicas son modificadas. Reconociendo los contrastes con la extinción de especies, el concepto de colapso del ecosistema se define como la transición más allá de un intervalo acotado en una o más variables que definen la identidad del ecosistema. El colapso es una transformación de la identidad, una pérdida de los rasgos característicos, y/o el reemplazo por un ecosistema diferente. Un ecosistema está colapsado cuando todas las ocurrencias pierden las características bióticas o abióticas que lo definen, la biota nativa característica ya no puede ser sustentada, y se han trasladado fuera de su intervalo natural de variación espacial y temporal en composición, estructura y/o función. Esto se puede ilustrar por el familiar modelo de las "canicas" de la teoría de estados y transiciones (Fig. 2) y por ejemplos claves tales como el del Mar Aral (Caja 1). En teoría, el colapso del ecosistema puede ser reversible-dado un largo período de tiempo, o por medio de la reintroducción de la biota característica y/o la restauración de la función del ecosistema —pero en muchos sistemas la recuperación no será posible. 
Las transiciones al colapso pueden ser graduales, repentinas, lineales, no lineales, determinísticas o altamente estocásticas. Estas incluyen cambios de régimen (Scheffer et al., 2001), pero también otros tipos de transiciones que pueden no involucrar retroalimentación. La dinámica dominante en un ecosistema dependerá de factores abióticos o influencias externas (p. ej. patrones climáticos o perturbaciones humanas), procesos bióticos internos (p. ej. competencia, depredación, o epidemias), legados históricos (p. ej. historia climática, deuda de extinción o explotación), y del contexto espacial (p. ej. localidad, tamaño y dispersión de la distribución). Un ecosistema puede entonces ser llevado al colapso por diferentes procesos que supongan una amenaza y a través de múltiples vías. Las cascadas tróficas (Estes et al., 2011), la pérdida de especies fundadoras (Diamond, 2007), la degradación ambiental (UNEP, 2001) y la transformación del clima (Grebmeier et al., 2006) son vías comunes que conducen al colapso del ecosistema. Los síntomas del colapso pueden diferir dependiendo de las características del ecosistema, la naturaleza de los procesos amenazantes, y las vías de degradación que estos generan. El protocolo de la LRE tiene flexibilidad para permitir que las amenazas de colapso sean expresadas en términos apropiados para los diferentes tipos de ecosistemas.

La definición de colapso del ecosistema puede ser más clara para ecosistemas que ya han colapsado y para los cuales existan series temporales de datos para variables relevantes. A menudo será posible inferir características de colapso a partir de las ocurrencias dentro de la distribución del ecosistema donde los rasgos característicos se han perdido, incluso si la mayoría del ecosistema persiste. Los cambios importantes en ecosistemas funcionalmente similares también pueden proporcionar una orientación para definir los síntomas de colapso en sistemas de interés. Esto puede proporcionar una base para la definición de los síntomas espaciales y funcionales de colapso del ecosistema.

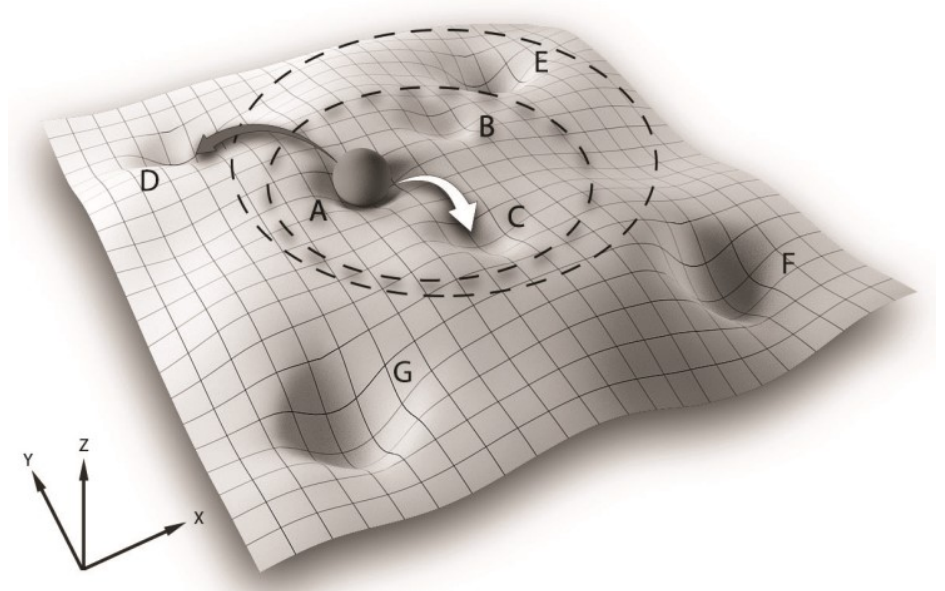

Figura 2. Esquema generalizado ilustrando la interpretación del colapso del ecosistema en un marco de estados y transiciones (Keith et al., 2015). Los estados A-G son definidos por dos variables de estado representadas en los ejes $\mathrm{X}$ e $\mathrm{Y}$. El eje vertical $(Z)$ representa el potencial para el cambio. Las dos líneas discontinuas representan interpretaciones alternativas del colapso del ecosistema. Para la línea interior, las transiciones entre los estados A, B y C (p. ej., la flecha blanca) representan la variabilidad natural sin pérdida de los rasgos característicos, mientras que las transiciones que atraviesan las líneas discontinuas ( $p$. ej. la flecha gris) a los estados D, E, F y $G$ representan el colapso y el reemplazo por ecosistemas emergentes. La progresión a lo largo de las diferentes vías de colapso es evaluada con las variables $\mathrm{X}$ e $\mathrm{Y}$, u otras variables diagnósticas específicas de los ecosistemas que reflejen la pérdida de biota nativa característica y función. La línea discontinua exterior representa una interpretación alternativa del colapso del ecosistema en la que el estado $\mathrm{E}$ está incluido dentro de la variación natural del ecosistema tipo. 
Caja 1. colapso del ecosistema en el Mar de Aral

El mar de Aral - el cuarto cuerpo de agua continental más grande del mundo- es alimentado por dos ríos principales, el Syr Dar'ya y el Amu Dar'ya (Aladin \& Plotnikov, 1993). Su biota nativa característica incluye peces de agua dulce (20 especies), una fauna invertebrada única $(>150$ especies) y cañaverales costeros, los cuales proporcionan hábitats para aves acuáticas, incluyendo especies migratorias (Keith et al., 2013). Hidrológicamente el mar era más o menos estable durante el período comprendido entre 1911 y 1960, con las entradas de agua en equilibro con la evaporación neta (Micklin \& Aladin, 2008). La intensificación de la extracción de agua para apoyar la expansión de la agricultura de riego llevó a la contracción y salinización del mar. Para el año 2005, sólo se registraron 28 de las especies acuáticas (incluyendo peces e invertebrados), los cañaverales se habían secado y desaparecido, el mar se había contraído a una fracción de su volumen y área de superficie anterior, y la salinidad se había incrementado diez veces (Micklin \& Aladin, 2008).

De forma consistente con la definición de colapso del ecosistema, estos cambios sugieren que el mar de Aral sufrió una transformación de identidad, perdiendo muchos de sus rasgos característicos (biota acuática, cañaverales, aves acuáticas, balance hidrológico e hidroquímica salobre) y fue reemplazado por ecosistemas emergentes (lagos salinos y llanuras desérticas). Bajo esta interpretación, el colapsó ocurrió antes de que el volumen y área de superficie del agua estancada disminuyera a cero. Aunque el punto exacto de colapso del ecosistema es incierto, series temporales de datos de diversas variables son adecuadas para definir un estado de referencia funcional (antes del inicio del cambio en 1960) y umbrales acotados del colapso, asumiendo que este ocurrió en algún momento entre 1976 y 1989 cuando la mayoría de la biota desapareció (Keith et al., 2013).

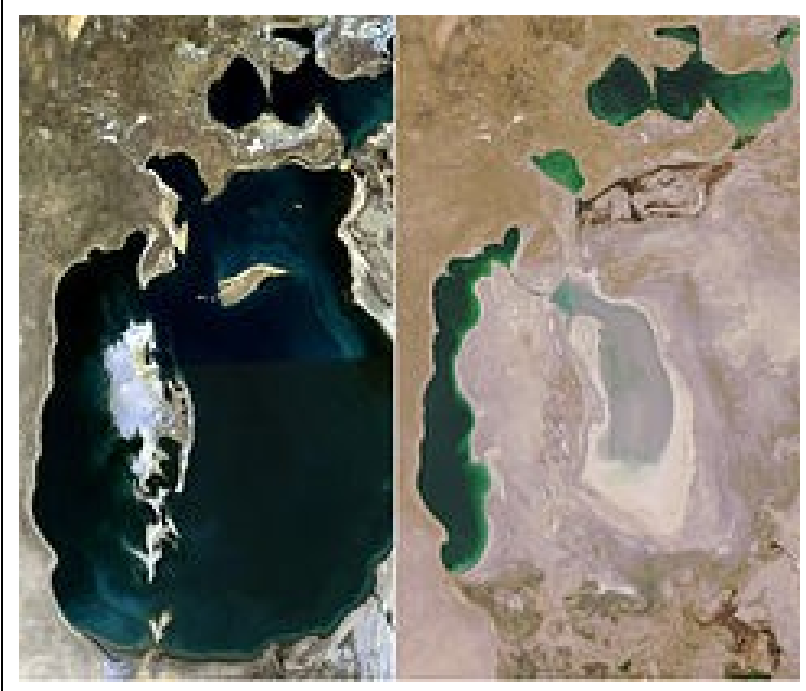

La elección de las variables disponibles para evaluar el estatus de un ecosistema dependerá de cuan adecuadamente éstas representan los rasgos característicos del ecosistema, de la cantidad y calidad de los datos, y de la sensibilidad de las variables alternativas al cambio ecológico. De las variables listadas anteriormente, la riqueza y abundancia de las especies de peces puede ser la variable biótica más próxima a los rasgos que definen la identidad del ecosistema del mar de Aral. El volumen del mar puede ser un indicador abiótico razonable, debido a que el volumen está funcionalmente ligado a la salinidad, la cual a su vez media la persistencia de la fauna marina y dulce acuícola característica. El área de la superficie marina tiene menos relación directa con estas características y procesos, pero puede ser fácilmente estimada por medio de sensores remotos y puede ser de utilidad en las evaluaciones cuando no hay datos disponibles para otras variables.

El colapso del ecosistema del mar de Aral puede o no ser reversible. Si bien podría ser posible restaurar el régimen hidrológico sobre una pequeña porción del antiguo mar (Micklin \& Aladin, 2008), algunos componentes de la biota característica están aparentemente extintos (p. ej. el salmón de Aral, Salmo trutta aralensis), impidiendo la reconstrucción del ecosistema pre-colapso. Imagen: @ NASA 


\subsubsection{Incertidumbres en los puntos finales para la evaluación de riesgo}

La evaluación de riesgo se basa en la definición de un resultado adverso, típicamente un punto o evento final discreto que afecta el recurso bajo evaluación. La aplicación de la evaluación de riesgo enfrenta incertidumbres en dos áreas: la definición del recurso en sí mismo, y la definición del punto final. Los límites que delimitan a un ecosistema tipo puede ser inciertos debido al conocimiento imperfecto de la variabilidad natural dentro del ecosistema, a los patrones continuos de variabilidad con otros ecosistemas, y a cambios en la clasificación de ecosistemas a lo largo del tiempo, así como incertidumbres asociadas al mapeo de las distribuciones (Keith et al., 2013). La definición de colapso del ecosistema también está sujeta a incertidumbre lo cual puede afectar la estimación de los síntomas espaciales y funcionales de colapso (Fig. 3). Todas las aplicaciones de las Categorías y Criterios de la Lista Roja de Ecosistemas de UICN deben considerar estas fuentes de incertidumbre y discutirlas en la documentación de la evaluación. Ejemplos de cómo lidiar con estas incertidumbre dentro del proceso de evaluación son descritas más adelante, reconociendo que las incertidumbres en los sistemas espaciales y funcionales usualmente están relacionadas.

\section{Incertidumbre en los síntomas espaciales}

Durante el proceso de degradación, un ecosistema puede pasar a estado(s) colapsado en algunas partes de su distribución antes que en otras. En áreas donde la transición ha ocurrido, el ecosistema puede ser descrito como 'colapsado localmente'. Espacialmente, un ecosistema está colapsado cuando todas las ocurrencias existentes del ecosistema han colapsado (i.e. área de ocupación $=0$ celdas de cuadrícula de $10 \times 10 \mathrm{~km}$ y la extensión de la presencia $=0 \mathrm{~km}^{2}$ ). Para cuantificar las pasadas disminuciones en la distribución y en la función, los evaluadores deben identificar dónde existe actualmente el ecosistema tipo, y dónde existió previamente (dentro del período de tiempo de la evaluación) y está ahora en un estado colapsado. Similarmente, para cuantificar las disminuciones futuras en la distribución y función, los evaluadores deben proyectar el área en el cual el ecosistema colapsará en el período de tiempo futuro de la evaluación. Todas estas estimaciones y proyecciones implican incertidumbres. La incertidumbre epistémica (p. ej. Incertidumbre debido a la falta de conocimiento, en oposición a la incertidumbre inherente debido a la variabilidad en el sistema) existe debido a una variedad de errores de medición y clasificación:

1. Incertidumbre temática causada por decisiones relacionadas con el umbral a partir del cual se considera que un ecosistema tipo se ha movido fuera de sus límites naturales de variabilidad, y debe entonces ser considerado como un ecosistema tipo diferente (Payet et al., 2013).

2. Error de medición debido a mediciones imperfectas o técnicas de mapeo que resultan en estimaciones de área que no son precisamente repetibles y fluctúan al azar (Elith et al., 2002; Olofsson et al., 2014; Fuller et al., 2003).

3. Error sistemático debido a métodos de mapeo que consistentemente producen estimados de superficie sesgados (Congalton \& Green, 2008). 
4. Errores de clasificación que resultan en una clasificación errónea de píxeles en un mapa de distribución, generalmente denominados errores de omisión o comisión (Congalton \& Green, 2008; Foody, 2011).

5. Errores de escala donde el tamaño de grano al cual el ecosistema es mapeado resulta en estimados de área que son dependientes de la escala en la cual son mapeados (Hartley \& Kunin, 2003; Gaston \& Fuller, 2009).

\section{Incertidumbre en los síntomas funcionales}

Un ecosistema colapsado puede ser reemplazado por un ecosistema emergente con características fuertemente contrastantes. Cuando los pastizales reemplazan a los bosques, el cambio en la estructura de la vegetación puede ser detectado fácilmente por una variedad de métodos próximos y de sensores remotos. En otros casos, los ecosistemas pueden perder sus rasgos característicos y colapsar, pero el ecosistema emergente puede parecerse al anterior, haciendo que los síntomas del colapso sean más difíciles de detectar. Burns et al. (2015) describen un ejemplo de ecosistema boscoso caracterizado por una biota asociada a grandes árboles viejos. Cuando las densidades de grandes árboles viejos caen por debajo de un nivel crítico, la biota nativa característica desaparece del sistema. Esto incluye aves y mamíferos que tienen sus nidos y refugios en los huecos de los árboles, e invertebrados que viven bajo la corteza suelta y en camas de hojarasca profundas. Después de estos cambios, el ecosistema emergente aún conserva una estructura de bosque, aunque uno caracterizado por árboles pequeños y carentes de la biota asociada con árboles de gran tamaño. Similarmente, Barrett \& Yates (2015) describieron el colapso de un matorral rico en especies como la eliminación de grupos de especies de plantas eliminados por una enfermedad transmitida por el suelo. El ecosistema emergente que reemplaza al anterior consiste de un matorral de estructura similar, pero con una composición y función diferentes. Estos y otros ejemplos ilustran las incertidumbres en la delimitación de los estatus existente y colapsado, los cuales dependen de las características del ecosistema anterior, el camino al colapso, y las características del nuevo ecosistema. Las fuentes de incertidumbre incluyen:

1. Definición de los estados de referencia del ecosistema, y la variabilidad natural dentro de ellos.

2. Definición de los estados colapsados del ecosistema, los cuales representan desviaciones críticas de la variabilidad natural. Los puntos de transición de los ecosistemas originales a los emergentes son inherentemente inciertos, pero pueden ser estimados dentro de límites plausibles (Fig. 3). El primer valor representa la ausencia de duda de que el ecosistema ha colapsado, mientras que el segundo es un valor razonable basado en observaciones o deducciones.

3. Variación en estados colapsados causados por diferentes procesos amenazantes. Las amenazas catastróficas pueden causar el colapso funcional y espacial total del ecosistema. Otras amenazas, tales como la degradación ambiental o la propagación de especies invasoras pueden causar diferentes cambios funcionales en la biota característica. Estas diferentes vías de colapso deben reflejarse dentro de la evaluación de riesgo. 
4. Incertidumbre en la medición de las variables que representan la función del ecosistema y el colapso. Al igual que con las variables espaciales, el error de medición en las variables funcionales puede afectar la evaluación de colapso del ecosistema a través de los errores aleatorios o de sesgo sistemático.
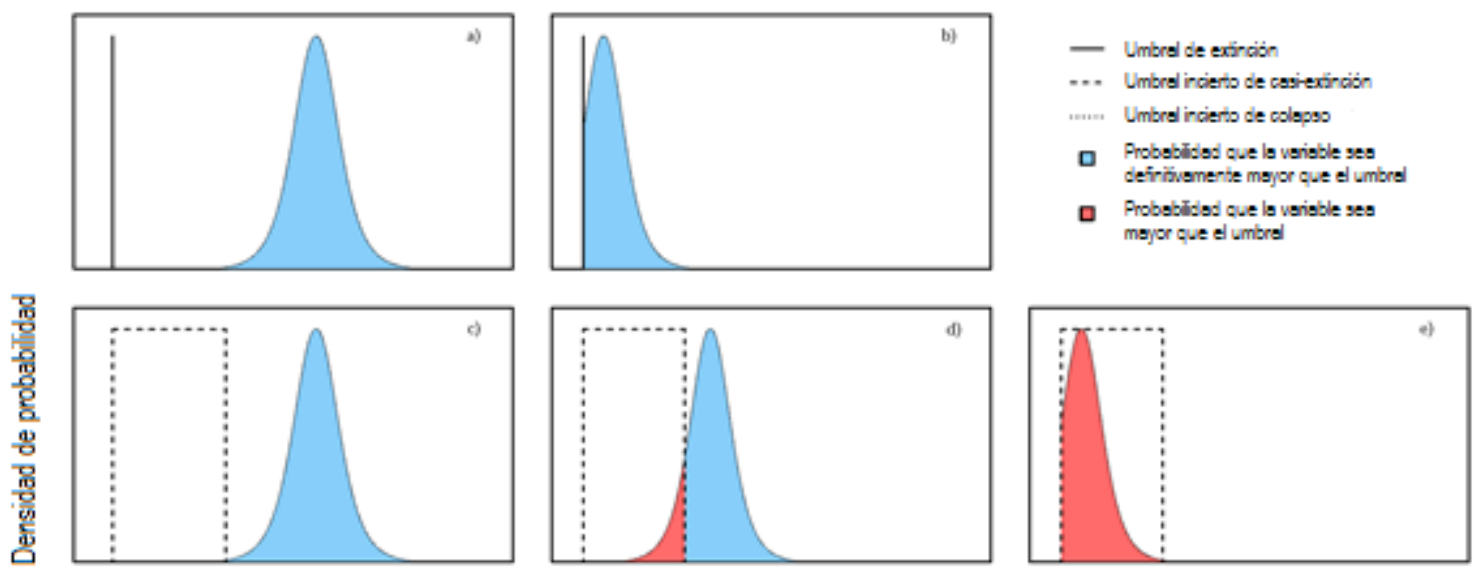

Variable poblacional
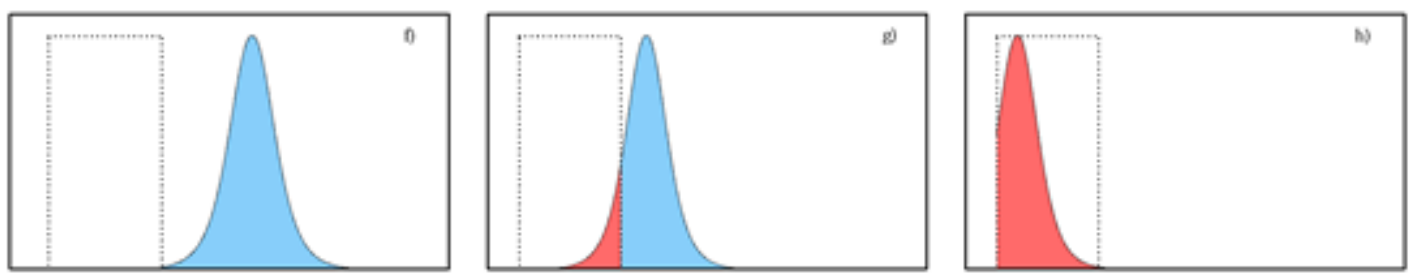

Variable ecosistémica

Figura 3. Funciones de densidad de probabilidad para las variables poblacionales y del ecosistema que miden la proximidad a los umbrales que definen la extinción de especies (a, b), la casi-extinción de especies (c-e), y el colapso del ecosistema (f-h). Para las especies, el umbral poblacional que define la extinción es conocido con certeza (p. ej. abundancia igual a cero, descrito por la línea vertical en (a) y (b)). En la práctica, los Análisis de Viabilidad Poblacional son calibrados en umbrales de casi-extinción más altos que los de extinción, para considerar la incertidumbre de predicción y manejo. Un límite inferior en el valor de extinción (abundancia cero), y un límite superior putativo para el valor de casi-extinción pueden ser representados por un recuadro punteado (c-e). Para los ecosistemas (f-h) el eje $x$ puede representar las características o procesos claves ( $p$. ej. distribución espacial, número de especies, calidad del agua). La definición límite de colapso es análoga a la definición de casi-extinción en las especies. El ancho del recuadro punteado representa la incertidumbre en la definición de colapso. El área azul representa la probabilidad de que el ecosistema sin duda persista, mientras que el área roja representa la probabilidad de que el ecosistema pueda persistir (adaptado de Keith et al., 2013). 


\subsection{Protocolo de evaluación de riesgo}

El protocolo de la LRE comprende cinco criterios basados en reglas para evaluar los riesgos a los ecosistemas. Los riesgos para los ecosistemas pueden ser causados por una variedad de procesos amenazantes que se expresan a través de diferentes síntomas de colapso del ecosistema (Keith, 2015). El protocolo de la LRE agrupa los síntomas de colapso del ecosistema en cuatro tipos principales e identifica los mecanismos correspondientes que enlazan los síntomas al riesgo de que el ecosistema pierda sus rasgos característicos (Fig. 4). Dos de los cuatro mecanismos producen síntomas de distribución: (A) disminución en la distribución, lo que reduce la capacidad de carga para la biota dependiente; y (B) distribución restringida, la cual predispone el sistema a las amenazas espacialmente explícitas. Otros dos mecanismos producen síntomas funcionales: (C) degradación del ambiente abiótico, reduciendo la calidad del hábitat o la diversidad del nicho abiótico para el componente biótico; y (D) alteración de los procesos e interacciones bióticas, resultando, por ejemplo, en la pérdida de mutualismos, diversidad del nicho biótico, o exclusión de algunos componentes bióticos por otros. Las interacciones entre dos o más de estos mecanismos contrastantes pueden producir síntomas adicionales de transición hacia el colapso del ecosistema. Múltiples mecanismos y sus interacciones pueden ser integrados en un modelo de simulación de la dinámica del ecosistema para producir estimados cuantitativos del riesgo de colapso (E). Estos cinco grupos de síntomas son la base de los criterios de la LRE. Un ecosistema tipo en evaluación debe ser evaluado usando todos los criterios para los cuales haya datos disponibles. El estatus de riesgo global del ecosistema tipo es asignado como la categoría de riesgo más alta obtenida a través de cualquier criterio.

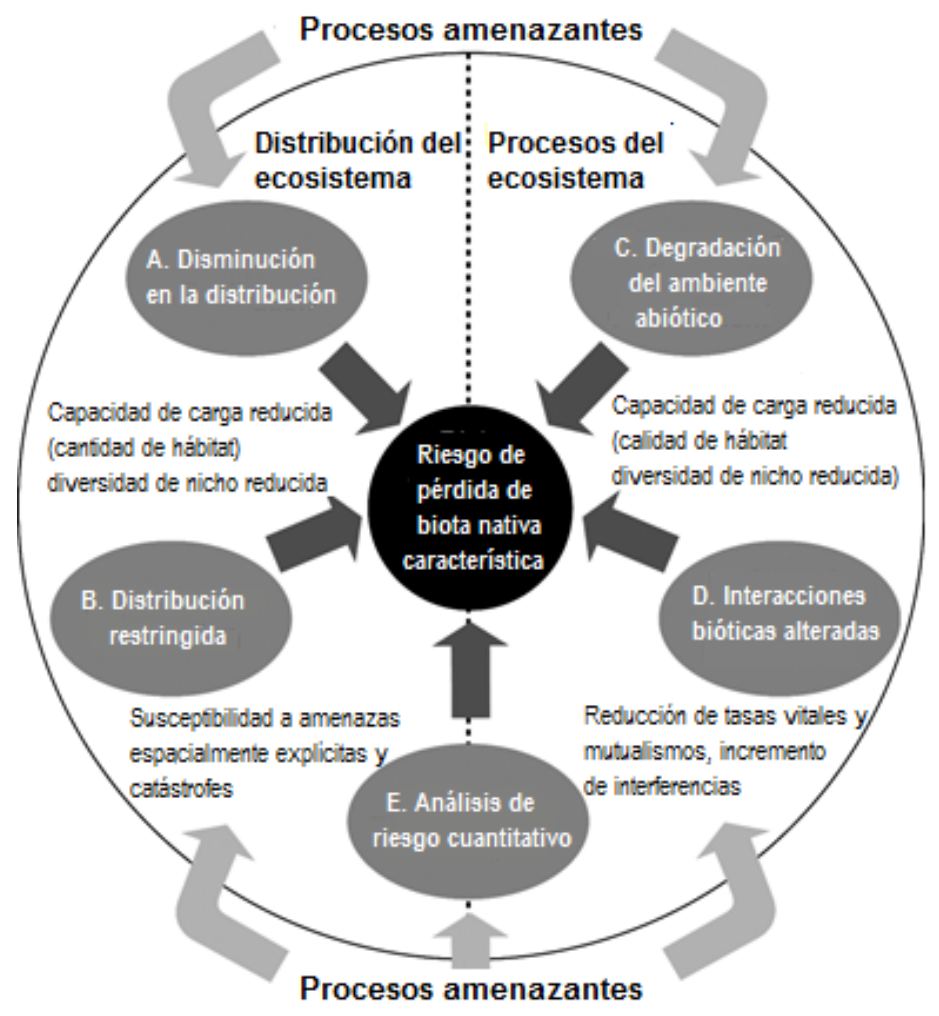

Figura 4. Mecanismos de colapso del ecosistema y síntomas de riesgo de colapso (fuente: Keith et al., 2013). 


\subsubsection{Períodos de tiempo}

Los criterios evalúan la degradación a lo largo de cuatro períodos de tiempo específicos: el pasado reciente, el presente, el futuro y el pasado histórico (Fig. 5). El período de tiempo denominado 'pasado reciente' abarca los últimos 50 años, lo cual es lo suficientemente reciente para capturar las tendencias actuales, pero lo suficiente largo como para distinguir un cambio de dirección de la variabilidad natural. El protocolo de la LRE supone que las disminuciones ocurridas durante este período de tiempo son indicativas del riesgo futuro independientemente de la causa.

La evaluación de futuras disminuciones requiere predicciones de cambios durante los próximos 50 años o cualquier período de 50 años, incluyendo el presente y futuro (Fig. 5). Las disminuciones pasadas pueden proporcionar una base para tales predicciones, pero otra información puede soportar predicciones e inferencias sobre las tasas de disminución futuras, incluso cuando el ecosistema está estable. Tales predicciones requieren hipótesis defendibles sobre el patrón de cambio en el futuro (p. ej. aceleración, constante, deceleración). Modelos alternativos razonables de cambio deben ser explorados cuando sea apropiado, pero una tasa de disminución proporcional constante es a menudo una suposición por defecto razonable (Sección 5).

Las evaluaciones de disminuciones históricas son esenciales para los ecosistemas que contienen biotas con tiempos generacionales largos y lenta rotación de las poblaciones (Mace et al., 2008). También son esenciales para las especies fundamentales con tiempos generacionales cortos que pueden haber sufrido grandes reducciones históricas (p. ej. los arrecifes de ostras: Kirby, 2004; Beck et al., 2011). Aun cuando las tasas futuras de diminución se reduzcan, las disminuciones históricas en distribución o función pueden predisponer a un ecosistema a amenazas adicionales y reducir su capacidad para absorber cambios adversos (Folke et al., 2004). Las disminuciones históricas son evaluadas en relación con el estatus del ecosistema en una fecha de referencia teórica de 1750 , que corresponde aproximadamente a la primera aparición de la explotación a escala industrial de los ecosistemas. En las partes del mundo donde la explotación a escala industrial de los ecosistemas comenzó antes o después de 1750, es razonable evaluar disminuciones históricas con una línea base diferente. Los modelos de distribución con predictores ambientales pueden ser utilizados para estimar disminuciones históricas basadas en la diferencia entre el estado actual de un ecosistema y el estado esperado en la ausencia de efectos antropogénicos de escala industrial. Tales enfoques son más útiles en las regiones donde el cambio a escala del paisaje no ocurrió antes de la era industrial. 


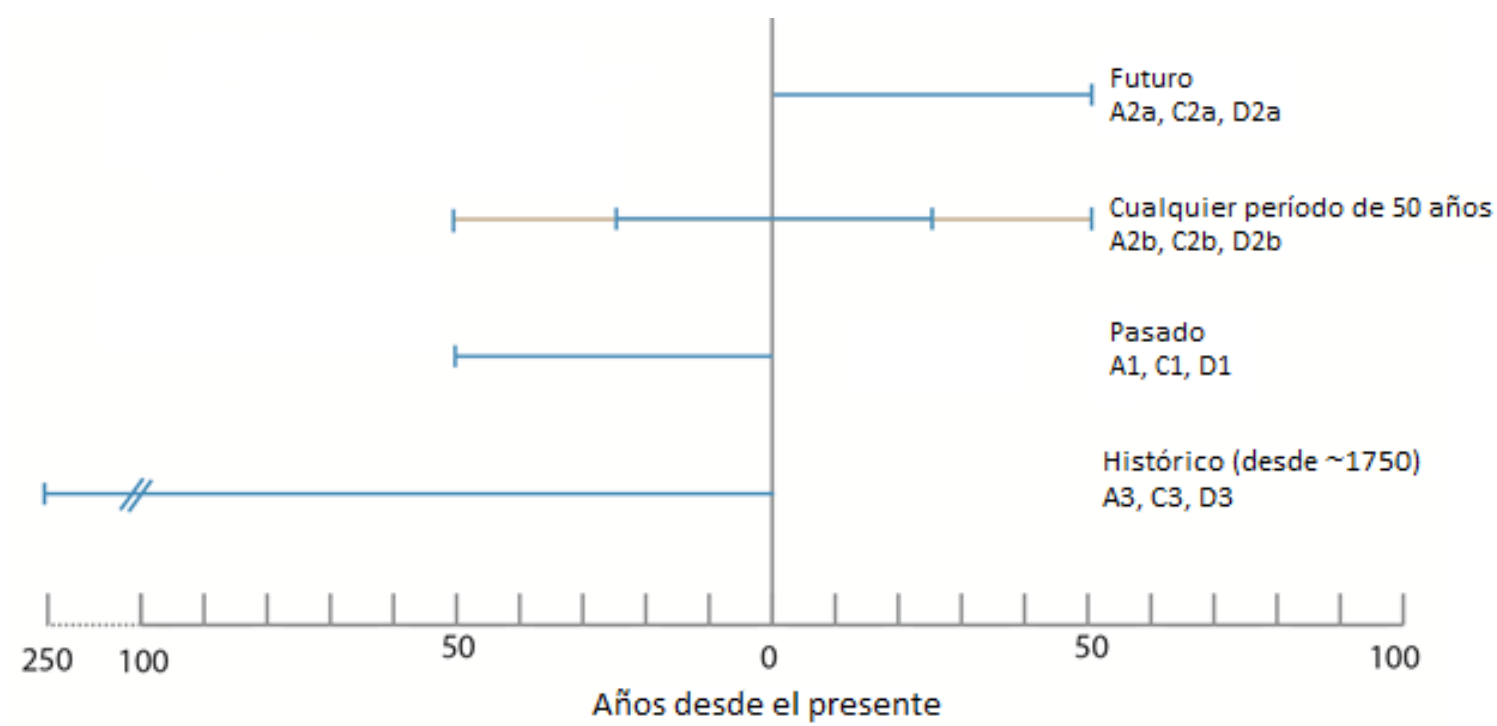

Figura 5. Períodos de tiempo para la evaluación de los cambios bajo los criterios A, C y D (adaptado de Keith et al., 2013).

\subsubsection{Umbrales de disminución}

Las categorías de riesgo ordinales (Sección 3) están delimitadas por los umbrales definidos en las Categorías y Criterios de la Lista Roja de Ecosistemas de UICN (Apéndice 2). La justificación de los criterios y categorías ordinales está basada en la teoría (Keith et al., 2013). Sin embargo, los valores de los umbrales que delimitan las categorías están basados parcialmente en consideraciones teóricas y parcialmente en consideraciones utilitarias (Keith et al., 2015). La teoría proporciona una base cualitativa para umbrales ordenados de la diminución, pero ofrece poca orientación para el establecimiento de sus valores absolutos. El propósito de estos umbrales de decisión es clasificar los ecosistemas en categorías ordinales informativas de riesgo, más que estimar las probabilidades exactas de colapso. Consecuentemente, para los criterios A, C y D, los valores de los umbrales fueron fijados a intervalos relativamente uniformes para las disminuciones actuales y futuras en la distribución o función del ecosistema (Vulnerable: 30\%, En Peligro: 50\%, En Peligro Crítico: $80 \%$ ). El rango de umbrales entre 0 y $100 \%$ busca lograr una clasificación informativa más que una clasificación muy sesgada de los ecosistemas entre las categorías. El umbral más bajo para un ecosistema tipo amenazado $(30 \%)$ reconoce que se necesita una evidencia de una disminución apreciable en la distribución y función del ecosistema para para apoyar su inclusión en una categoría de amenaza. Estos umbrales son consistentes con los umbrales de disminución poblacional de la Lista Roja de Especies Amenazadas de UICN (IUCN, 2001,2012 ). Los umbrales para las disminuciones históricas son más altos (A3, C3, D3; $50 \%, 70 \%, 90 \%$ ) debido a que los marcos de tiempo son más largos.

Cuando las disminuciones están cercanas en 5-10\% a los umbrales para la categoría Vulnerable, se puede justificar la inclusión del ecosistema dentro de la categoría Casi Amenazado, aunque no existen umbrales cuantitativos para esta categoría (Sección 3). Por ejemplo, un ecosistema tipo con una extensión de la presencia de 50.000 a $55.000 \mathrm{~km}^{2}$ que califique para al menos uno de los tres subcriterios del criterio $B$ puede calificar a ser listado como Casi Amenazado. Un ecosistema tipo con una disminución en una variable abiótica de $20 \%$ a $30 \%$ de severidad relativa y $100 \%$ de extensión puede calificar como Casi Amenazado bajo el subcriterio $\mathrm{C} 1$ o $\mathrm{C} 2$. 


\subsubsection{Estándares de evidencia y el tratamiento de la incertidumbre}

Lograr una evaluación robusta y repetible de un ecosistema tipo requiere gran cantidad de datos, a menudo a partir de fuentes dispares. Las categorías y criterios fueron específicamente diseñadas para permitir la inclusión de varios tipos de datos provenientes de una gama de fuentes, pero es responsabilidad del evaluador el evaluar críticamente si la cantidad y calidad de los datos son suficientes para apoyar el resultado determinante de una evaluación. Para obtener orientación sobre esta evaluación, los evaluadores son referidos a los principios adoptados por el Panel Intergubernamental sobre el Cambio Climático para el tratamiento coherente de la incertidumbre (Mastrandrea et al., 2010). En resumen, los principios clave incluyen:

1. Evaluar el tipo (Tabla 2), cantidad, calidad y consistencia de la evidencia (descriptores resumen: "limitado," "medio," o "robusto");

2. Evaluar el grado de concordancia entre las diferentes fuentes de evidencia (descriptores resumen: "bajo," "medio," o "alto");

3. Proporcionar una explicación trazable que describa la evaluación de la evidencia y la concordancia;

4. Evaluar la posibilidad (Tabla 3) de categorías alternativas como el resultado de una evaluación;

5. Comunicar la incertidumbre en los resultados de una evaluación al reportar la categoría más probable así como las categorías que representan razonablemente los límites superiores e inferiores del resultado de una evaluación (Sección 4.4.1).

El estándar de evidencia para la LRE debe ser suficiente para apoyar inferencias de que:

1. Algunas categorías (LC, NT, VU, EN o CR) son resultados 'muy improbables' de una evaluación (es decir, probabilidad $<10 \%$, Tabla 3). Si ninguna categoría es un resultado de evaluación muy improbable, entonces el estatus debe ser asignado como Datos Insuficientes (DD);

2. Los límites factibles de resultados de la evaluación incluyen todas las categorías necesarias para garantizar que colectivamente sean 'muy probable' para abarcar el estado verdadero (es decir, probabilidad $>90 \%$, Tabla 3 ). Si todas las categorías (LC-CR) están dentro de los límites posibles, entonces el estatus debe ser asignado como Datos Insuficientes (DD);

3. El mejor estatus global (i.e., categorización de un ecosistema) es más probable que cualquier categorización alternativa y dentro de los límites factibles; y

4. Todas las categorizaciones de un estado global en la categorías Colapsado (CO) son 'prácticamente seguras' (i.e., certeza $>99 \%$, Tabla 3). Cuando este no es el caso y CO es la categoría más probable, el mejor estatus global debe ser asignado como $\mathrm{CR}$, y CO reportado como el límite superior del resultado de la evaluación. 
Tabla 2. Los descriptores para los tipos de evidencia (IUCN, 2001, 2012) típicamente soportarán las inferencias durante una evaluación. Esto aplica a variables cuantitativas (tales como las tasas de cambio en la distribución) e inferencias binarias (tales como si hay o no una disminución continua en la distribución).

\begin{tabular}{|c|c|}
\hline Descriptor & Explicación \\
\hline Observado & $\begin{array}{l}\text { Información que está basada directamente en registros bien documentados de } \\
\text { todas las ocurrencias de un ecosistema (IUCN Standards and Petitions } \\
\text { Subcommittee, 2014). }\end{array}$ \\
\hline Estimado & $\begin{array}{l}\text { Información que está basada en cálculos que pueden incluir suposiciones } \\
\text { estadísticas sobre la muestra, o suposiciones biológicas sobre la relación entre } \\
\text { la variable observada y la variable de interés (p. ej. la relación entre el índice de } \\
\text { abundancia y el número de individuos maduros; IUCN Standards and } \\
\text { Petitions Subcommittee, 2014). Estas suposiciones deben ser indicadas y } \\
\text { justificadas en la documentación de la evaluación. La estimación también puede } \\
\text { implicar la interpolación en el tiempo para el cálculo de la variable de interés en } \\
\text { un momento particular (p. ej. una disminución en } 50 \text { años en la distribución } \\
\text { basada en observaciones de distribución de } 40 \text { y } 60 \text { años atrás). }\end{array}$ \\
\hline Inferido & $\begin{array}{l}\text { Información que está basada en evidencia indirecta y en variables que están } \\
\text { indirectamente relacionadas con la variable de interés, pero en el mismo tipo } \\
\text { general de unidades (IUCN Standards and Petitions Subcommittee, 2014). Los } \\
\text { valores inferidos se basan más en suposiciones que en valores estimados. Por } \\
\text { ejemplo, inferir la interrupción de las interacciones bióticas a partir de las } \\
\text { estadísticas de captura no sólo requiere supuestos estadísticos (p. ej. muestreo } \\
\text { aleatorio) y suposiciones biológicas (sobre la relación de la sección de cosecha } \\
\text { de la población con la población total), sino también suposiciones acerca de las } \\
\text { tendencias en el esfuerzo, la eficiencia y la distribución espacial y temporal de la } \\
\text { cosecha en relación con la población. La inferencia también puede involucrar la } \\
\text { extrapolación de cantidades observadas o estimadas de ocurrencias conocidas } \\
\text { de un ecosistema para calcular la misma cantidad para otras ocurrencias. El que } \\
\text { haya suficientes datos para hacer tal inferencia dependerá del tamaño de las } \\
\text { ocurrencias conocidas en términos de la proporción de la distribución total, y la } \\
\text { aplicabilidad de las amenazas y tendencias observadas en las ocurrencias } \\
\text { conocidas al resto del ecosistema. }\end{array}$ \\
\hline Proyectado & $\begin{array}{l}\text { Igual que para el estimado, pero la variable de interés es extrapolada en el } \\
\text { tiempo hacia el futuro (IUCN Standards and Petitions Subcommittee, 2014). Las } \\
\text { variables proyectadas requieren una discusión del método de extrapolación (p. } \\
\text { ej. justificación de las suposiciones estadísticas o del modelo de ecosistema } \\
\text { usado) así como la extrapolación de amenazas actuales o potenciales en el } \\
\text { futuro, incluyendo sus tasas de cambio. }\end{array}$ \\
\hline
\end{tabular}


Tabla 3. Lenguaje calibrado para describir la incertidumbre cuantificada (fuente: Mastrandrea et al., 2010). Puede ser usado para expresar el estimado de probabilidad de una cantidad, una inferencia binaria o un resultado de una evaluación (p. ej. una magnitud de cambio en la distribución, ya sea que haya o no un cambio, si el estatus de un ecosistema está dentro de un determinado rango). La probabilidad puede basarse en análisis estadísticos o de modelado, la obtención de puntos de vista de expertos, u otros análisis cuantitativos. Se puede considerar que las categorías definidas en la presente tabla tienen límites "borrosos" (Kauffman \& Gupta, 1991).

\begin{tabular}{|ll|}
\hline Término & $\begin{array}{l}\text { Posibilidad de un } \\
\text { resultado (probabilidad) }\end{array}$ \\
\hline Prácticamente seguro & $99-100 \%$ \\
\hline Muy probable & $90-100 \%$ \\
\hline Probable & $66-100 \%$ \\
\hline Más probable que no & $50-100 \%$ \\
\hline Tan probable como no & $33-66 \%$ \\
\hline Improbable & $0-33 \%$ \\
\hline Muy improbable & $0-10 \%$ \\
\hline Excepcionalmente improbable & $0-1 \%$ \\
\hline
\end{tabular}




\section{Proceso de evaluación}

Evaluar un ecosistema tipo contra las Categorías y Criterios de la Lista Roja de Ecosistemas de UICN es un proceso secuencial. Todos los componentes deben ser completados antes de la presentación de la evaluación (Fig. 6).

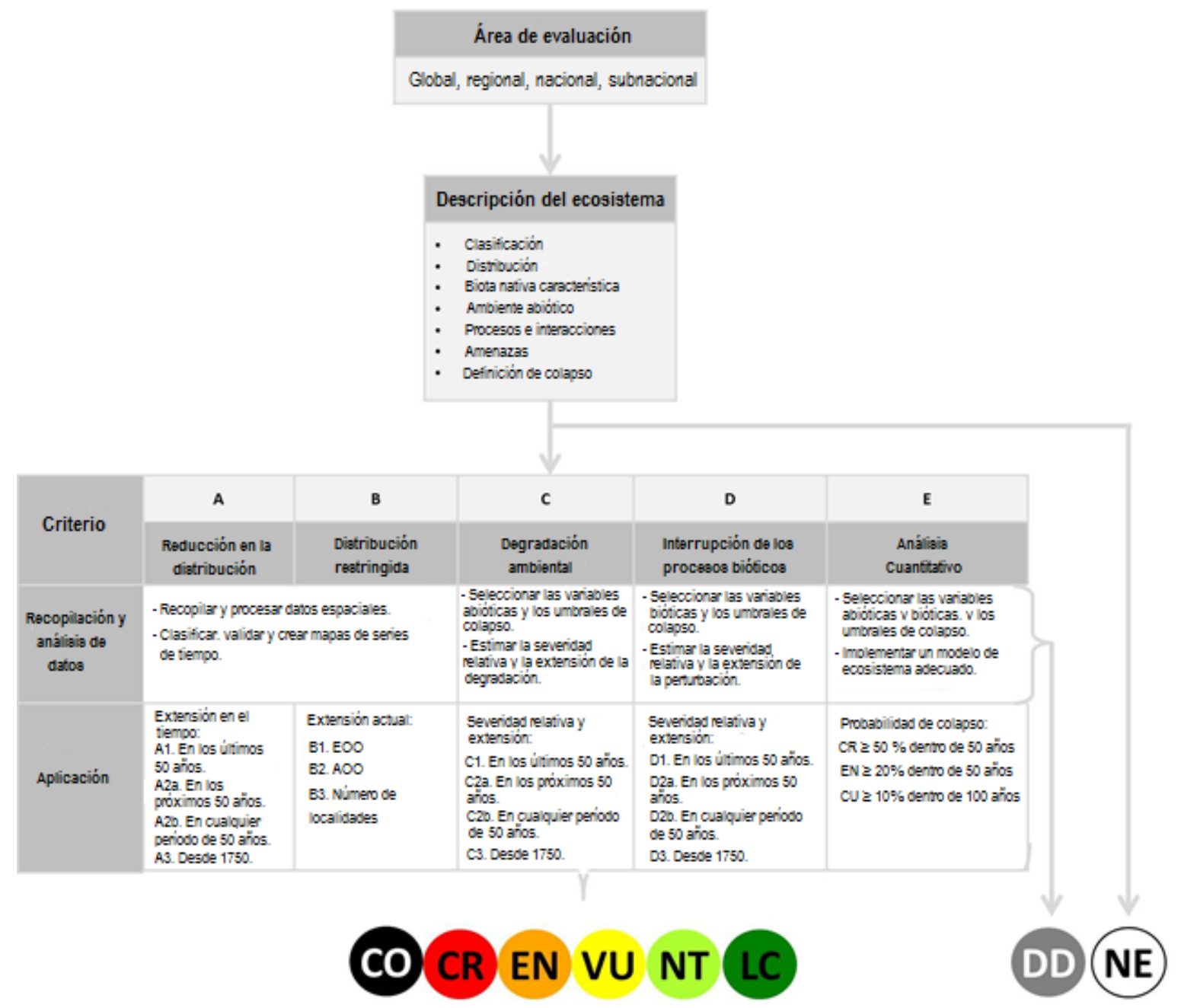

Figura 6. Procesos para la evaluación de riesgo de colapso de un ecosistema tipo. 


\section{1 Área de evaluación}

Las evaluaciones de la Lista Roja de Ecosistemas (LRE) pueden ser llevadas a cabo dentro de diferentes áreas geográficas. Las evaluaciones globales consideran todas las ocurrencias de un ecosistema tipo alrededor del mundo. Esto es esencial para el conjunto de ecosistemas tipo ampliamente definidos que formarán la LRE global, y para informar las metas internacionales de diversidad biológica y las estrategias de conservación. Las evaluaciones sub-globales son posibles: están típicamente definidas por fronteras políticas (evaluaciones continentales, nacionales o estadales) o eco-regionales (cuencas oceánicas y de captación). Ya existen muchas listas sub-globales de ecosistemas, tales como la lista de ecosistemas amenazados de Alemania, (Blab et al., 1995), Australia Occidental (DEC, 2007), Finlandia (Kontula \& Raunio, 2009), Venezuela (Rodríguez et al., 2010), Austria (Essl \& Egger, 2010), Noruega (Lindgaard \& Henriksen, 2011), Sudáfrica (Driver et al., 2012), Nueva Zelandia (Holdaway et al., 2012) y El Salvador (Crespin \& Simonetti, 2015), aunque sólo la última utilizó la Versión 2.0 de las Categorías y Criterios de la Lista Roja de Ecosistemas de UICN.

Para las evaluaciones de áreas sub-globales, usualmente será apropiado evaluar ecosistemas tipo de una resolución temática más refinada que para las evaluaciones globales, ya que las evaluaciones sub-globales usualmente requerirán detalles más refinados para apoyar la toma de decisiones sobre el uso de las tierras y aguas. Por ejemplo, una LRE nacional puede tener un mayor número de evaluaciones de ecosistemas tipo divididos más finamente para un área determinada, en comparación con una evaluación de la LRE a nivel global.

El mismo ecosistema tipo puede ser asignado a diferentes categorías de riesgo en evaluaciones sub-globales y globales. La diferencia en el estatus depende de la distribución de los procesos de amenaza a lo largo del rango del ecosistema tipo en relación con los límites de la evaluación sub-global. A pesar de que aún no han sido desarrolladas directrices regionales para la aplicación de las Categorías y Criterios de la Lista Roja de Ecosistemas de UICN, algunas reglas generales aplican:

1. Una descripción detallada de la unidad de evaluación (ecosistema tipo) sigue siendo requerida. El área de evaluación (p. ej. fronteras políticas) debe ser claramente definida y respaldada con mapas u otros datos espaciales.

2. No se requieren modificaciones de las categorías o criterios $A, C, D \circ E$ cuando se realizan evaluaciones sub-globales de los ecosistemas. Por lo tanto, todos los umbrales, período de tiempos, definiciones y requisitos de datos se mantienen sin alteración para las aplicaciones sub-globales de la LRE.

3. La aplicación del subcriterio B1 y sus umbrales permanece sin cambios (Sección 5.2). Se aplica un polígono convexo mínimo que encierre todas las ocurrencias de un ecosistema tipo, independientemente de si los bordes cruzan los límites del área de evaluación. No se permiten huecos o cortes en el polígono convexo mínimo, independientemente de los límites del área de evaluación. 
4. Cuando el área de evaluación sea similar o más pequeña que los umbrales de EOO o AOO para la categoría Vulnerable, el listado de los ecosistemas tipo bajo el criterio $B$ dependerá solamente del cumplimiento del subcriterio. Actualmente están en progreso investigaciones para apoyar directrices y herramientas específicas para aplicar el criterio B en áreas de evaluación pequeñas.

\subsection{Describiendo la unidad de evaluación}

Para garantizar la repetitividad de la aplicación de las Categorías y Criterios de la Lista Roja de Ecosistemas de UICN, la descripción y definición detallada de las unidades de evaluación es un componente esencial del proceso de evaluación. La descripción y evaluación están basadas en una recopilación exhaustiva de toda la información disponible sobre el ecosistema tipo bajo consideración. La descripción de un ecosistema tipo debe proporcionar información contextual sobre su clasificación; describir claramente los cuatro elementos que definen el ecosistema tipo (biota nativa característica; ambiente abiótico; procesos e interacciones clave; y distribución espacial); y describir las amenazas y los estados colapsados.

Los evaluadores deben usar la plantilla de descripción para ecosistemas tipo (Tabla 4) y justificar por qué la unidad seleccionada para la evaluación es considerada un ecosistema tipo diferente de un ecosistema tipo adyacente o similar ¿Cuáles son las principales características que distinguen al ecosistema tipo focal de otros ecosistemas tipo? La información que sustenta la descripción del ecosistema tipo debe ser incluida en la documentación de la evaluación, y será evaluada en la revisión por expertos. Se espera que todas las propuestas a la LRE global incluyan información de apoyo relevante, incluyendo una lista de referencias totalmente poblada, mapas, coordenadas geográficas, fotografías ejemplares y cualquier otra información que aumente la capacidad de repetir la evaluación. Estas propuestas estarán libremente disponibles en el sitio web de la Lista Roja de Ecosistemas de UICN (www.iucnrle.org). 
Tabla 4. Plantilla de descripción para ecosistema tipos.

\begin{tabular}{|c|c|}
\hline Elementos & Descripción \\
\hline Clasificación & $\begin{array}{l}\text { Referencias cruzadas con clasificaciones ecológicas } \\
\text { relevantes: } \\
\text { a. Clasificación de origen. } \\
\text { b. Esquema de clasificación de hábitats de UICN. } \\
\text { c. Clasificaciones ecoregionales. }\end{array}$ \\
\hline Distribución espacial & $\begin{array}{l}\text { Describir la distribución y extensión: } \\
\text { a. Datos precisos de distribución espacial. } \\
\text { b. Estimados de área. } \\
\text { c. Series de tiempo, proyecciones (pasadas, presente, } \\
\text { futuras). }\end{array}$ \\
\hline Biota nativa característica & $\begin{array}{l}\text { Identificar los rasgos bióticos determinantes: } \\
\text { a. Taxones nativos diagnóstico y su abundancia relativa } \\
\text { en comparación con otros ecosistemas tipo. } \\
\text { b. Componentes funcionales de la biota característica y } \\
\text { sus papeles en el sistema focal en comparación con } \\
\text { otros. } \\
\text { c. Límites de la variabilidad especial y temporal en la } \\
\text { biota del ecosistema. } \\
\text { d. Fotografías ejemplares. }\end{array}$ \\
\hline Ambiente abiótico & $\begin{array}{l}\text { Identificar los rasgos abióticos determinantes: } \\
\text { a. Textos descriptivos y referencias de los estados o } \\
\text { valores característicos de las variables abióticas. } \\
\text { b. Descripciones gráficas de las variables abióticas. } \\
\text { c. Fotografías ejemplares. }\end{array}$ \\
\hline $\begin{array}{l}\text { Procesos e interacciones: } \\
\text { - Dentro de la biota } \\
\text { - Entre la biota y el entorno }\end{array}$ & $\begin{array}{l}\text { Describir los controladores (drivers) clave del ecosistema: } \\
\text { a. Textos descriptivos y referencias. } \\
\text { b. Modelo conceptual. } \\
\text { c. Fotografías ejemplares. }\end{array}$ \\
\hline Amenazas & $\begin{array}{l}\text { Describir las principales amenazas e impactos en el } \\
\text { funcionamiento del ecosistema: } \\
\text { a. Textos descriptivos y referencias. } \\
\text { b. Diagnóstico basado en el esquema de clasificación } \\
\text { de amenazas de UICN. } \\
\text { c. Fotografías ejemplares. }\end{array}$ \\
\hline Definición de colapso & $\begin{array}{l}\text { Describir el(los) estado(s) colapsado(s) y sus umbrales } \\
\text { específicos al ecosistema bajo evaluación. }\end{array}$ \\
\hline
\end{tabular}

\subsubsection{Clasificación}

Los ecosistemas tipo deben tener referencias cruzadas a cualquier clasificación de ecosistemas relevante, incluyendo clasificaciones de origen (tales como clasificaciones de vegetación para sistemas terrestres), clasificaciones eco-regionales y el esquema de clasificación de hábitats de UICN (www.iucnredlist.org/technical-documents/classificationschemes/habitats-classification-scheme-ver3). Está disponible orientación adicional para el uso del Esquema de Clasificación de Hábitats de UICN. Cuando la tipología global de la LRE esté disponible, también se requerirá la referencia cruzada con ella (3.1.1 Tipologías de ecosistemas ). 


\subsubsection{Distribución espacial}

La mejor forma de representar la información sobre la distribución espacial de un ecosistema tipo es a través de mapas o inventarios de localidades. Estos pueden derivarse de sensores remotos, modelos biofísicos de distribución, observaciones de campo o una combinación de los tres (Caja 2). Las características espaciales de algunos ecosistemas (tales como ambientes pelágicos) son inherentemente dinámicos a lo largo de períodos de tiempo relativamente cortos, por lo que las distribuciones espaciales sólo pueden ser descritas a niveles de resolución muy gruesa. Dada la diversidad de métodos y mapas disponibles, un aspecto importante de la descripción es justificar por qué un conjunto de datos espaciales en particular es una representación adecuada de la distribución de los ecosistemas. En las secciones 5.1 y 5.2 se proporciona más información sobre cómo describir claramente la distribución espacial de un ecosistema tipo. Se anima a los evaluadores a depositar el mapa del ecosistema en un repositorio en línea adecuado.

Caja 2. Mapa de distribución del ecosistema de llanuras intermareales del Mar Amarillo

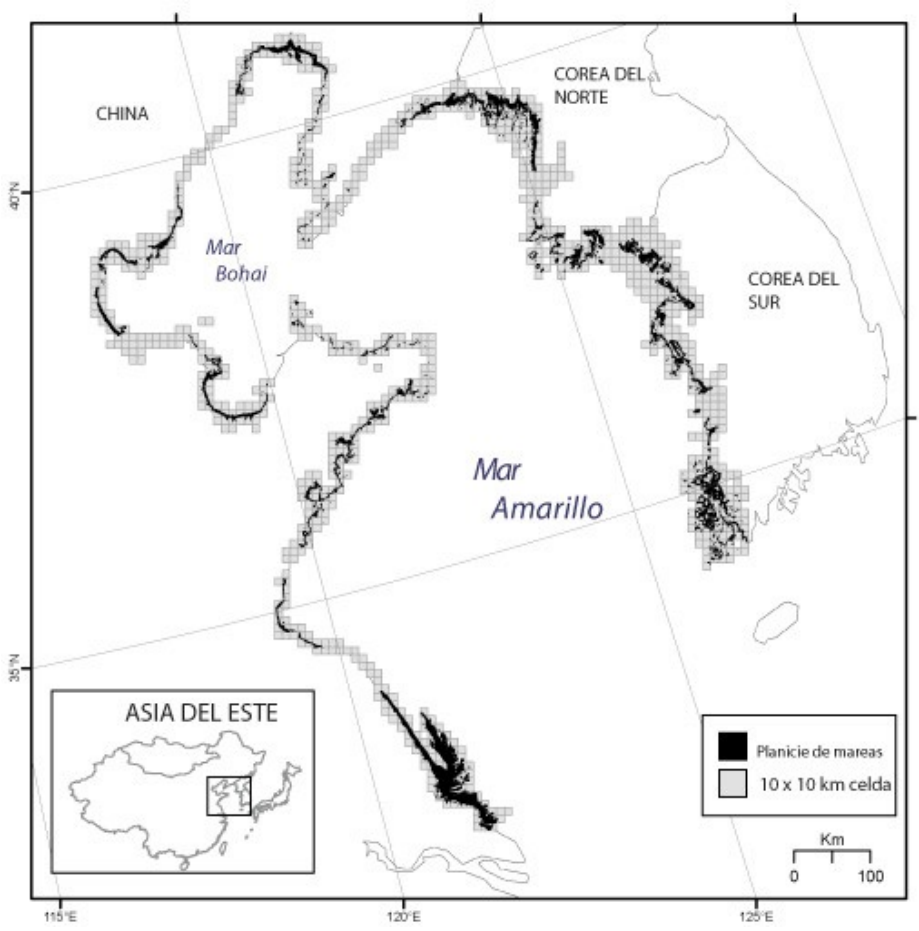

La distribución del ecosistema de Ilanuras intermareales del Mar Amarillo fue mapeada mediante la aplicación de un método de clasificación de sensores remotos a imágenes de satélite del Archivo Landsat (Murray et al., 2012; Murray et al., 2014; Murray \& Fuller, 2015). El mapa clasificado tiene una precisión global > $94 \%$ cuando es evaluado utilizando una matriz de confusión, un método ampliamente aplicado para evaluar la exactitud de mapas clasificados (Murray et al., 2014; Congalton \& Green, 2008). Los estimados de área del ecosistema tipo para el criterio A son derivados de la distribución del ecosistema (negro), mientras que el área de ocupación (AOO) es determinada por el conteo de número de celdas de 10x10 km en las cuales hay ocurrencias del ecosistema tipo $>1 \mathrm{~km}^{2}$ (Murray et al., 2015).

\subsubsection{Biota nativa característica}

El concepto de biota nativa característica es fundamental para la evaluación de riesgo de los ecosistemas y, por tanto, es un componente importante de su descripción (Caja 3). La biota nativa característica incluye los genes, poblaciones, especies, ensambles de especies y sus interacciones clave que: (i) distinguen composicionalmente a un ecosistema tipo de otros (componentes diagnósticos); y (ii) son centrales en la dinámica y función del 
ecosistema, tales como ingenieros de ecosistema, dominantes tróficos o estructurales o elementos funcionalmente únicos (componentes funcionales). Los componentes diagnósticos de la biota nativa característica deben demostrar un nivel composicional único e identificar elementos funcionalmente importantes. En general, la descripción no necesita incluir inventarios de especies exhaustivos.

La biota nativa característica es crucial en el diagnóstico de colapso del ecosistema debido a que define parte de la 'identidad' del ecosistema tipo. Por lo tanto, la pérdida de biota nativa característica o de procesos en los ésta juega un papel funcional indican una transformación de la identidad, el colapso del ecosistema tipo y la sustitución por un sistema emergente.

La biota nativa característica puede ser definida en términos de taxonomía o de rasgos funcionales (p. ej. composición del gremio, espectros de rasgos, características estructurales tales como la arquitectura de árboles o corales) y excluye especies exóticas y raras o especies errantes que contribuyen poco a la función del ecosistema. Los ejemplos de biota nativa característica incluyen especies que son endémicas o casi-endémicas del ecosistema tipo, predadores que estructuran las comunidades animales, especies de árboles que crean microclimas a nivel de dosel o a nivel del suelo, corales y ostras creadores de arrecifes que promueven la diversidad de nicho para que cohabiten peces y macroinvertebrados, plantas nodrizas y aquellas que proporcionan espacios para evitar a los depredadores, animales de madriguera, agrupaciones fijadoras de nitrógeno, agentes de dispersión clave responsables del movimiento de la biota o de los recursos, plantas formadoras de turba, gremios detritívoros y plantas inflamables que promueven fuegos recurrentes.

Caja 3. Describiendo la biota nativa característica (adaptado del Apéndice S2 en Keith et al., 2013).

Turberas altas, Alemania

Este ecosistema tipo está caracterizado por vegetación dominada por musgos de turba (p. ej. Sphagnum magellanicum, Sphagnum fuscum) y plantas insectívoras como el rocío de sol (Drosera sp.). El dominio de los musgos de turba junto con los procesos geomorfológicos e hidrológicos distingue a las turberas altas de otros ecosistemas tipo. Otras especies típicas de las turberas altas en Alemania son las plantas vasculares pantano-romero (Andromeda polifolia) y arándano (Vaccinium oxycoccos), la especie de mariposa Boloria aquilonaris, la polilla Carsia sororiata y el escarabajo de tierra Agonum ericeti (Blab et al., 1995).

\section{Alvar de los Grandes Lagos, Norte América}

Este ecosistema tipo está caracterizado por una fisonomía variable, desde praderas abiertas perennes (raramente anuales) o matorrales y pavimento no vascular (5-25\% cubierta de hierba y/o arbustos) hasta densas praderas o matorrales (>25\%) con árboles de coníferas siempre verdes dispersos (más raramente caducifolio de hoja ancha) (Reschke et al., 1999; Catling \& Brownell, 1995). La composición de especies contiene una mezcla de praderas de pastos altos graminoides y malezas, y arbustos y árboles sub-boreales a boreales. Los dominantes claves y diferenciales incluyen las perennes Schizachyrium scoparium, Sporobolus heterolepis, Danthonia spicata y Deschampsia caespitosa; junto con las menos comunes Sporobolus neglectus, Sporobolus vaginiflorus, y Panicum philadelphicum. Los arbustos clave, cuando están presentes, son Juniperus communis, J. horizontalis, Dasiphora fruticosa ssp. floribunda y Rhus aromatica. Los árboles, cuando están presentes, incluyen Thuja occidentalis, Picea glauca, Pinus banksiana, 
y Abies balsamea (en los sitios más al norte) y Juniperus virginiana, Quercus macrocarpa o Quercus muehlenbergii (en los sitios más al sur).

Los bosques de algas marinas gigantes, Alaska

Los bosques de algas marinas de Alaska son ensambles estructural y funcionalmente diversos. Se caracterizan por especies de algas pardas del Orden Laminariales incluyendo Nereocystis luetkeana, Laminaria groenlandica, Alaria fistulosa, Agarum fimbriatum y Thalassiophyllum sp. (Steneck et al., 2002). Estas crean unos bosques de arquitectura compleja y dinámica en capas de hasta $15 \mathrm{~m}$ de altura que proporcionan sustrato, refugio y recursos de forrajeo para un amplio conjunto de fauna de invertebrados epibentónicos herbívoros y depredadores pelágicos vertebrados (Steneck \& Watling, 1982; Estes et al., 2009). Los invertebrados característicos incluyen erizos, Strongylocentrotus franciscanus, S. purpuratus y S. droebachiensis, lapas, y estrellas de mar, Solaster spp. Los peces, incluyendo el bacalao del Pacífico (Gadus macrocephalus) y las molvas de roca (Hexagrammos lagocephalus,) son depredadores importantes que dependen directa o indirectamente del ecosistema (Reisewitz et al., 2006). Los meso-depredadores característicos incluyen a las nutrias de mar, (Enhydra lutris), focas (Phoca vitulina), leones marinos de Steller (Eumetopias jubatus) y los osos marinos árticos (Callhorinus ursinus). La vaca marina de Steller (Hydrodamalis gigas), ahora extinta, era un miembro herbívoro funcionalmente único del ensamble de vertebrados (Domning, 1972). Los depredadores pelágicos grandes son también componentes importantes del ecosistema, incluyendo las orcas (Orcinus orca) y más de 15 especies de ballenas grandes, incluyendo a los cachalotes (Physeter macrocephalus) y los rorcuales (Balaenoptera physalus). Los bosques de algas marinas son generalmente separados geográficamente por masas continentales o aguas profundas. Los bosques de algas marinas de Alaska son continuos con los de California, pero difieren composicionalmente en su conjunto más diverso de macroalgas, incluyendo la Macrocystis pyrifera.

Comunidades de invertebrados bentónicos distribuidas a poco profundidad bajo el hielo (fuente: Clark et al., 2015)

Las comunidades bajo el hielo están típicamente compuestas de una mezcla de suspensívoros sésiles y macro-invertebrados móviles, elementos que son una reminiscencia de la fauna de aguas profundas, pero ocurren en profundidades tan superficiales como unos pocos metros. La fauna sésil incluye Porifera (Demospongia, Hexactinellida, Calcaria), Gorgonaria, Pennatularia, Alcyonaria, Stolonifera, Hydrozoa, Actiniaria, Bryozoa, Brachiopoda, Polychaeta, y Ascidiacea tanto solidaria como colonial (Dayton, 1990; Gili et al., 2006). Se sabe que a escalas locales ocurre dominancia de algunos taxones sésiles, tales como las esponjas (Dayton, 1979, McClintock et al., 2005) y ascidias (obs. pers.). La fauna con esqueletos frágiles es claramente abundante, lo que se cree es debido a la falta de depredadores durófagos (trituradores de esqueleto) (Aronson \& Blake, 2001), aunque también puede relacionarse a la baja energía del oleaje en costas protegidas por el hielo. Los invertebrados móviles ocurren con esta fauna sésil o pueden dominar en algunas áreas. Los taxones que ocurren comúnmente incluyen a los Echinodermata (Echinoidea, Asteroidea, Ophiuroidea, Holothurioidea) y Peracarida (Amphipoda, Isopoda, Tanaidacea, Mysidacea, Cumacea) ambos de los cuales tienen mucho éxito en la Antártida y pueden exhibir altas abundancias o dominancia de especies particulares. Otras epifaunas móviles comunes incluyen a Pycnogonida, Ostracoda, Caridea, Teleostei, Prosobranchia, Opisthobranchia, Polyplacophora, Bivalvia y Nemertinea (Dayton, 1990; Gili et al. 2006). Muchos de estos son simbiontes y utilizan a los invertebrados sésiles como hábitat, incluyendo depredadores especializados, como los nudibranquios, los asteroides, y los gasterópodos. Parte de la fauna, como los pycnogonidos muestran gigantismo, donde los individuos crecen hasta tamaños mucho más grandes que los taxones relacionados en las regiones no polares (Chapelle \& Peck, 1999). 


\subsubsection{Ambiente abiótico}

Las descripciones deben identificar las características abióticas más destacadas que influyen en la distribución o función de un ecosistema tipo, definen su rango natural de variabilidad, sostienen su biota nativa característica, y lo diferencian de otros sistemas. Para ecosistemas terrestres, las características abióticas sobresalientes pueden incluir sustratos, suelos y formaciones de tierra, así como los rangos de variables climáticas clave, mientras que para los ecosistemas marinos y de agua dulce se pueden incluir aspectos clave de los regímenes de agua, regímenes de luz, mareas, corrientes, factores climáticos y propiedades físicas y químicas de la columna de agua (Caja 4).

Caja 4. Describiendo el ambiente abiótico (adaptado del Apéndice S2 en Keith et al., 2013)

Bosque nublado de musgo nudoso, isla Lord Howe, Australia (fuente: Auld \& Leishman, 2015)

El Bosque nublado de musgo nudoso de la isla de Lord Howe ocurre en la cima de la meseta y en las cumbres de dos montañas en la isla Lord Howe. El clima es templado, y en partes de la isla a nivel del mar tiene una temperatura media anual de $19,2^{\circ} \mathrm{C}$, que va desde $17^{\circ} \mathrm{C}-25^{\circ} \mathrm{C}$ en verano a $14^{\circ} \mathrm{C}-18^{\circ} \mathrm{C}$ en invierno (Mueller-Dombois \& Fosberg, 1998). A nivel del mar, la precipitación media anual es de $1.717 \mathrm{~mm}$, con un máximo de $2.886 \mathrm{~mm}$ y un mínimo de $998 \mathrm{~mm}$ (Mueller-Dombois \& Fosberg, 1998). La temperatura disminuye con la altitud en las montañas del sur $\left(0,9^{\circ} \mathrm{C}\right.$ por cada $100 \mathrm{~m}$ de aumento; Simmons et al., 2012). Los bosques nublados en las islas del Pacífico ocurren típicamente entre 800 y 900 m.s.n.m (Meyer, 2011), y en la isla Lord Howe, el ecosistema del bosque nublado de musgo nudoso ocurre entre los 750 y 875 m.s.n.m. Se piensa que la precipitación anual en el bosque nublado de musgo nudoso es mucho mayor que a nivel del mar (aunque esto no ha sido cuantificado) y se extiende durante todo el año (DECC, 2007). Las dos montañas del sur (Mounts Gower y Lidgbird) obtienen humedad significativa tanto de las precipitaciones como de la intercepción directa del agua de las nubes por el dosel (precipitación horizontal o extracción de nubes), y sus picos están a menudo envueltos por nubes (Auld \& Hutton, 2004). Los bosques nublados están caracterizados por mayores precipitaciones y temperaturas más frías que en los bosques sin nubes (Jarvis \& Mulligan, 2011), y esto se piensa que es aplicable también para el ecosistema del bosque nublado de musgo nudoso (Auld \& Leishman, 2015).

Llanuras intermareales del mar Amarillo, Este de Asia (fuente: Murray et al., 2015) El mar Amarillo es un mar poco profundo (profundidad media cerca de $45 \mathrm{~m}$ ), semi-cerrado y con geografía circundante que varía desde cadenas montañosas en Corea del Sur hasta llanuras costeras de baja altitud en gran parte de las regiones del norte y oeste (Healy et al., 2002; MacKinnon et al., 2012). Las llanuras intermareales del mar Amarillo están entre las más grandes en la Tierra; en áreas donde ocurre alta amplitud de marea (macromareal, $>4 \mathrm{~m}$ ) pueden alcanzar un ancho de casi $20 \mathrm{~km}$ cuando están expuestas durante la marea baja (Healy et al., 2002). Una característica clave de las llanurasintermareales del Mar Amarillo es el cambio estacional de un sistema dominado por la erosión a un sistema dominado por la acreción en algunas zonas, en función de la aparición de la temporada de monzón (Wang \& Zhu, 1994). El ecosistema es dependiente de la operación continua de un conjunto de procesos costeros que se centran en el transporte y la dinámica de sedimentos. Los sedimentos son transportados a las llanuras intermareales por las corrientes costeras y de mareas, donde el proceso de deposición es influenciado por factores tales como la textura del sedimento y su tamaño, la ocurrencia de vegetación, la dinámica de las olas, la lluvia y la composición de la comunidad bentónica, lo que facilita la bioturbación local, la biodeposición y la biotransportación (Wang et al., 2012). Las tormentas, el viento y la acción de las olas causan la erosión en dirección al mar de las llanuras 
intermareales, y la compactación y subsidencia reducen su elevación, por lo que se requiere de la captura de sedimentos y la reposición para compensar estos procesos y mantener la extensión de las llanuras intermareales. Sin embargo, una característica que distingue a las llanuras intermareales del mar Amarillo de las regiones adyacentes es que el ecosistema de llanura intermareal está dominado en gran medida por la erosión, lo que requiere de la reposición y transporte continuo de sedimentos para persistir (Healy et al., 2002). Por lo tanto, la interrupción del suministro de sedimentos por la reducción de fuentes de suministro tales como ríos, y la interrupción de los mecanismos de transporte y deposición de sedimentos, se consideran como los principales procesos que conducen a la degradación del ecosistema (Wang et al., 2012).

\subsubsection{Procesos e interacciones}

Una comprensión cualitativa de la dinámica de los ecosistemas es esencial para evaluar los riesgos relacionados con el deterioro funcional. Mecanismos genéricos de dinámica de los ecosistemas a menudo pueden ser inferidos a partir de sistemas relacionados si el ecosistema tipo que está siendo evaluado carece de estudios directos. Por ejemplo, los sistemas marinos pelágicos son generalmente dominados por interacciones tróficas en las que se conocen los elementos de los principales niveles tróficos, incluso si se desconocen determinadas relaciones depredador-presa (Estes et al., 2009). Las dinámicas de árboles y gramíneas en las sabanas de todo el mundo están influenciadas por los regímenes de incendios, los herbívoros y las precipitaciones, aunque sus roles relativos pueden variar entre los tipos de sabana (Lehmann et al., 2014). Todas las descripciones de los ecosistemas tipo deben incluir una descripción narrativa de la dinámica de los ecosistemas que aborde los procesos ecológicos claves que definen la identidad y el comportamiento del ecosistema tipo y las amenazas que pueden causar su pérdida o perturbación.

Se requiere un modelo conceptual de las dinámicas clave de los ecosistemas para cada ecosistema tipo como parte de su evaluación. Un modelo conceptual es un diagrama de los procesos y amenazas clave del ecosistema, y tiene cuatro objetivos. En primer lugar, la creación de un modelo conceptual obliga al evaluador a pensar a través de y aclarar sus suposiciones y comprensión de los procesos del ecosistema. En segundo lugar, el modelo conceptual proporciona una base para la realización de la evaluación de riesgo, informando la selección de variables relevantes para la evaluación de los criterios C y D ( 
5.3.3 Aplicación). En tercer lugar, el modelo conceptual es una herramienta de comunicación que resume de manera efectiva las características clave de un ecosistema tipo para los gestores de riesgos, profesionales de la conservación, revisores expertos y la comunidad en general. Por último, el modelo conceptual es útil para sustentar el desarrollo de un modelo cuantitativo para el criterio $\mathrm{E}$.

Dos tipos de modelos conceptuales son particularmente útiles para las evaluaciones de la LRE: modelos causa-efecto y modelos de estado-y-transición (Caja 5). Los modelos de causa-efecto representan las interacciones y dependencias entre los componentes del modelo, como la biota característica, el ambiente abiótico y las amenazas (Caja 5a). Los modelos de estado-y- transición representan los cambios entre los estados del ecosistema debido a cambios en el ambiente abiótico o los procesos del ecosistema (Caja 5b). Por ejemplo, los cambios en el nivel promedio del agua determinan las transiciones entre los estados hipersalinos degradados e hipersalinos poco saludables en la laguna Coorong (Apéndice S2 en Keith et al., 2013; Lester \& Fairweather, 2011; Lester \& Fairweather, 2009).

Un repertorio visual estándar puede ayudar a desarrollar modelos causa-efecto consistentes (Fig. 7). La biota nativa característica está representada por hexágonos verdes, los elementos del ambiente abiótico por hexágonos azules, los procesos bióticos por óvalos verdes, los procesos abióticos por óvalos azules, y las amenazas por rectángulos rojos. Las relaciones positivas, negativas e hipotéticas pueden ser representadas por símbolos apropiados. No se recomienda el uso de flechas acompañadas de signos de más y menos. Distintos componentes del ecosistema funcionando juntos deben formar parte de un compartimiento. Por ejemplo, el bosque Gonakier en Senegal (Apéndice S2 en Keith et al., 2013) puede ser descrito por dos compartimentos de fauna y flora, impulsados por procesos abióticos que son influenciados por las amenazas al bosque (Caja 5c).

Las directrices generales para desarrollar modelos conceptuales para las evaluaciones de la LRE incluyen:

1. Los modelos conceptuales de ecosistemas tipo deben ser completos, inequívocos y fáciles de entender. Deben ser consistentes con la descripción narrativa de los procesos y funciones de los ecosistemas, y no deben introducir elementos que no han sido descritos en la narrativa. Deben enfocarse en procesos especialmente relevantes para la aplicación de los criterios $\mathrm{C}$ y $\mathrm{D}$, y con la definición del estado colapsado del ecosistema tipo.

2. Deben evitarse modelos conceptuales excesivamente complejos, de forma tal que los modelos típicamente incluirán menos detalles que los textos narrativos. Los evaluadores son animados a pensar cuidadosamente sobre el nivel de complejidad y organización jerárquica del modelo conceptual, repasando el propósito de desarrollar el modelo conceptual descrito anteriormente si es necesario. En general, el modelo menos complejo que cubra todos los procesos del ecosistema será el más apropiado (típicamente menos de 12 elementos).

3. No se recomienda la inclusión de procesos relevantes de otros ecosistemas tipo (pero no del ecosistema tipo de interés). 
4. Debe evitarse la repetición de componentes y relaciones.

5. A los evaluadores se les recomienda el uso del Esquema de Clasificación de Amenazas de UICN para seleccionar las amenazas apropiadas a su sistema. No se recomienda la inclusión de conductores (drivers) genéricos tales como el crecimiento de la población humana o factores económicos.

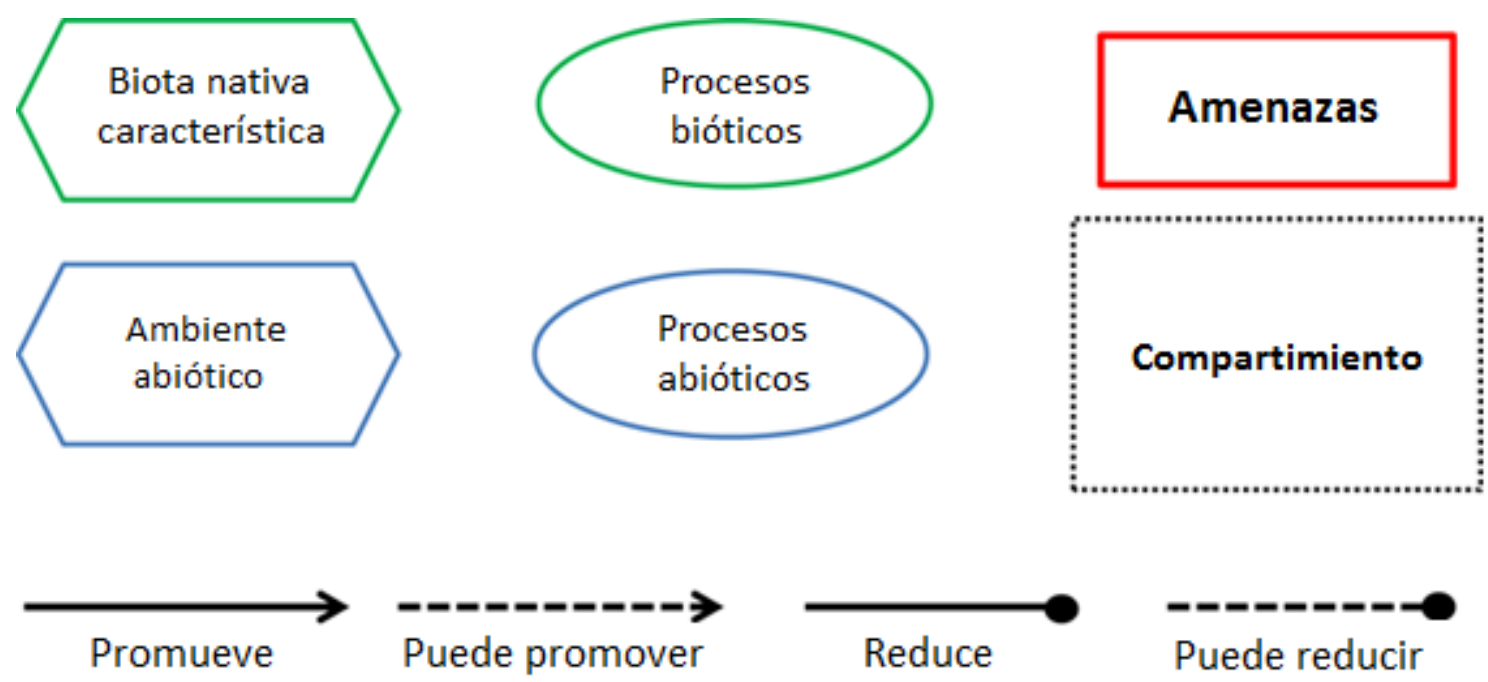

Figura 7. Un repertorio visual común para los modelos de causa-efecto.

El desarrollo del modelo conceptual puede revelar las incertidumbres en la comprensión de los procesos del ecosistema. Puede que sea necesario desarrollar dos o más modelos conceptuales alternativos para representar esta incertidumbre. Refinar el modelo varias veces puede ayudar a explorar y depurar los procesos del ecosistema y aclarar la disposición del modelo. Se debe hacer un esfuerzo para llegar a un consenso del modelo conceptual para el ecosistema tipo, utilizando el texto narrativo para resaltar las mayores fuentes de incertidumbre. Al evaluar el criterio $\mathrm{E}$, puede ser útil incluir un segundo modelo, más complejo, para describir los indicadores seleccionados y las relaciones entre los componentes modelados. Actualmente se encuentran en desarrollo herramientas para ayudar en la construcción de modelos conceptuales, incluyendo un programa computarizado para apoyar el desarrollo de modelos conceptuales internamente consistentes. El programa permitirá a los usuarios guardar y recuperar los modelos conceptuales para una gama de ecosistemas, utilizar un repertorio visual común y evaluar los efectos de las amenazas sobre los procesos del ecosistema.

Caja 5. Modelos conceptuales representando procesos e interacciones

(A) Modelo causa-efecto

Modelo causa-efecto de un arrecife coralino caribeño (Apéndice S2 en Keith et al., 2013). El calentamiento, 


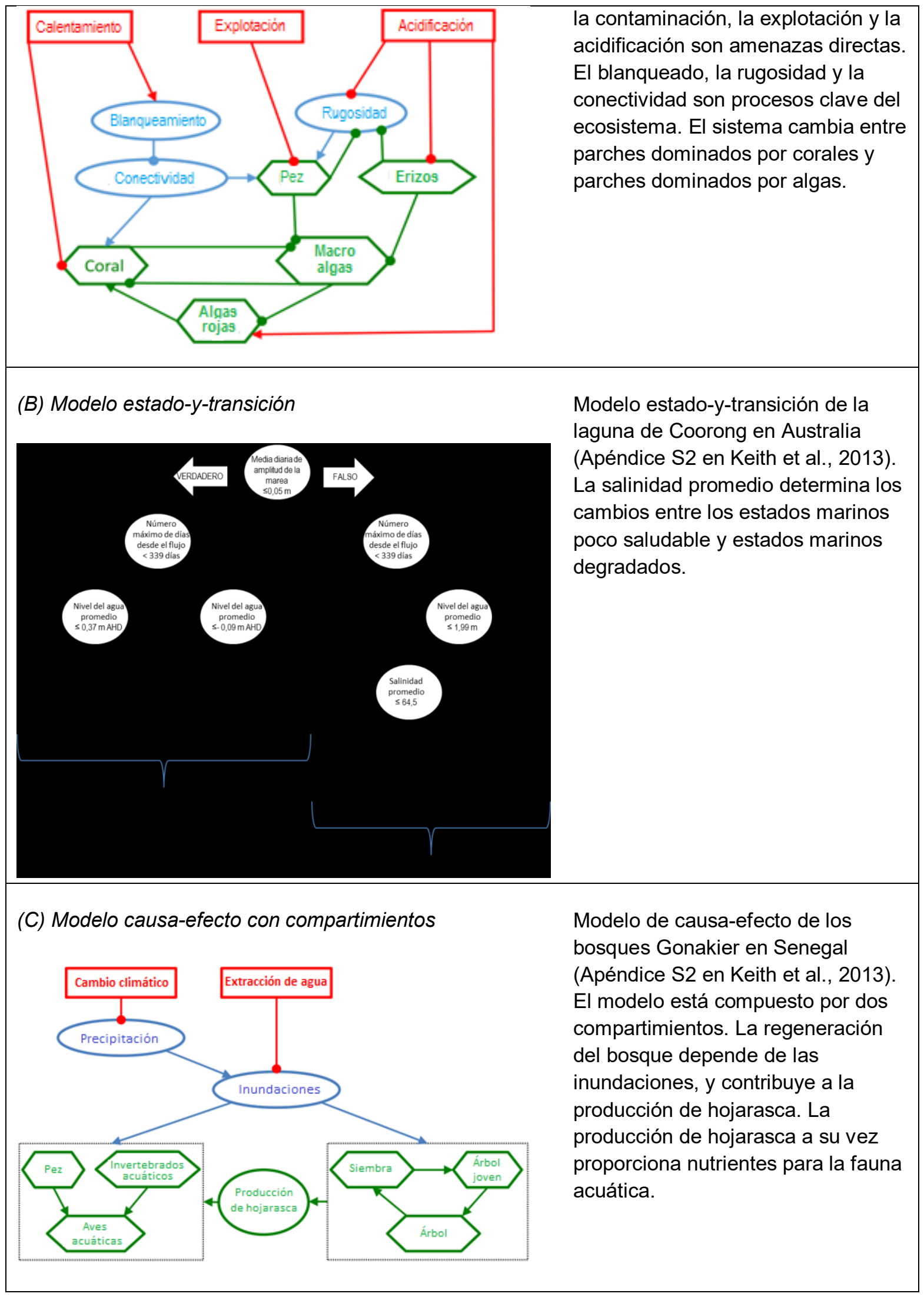

\subsubsection{Amenazas}


Acompañando a la descripción de un ecosistema tipo debe estar una revisión completa de los procesos de amenaza que causan cambios en los ecosistemas. Describir las amenazas de un ecosistema tipo requiere dos elementos: (i) una breve descripción y explicación de las principales amenazas que causan cambios en el ecosistema; (ii) identificación de amenazas con referencia al Esquema de Clasificación de Amenazas, usado en la Lista Roja de Especies Amenazadas de UICN (IUCN, 2015). Cuando son combinadas, la descripción de los procesos de amenaza y estresores, la clasificación de amenazas bajo el Esquema de Clasificación de Amenazas de UICN y el modelo conceptual para un ecosistema ayudarán a identificar los estados colapsados y las variables clave para evaluar el cambio en las funciones bióticas y abióticas. El marco presentado a continuación (conductores, amenazas y estresores) describe cómo las amenazas afectan a los ecosistemas.

\section{Antecedentes}

Se necesitan términos consistentes para conductores (drivers), amenazas y estresores para la evaluación de los ecosistemas (Tabla 5). Una amenaza directa para el ecosistema tipo u organismo puede ser una amenaza indirecta para otro o no suponer una amenaza para otros organismos. Por ejemplo, la pesca insostenible amenazará directamente las especies objetivo y de captura secundaria y también puede tener efectos indirectos (positivos o negativos) sobre las especies que depredan, compiten con o son presa de las especies objetivo. La complejidad de los efectos requiere una cuidadosa consideración y definición de amenazas para cada ecosistema tipo.

Tabla 5. Definiciones de amenazas, conductores y estresores (Salafsky et al., 2008).

\begin{tabular}{|c|c|c|}
\hline Término & Definición & Sinónimos \\
\hline Conductor & $\begin{array}{l}\text { Los factores últimos, por lo general sociales, } \\
\text { económicos, políticos, institucionales, o culturales que } \\
\text { permiten o de otra forma contribuyen a la ocurrencia o } \\
\text { persistencia de las amenazas directas inmediatas. } \\
\text { Típicamente existe una cadena de conductores detrás } \\
\text { de cualquier amenaza directa dada. }\end{array}$ & $\begin{array}{l}\text { Factores } \\
\text { contribuyentes, } \\
\text { factores } \\
\text { subyacentes, } \\
\text { causas raíz, } \\
\text { amenaza indirecta, } \\
\text { presiones. }\end{array}$ \\
\hline Amenaza & $\begin{array}{l}\text { Las amenazas directas son las actividades o procesos } \\
\text { próximos que han impactado, están impactando, o } \\
\text { pueden impactar el estatus del ecosistema objeto de } \\
\text { evaluación (por ejemplo, la pesca y la explotación } \\
\text { insostenible). Las amenazas pueden ser pasadas } \\
\text { (históricas), en curso, y/o pueden ocurrir en el futuro. } \\
\text { Los fenómenos naturales también son considerados } \\
\text { como amenazas directas en algunas situaciones. }\end{array}$ & $\begin{array}{l}\text { Amenazas directas, } \\
\text { fuentes de estrés, } \\
\text { presiones, } \\
\text { presiones } \\
\text { próximas, } \\
\text { estresores. }\end{array}$ \\
\hline Estresor & $\begin{array}{l}\text { Los estresores son los efectos sobre características del } \\
\text { ecosistema que están deterioradas directamente por las } \\
\text { amenazas (p. ej., reducción de la abundancia de } \\
\text { especies clave, fragmentación del hábitat). Un estresor } \\
\text { no es una amenaza en o por sí misma, sino más bien } \\
\text { una condición degradada o síntoma del objetivo que } \\
\text { resulta de una amenaza directa. El protocolo de riesgo } \\
\text { de la LRE pretende cuantificar estos síntomas para }\end{array}$ & $\begin{array}{l}\text { Síntomas, atributos } \\
\text { clave degradados. }\end{array}$ \\
\hline
\end{tabular}


evaluar la disminución hacia los estados colapsados.

Descripción de las amenazas

Un resumen de las principales amenazas que actualmente afectan o puedan afectar al ecosistema tipo es requerido como información de apoyo para todos los ecosistemas tipo. La descripción proporciona una breve explicación de las principales amenazas (pasadas, presentes y futuras), los conductores (drivers) de esas amenazas, y los estresores resultantes o síntomas del ecosistema. Identificar los estresores es altamente informativo para definir los estados colapsados y evaluar los criterios $C$ y D. La extensión geográfica de las amenazas también debe ser descrita. Los evaluadores pueden basar su descripción en clasificaciones regionales y / o nacionales de amenazas, pero éstas no se pueden utilizar directamente en el Esquema de Clasificación de Amenazas de UICN. En los casos en que se debe utilizar una clasificación nacional de amenazas, los evaluadores deben informar tanto la designación nacional como la del Esquema de Clasificación de Amenazas de UICN. Se recomienda usar gráficos, figuras y fotografías ejemplares para ilustrar el impacto de las amenazas en la biota nativa característica, el ambiente físico y las interacciones entre ellos. Un ejemplo de la descripción de amenazas es proporcionado en la Caja 6.

Esquema de Clasificación de Amenazas

La LRE adopta el Esquema de Clasificación de Amenazas de UICN (www.iucnredlist.org/technical-documents/classification-schemes/threats-classificationscheme) para ser consistente con la Lista Roja de Especies Amenazadas de UICN. EI Esquema de Clasificación de Amenazas es jerárquico, consiste de tres niveles cada uno con mayor detalle, y contiene 12 categorías de amenaza principales. Para una evaluación de la LRE, la descripción de amenazas de un ecosistema tipo debe corresponder con las amenazas del Esquema de Clasificación de Amenazas de UICN. La codificación de las principales amenazas que afectan a un ecosistema tipo es requerida como información de apoyo para todos los ecosistemas tipo excepto cuando no hay amenazas conocidas para los asignados a las categorías de Datos Insuficientes o Preocupación Menor. Los evaluadores deben diagnosticar y registrar amenazas al nivel más bajo posible en el Esquema de Clasificación de Amenazas.

No son requeridas la codificación de la temporización, el alcance y la severidad de cada amenaza importante, pero pueden ser proporcionados. Si los evaluadores deciden registrar también las amenazas menores (amenazas que afectan sólo una muy pequeña proporción de la distribución), entonces es esencial que la temporización, el alcance y la severidad se describan para todas las amenazas registradas. Esto permitirá que se identifiquen claramente las amenazas mayores y menores para el ecosistema tipo, y ayudará a un análisis de más alto nivel en la LRE. Orientación para usar el Sistema de Puntuación de 
Impacto de Amenaza de UICN

(www.iucnredlist.org/documents/Dec_2012_Guidance_on_Threat_Impact_Scoring.pdf) está disponible en el sitio web de la Lista Roja de Especies Amenazadas de UICN (www.iucnredlist.org). El Sistema de Puntuación de Impacto de Amenaza para la LRE está actualmente bajo revisión, por lo tanto el uso del Sistema de Puntuación de Impacto de Amenaza no es requerido en esta etapa para las evaluaciones de la LRE.

A pesar de que no es requerido registrar los estresores desde el Esquema de Clasisficación de Estresores de UICN (www.iucnredlist.org/technical-documents/classificationschemes/stresses-classification-scheme) para cada amenaza seleccionada, esto es altamente recomendado como información de apoyo para una evaluación. Esta información es útil para demostrar cómo las amenazas están afectando los ecosistemas tipo que aparecen en la LRE, y puede proporcionar una guía útil para que los tomadores de decisiones puedan hacer frente a las causas últimas. Es posible registrar múltiples estresores, simplemente seleccionando el código de amenaza.

Caja 6. Describiendo las amenazas

El Bosque de Coolibah - Boj negro del sudeste de Australia es un ecosistema tipo de bosques dependiente de las inundaciones afectado por cinco amenazas principales (Apéndice S2 en Keith et al., 2013; NSW Scientific Committee, 2004). La expansión e intensificación del uso de la tierra agrícola ha sustituido grandes extensiones de bosque con cultivos y pastizales durante las últimas décadas (Keith et al., 2009). Por otra parte, la extracción de agua de los ríos para el riego ha alterado los regímenes de inundación y su extensión espacial, reduciendo las oportunidades de reproducción y dispersión de la fauna y flora características (Thoms \& Sheldon, 2000; Thoms,

2003; Kingsford \& Thomas, 1995; Kingsford \& Johnson, 1998; Kingsford \& Auld, 2005). Futuros cambios climáticos también pueden afectar la disponibilidad espacial y temporal de agua en el sistema. Las plantas invasorasse han extendido con la intensificación agrícola y están reduciendo la diversidad y la abundancia de la biota nativa. Además, la invasión de maleza formadora de estera Phyla canescens reduce la diversidad de las plantas de la capa de tierra nativa (Taylor \& Ganf, 2005). Esta especie se ha extendido rápidamente en respuesta a los regímenes de agua alterados y al persistente pastoreo de ganado pesado (Earl, 2003). Por último, el exceso de pastoreo por cabras salvajes, conejos y ganado doméstico ha alterado la composición y estructura de la vegetación de los bosques, a través del consumo selectivo de la capa a nivel del suelo de plantas nativas apetitosas y plántulas de árboles y arbustos (Reid et al., 2011; Robertson \& Rowling, 2000). Estos efectos son más marcados debajo de los árboles y alrededor de los puntos de agua donde el ganado concentra sus actividades.

Las amenazas que afectan a este ecosistema tipo se corresponden con cinco amenazas (subrayado) y sus categorías jerárquicas en el Esquema de Clasificación de Amenazas de la UICN:

2. Agricultura y Acuacultura:

2.1 Cultivos no-madereros anuales y perennes: 2.1.3 Cultivo agroindustrial; 


\begin{tabular}{|c|c|}
\hline & $\begin{array}{l}\text { 2.3 Cría y producción ganadera: } \\
\text { 2.3.3 Agroindustria de pastoreo, ganadería o agricultura } \\
\text { 7. Modificaciones de Sistemas Naturales: } \\
7.2 \text { Presas y Gestión/ Uso del Agua: } \\
\underline{7.2 .3 \text { Abstracción de la superficie de agua (uso agrícola) }} \\
\text { 8. Especies invasivas y Otras especies problemáticas, Genes y Enfermedades: } \\
8.1 \text { Especies invasoras no nativas/Exóticas/Enfermedades: } \\
\quad \frac{8.1 .2 \text { Especies nombradas - Phyla canescens }}{\text { 11. Cambio climático y el mal tiempo }} \\
11.2 \text { Sequías } \\
\text { La descripción de las amenazas y estresores respalda la selección de variables para la } \\
\text { evaluación de los criterios C y D y clarifica su enlace con el colapso de este ecosistema tipo. Bajo } \\
\text { los criterios A y B, para el ecosistema tipo se "asumió que había colapsado cuando su distribución } \\
\text { mapeada se había reducido a cero como consecuencia de la limpieza para la agricultura". } \\
\text { Debido a que los regímenes de inundación son fundamentales para la dinámica del ecosistema y } \\
\text { la extracción de agua para el riego es una amenaza importante, el caudal promedio diario del río } \\
\text { fue identificado como una variable adecuada para evaluar la degradación ambiental según el } \\
\text { criterio C. }\end{array}$ \\
\hline
\end{tabular}

\subsubsection{Describiendo los estados colapsados}

El colapso del ecosistema es un concepto clave en la LRE (Sección 3.2) y sustenta la aplicación de las Categorías y Criterios de la Lista Roja de Ecosistemas de UICN. Los evaluadores deben describir el(los) estado(s) colapsado(s) de un ecosistema, basados en la información resumida en la descripción del ecosistema tipo y el modelo conceptual. Si múltiples estados de colapso son posibles (p. ej. debido a diferentes amenazas), todos estos deben ser descritos con similares niveles de detalle. Las descripciones deben enfocarse en los rasgos característicos clave del ecosistema tipo. Los umbrales de colapso para la aplicación de los criterios A y B son típicamente definidos como el $100 \%$ de pérdida de la distribución espacial del ecosistema tipo (es decir, 100\% de disminución bajo el criterio $\mathrm{A} ; \mathrm{EOO}=0 \mathrm{~km}^{2} \mathrm{y} / \mathrm{O} \mathrm{AOO}=$ ninguna celda de la cuadrícula de $10 \times 10 \mathrm{~km}$ ocupada bajo el criterio B). La elección de umbrales de colapso diferentes para el criterio A o B debe ser justificada a fondo. Los umbrales de colapso para la aplicación de los criterios C, D y E deben ser identificados como parte de la evaluación de estos criterios ( 
5.3.3 Aplicación). A los evaluadores se les anima a dar ejemplos de ocurrencias del ecosistema tipo localmente colapsadas para apoyar sus descripciones de los estados colapsados.

Caja 7. Definiendo el colapso del ecosistema

El Bosque de fresno de montaña del sudeste de Australia es un ecosistema único dominado por las especies de plantas florales más altas del mundo (Eucalyptus regnans). El fresno de montaña sustenta una amplia gama de especies de plantas y una rica variedad de mamíferos y aves nativas, incluyendo al falangero de Leadbeater (considerado En Peligro) y la ardilla planeadora de vientre amarillo (considerada Vulnerable) (Lindenmayer, 2009). La disponibilidad de bosque maduro y huecos de árboles naturales es un factor crítico para la supervivencia de los animales que habitan en las cavidades (Keith et al., 2013; Burns et al., 2015).

Se considera que el colapso del ecosistema ocurre bajo cualquiera de las siguientes condiciones Burns et al., 2015):

1. El $100 \%$ del área donde el ecosistema actualmente ocurre ya no es adecuado bioclimáticamente (criterio C).

2. La abundancia de árboles con huecos cae por debajo de un promedio por hectárea en toda la distribución del ecosistema (subcriterio D2 y criterio E).

3. Menos del $1 \%$ del bosque maduro permanece en el ecosistema (subcriterio D1 y D3).

\subsection{Evaluando los criterios}

Cada ecosistema tipo debe ser evaluado contra todos los criterios de la LRE en la medida que los datos lo permitan. Para ayudar a este propósito, la Sección 5 proporciona información detallada sobre la forma de recopilación de los datos, el desarrollo de la evaluación, la consideración de la calidad e incertidumbre de los datos, y la documentación del resultado de la evaluación. Al inicio de una evaluación, todos los ecosistemas tipo se consideran No Evaluado (NE) para todos los criterios. El siguiente paso es determinar si existen datos adecuados para la aplicación de los criterios (Fig. 6), lo cual requiere la búsqueda de datos en la literatura científica, informes no publicados, opiniones de expertos, relatos históricos, mapas pasados y presentes, imágenes de satélite o cualquier otra fuente de datos relevantes. Si un evaluador decide no aplicar un criterio, el resultado de la evaluación de riesgo permanece como No Evaluado. Si un esfuerzo de búsqueda razonable indica que no se encuentran disponibles datos adecuados para evaluar un criterio, el resultado de la evaluación de ese criterio es Datos Insuficientes (DD). La diferencia entre No Evaluado y Datos Insuficientes es que el reporte de No Evaluado para cualquier criterio implica que no se hizo ningún intento de obtener datos relevantes ni de evaluar el ecosistema tipo bajo ese criterio. Si un intento decente fue realizado, pero los datos no estaban disponibles o no eran adecuados, entonces debe usarse el resultado Datos Insuficientes. Deben describirse brevemente los esfuerzos de búsqueda de los datos apropiados. 


\subsection{Resultado de la evaluación}

Una tabla resumen para cada ecosistema tipo reporta el resultado de la evaluación para todos los criterios (y subcriterios) así como el estatus global (Caja 8). Existe un total de 20 subcriterios en las Categorías y Criterios de la Lista Roja de Ecosistemas de UICN, cada uno de los cuales puede ser asignado una de las ocho categorías de riesgo (Fig. 1). Los resultados para todos los subcriterios bajo los criterios $A, B, C$ y $D$, así como los métodos que fueron empleados para evaluar los subcriterios (i, ii o iii), deben ser reportados durante el proceso de evaluación.

Algunos ecosistemas tipo tendrán el resultado de Datos Insuficientes o de No Evaluado para algunos de los subcriterios; esto debe ser incluido en la tabla resumen (Caja 8). Si todos los subcriterios tienen el resultado de Datos Insuficientes, el resultado global de la evaluación es Datos Insuficientes. Si todos los subcriterios tienen el resultado de No Evaluado, el resultado global de la evaluación es No Evaluado. Si todos los subcriterios tienen el resultado No Evaluado o Datos Insuficientes, el resultado global de la evaluación es Datos Insuficientes.

Siguiendo el principio de precaución y para asegurar que los síntomas más graves de riesgo son los que determinan el resultado de la evaluación, la categoría de riesgo más alta obtenida por cualquiera de los criterios evaluados será el estado de riesgo global del ecosistema. El principal método utilizado actualmente para la representación de la incertidumbre en la evaluación de los ecosistemas es el uso de estimaciones acotadas (4.4.1 Tratando con la incertidumbre). El límite inferior del estatus global es la más alta cota inferior a través de cualquiera de los subcriterios que devuelven la misma categoría que el estatus global. El límite superior del estatus global es la más alta cota superior a través de cualquiera de los subcriterios que devuelven la misma categoría que el estatus global. Por ejemplo, si un ecosistema tipo califica para EN (límites plausibles EN-CR) bajo el criterio B, EN (límites plausibles VU-CR) bajo el criterio $D$, y categorías menores bajo otros criterios ( $p$. ej. NT bajo el criterio A, LC bajo el criterio $C$, y DD bajo el criterio $E$ ), entonces su estatus global será EN (límites plausibles VU-CR).

Caja 8. Resultado de la evaluación (adaptado del Apéndice S2 en Keith et al., 2013)

Arrecifes coralinos caribeños

Los arrecifes coralinos caribeños son principalmente cadenas de arrecifes y bancos de barreras de coral separadas de las costas insulares y continentales por plataformas de arrecifes, aguas poco profundas o lagunas ligeramente profundas (Alevizon, 2010). Debido a las dificultades de medir remotamente la distribución de coral viviente y del mosaico marino del ecosistema, los ecosistemas son listados como Datos Insuficientes bajo todos los subcriterios del criterio A. El ecosistema es evaluado como Preocupación Menor bajo todos los subcriterios del criterio $B$ debido a su gran extensión de presencia, área de ocupación y número de localidades. Los datos

para el criterio C están actualmente bajo revisión; al momento de la escritura, el ecosistema está listado como No Evaluado bajo todos los subcriterios de criterio C. Los datos sobre la cobertura de coral y rugosidad de arrecifes conducen ambos a estimaciones similares para el subcriterio D1: En Peligro (rango plausible Vulnerable - En Peligro Crítico). No hay proyecciones disponibles 
para futuras interrupciones en las interacciones bióticas, por lo que el ecosistema es listado como Datos Insuficientes bajo D2. El ecosistema es listado como En Peligro bajo el subcriterio D3 basado en datos históricos. No se ha realizado ningún análisis cuantitativo para evaluar el criterio $\mathrm{E}$, por lo que el estatus es No Evaluado bajo el criterio E. El estatus de riesgo más apropiado para los arrecifes coralinos caribeños es determinado entonces como En Peligro (rango plausible En Peligro - En Peligro Crítico).

\begin{tabular}{lllllll}
\hline Criterio & A & B & C & D & E & Global \\
\hline Subcriterio 1 & DD & LC & NE & EN (VU-CR) & NE & EN (EN-CR) \\
Subcriterio 2 & DD & LC & NE & DD & & \\
Subcriterio 3 & DD & LC & NE & EN & & \\
\hline
\end{tabular}

Pantanos costeros de piedra arenisca de tierras altas del sureste de Australia Los pantanos costeros de piedra arenisca de tierras altas del sureste de Australia son ciénagas sin árboles que forman límites relativamente abruptos que están rodeados por bosques dominados por eucaliptos y zonas boscosas que ocupan suelos que drenan más libremente (Keith \& Myerscough, 1993). Ellos están fuertemente asociados con alta precipitación y humedad. Las interacciones entre los procesos hidrológicos y los regímenes de incendios son cruciales para el desarrollo de los pantanos de las tierras altas y el mantenimiento de su diversa y característica biota. Para evaluar el potencial futuro deterioro debido al cambio climático, Keith et al. (2013) utilizaron una gama de plausibles modelos de distribución bioclimáticas del ecosistema para predecir su distribución bajo escenarios climáticos futuros. Basado en estos modelos y escenarios, se proyectó que la distribución del ecosistema disminuiría en 58-90\% (mediana de $74 \%$ ) en los próximos 50 años. El estatus más apropiado del ecosistema fue entonces determinado como En Peligro (rango plausible En Peligro - En Peligro Crítico) bajo el subcriterio A2. Los mismos modelos de distribución utilizados para evaluar el cambio futuro en la distribución también se utilizaron para evaluar las tendencias de adecuación climática según el criterio $C$. Desde 1983 al 2009, la abundancia sumada de re-brotadores leñosos se redujo en una media de $37 \%$ en $72 \%$ de los sitios muestreados. Estos valores están justo por debajo de los umbrales de severidad y extensión, respectivamente, para Vulnerable según el criterio D1, suponiendo que la abundancia cero de re-brotadores marca el punto de colapso del ecosistema. No hay datos disponibles antes de 1983, pero si la disminución actual se iniciaron antes de ese tiempo, podrían superar el umbral para el estatus Vulnerable. Es probable que el estatus del ecosistema tipo sea Casi Amenazado (rango plausible Casi Amenazado - Vulnerable) bajo el subcriterio D1. El estado de riesgo global más apropiado para los pantanos costeros de piedra arenisca de tierras altas del sudeste de Australia es En Peligro (rango plausible En Peligro - En Peligro Crítico).

\begin{tabular}{lllllll}
\hline Criterio & A & B & C & D & E & Global \\
\hline Subcriterio 1 & LC & EN & LC & NT(NT-VU) & DD & EN(EN-CR) \\
Subcriterio 2 & EN(EN-CR) & EN & EN(EN-CR) & DD & & \\
Subcriterio 3 & LC & LC & DD & DD & & \\
\hline
\end{tabular}

\subsubsection{Tratando con la incertidumbre}

La incertidumbre en cualquier información utilizada para evaluar los criterios debe ser propagada a través de la evaluación y reportada como parte de los resultados. El reportar tanto la categoría de riesgo más probable como otras categorías posibles, teniendo en cuenta las incertidumbres en los datos, es más útil que simplemente informar de la 
categoría más probable. La forma más simple de caracterizar la incertidumbre es a través de estimaciones acotadas. Las estimaciones acotadas representan un rango de valores plausibles para una medida. Pueden tomar en cuenta la incertidumbre en la descripción de los umbrales de los estados colapsados (Fig. 3 y Caja 1), las estimaciones mapeadas del cambio en la distribución (Caja 9), y las estimaciones de las variables para medir la severidad relativa en los criterios C y D (Cajas 11 y 12). Los límites superiores e inferiores de una estimación pueden propagarse a través de una evaluación mediante la repetición del mismo análisis para la mejor estimación, y los límites inferiores y superiores. Por ejemplo, si se estima que la disminución en la distribución de un ecosistema tipo está entre $75-85 \%$ en los últimos 50 años, razonablemente podría estar En Peligro (disminución entre $50-80 \%$ basado en el límite inferior) o En Peligro Crítico ( $\geq 80 \%$ basado en el mejor estimado y límite superior) bajo el subcriterio $\mathrm{A} 1$. El tratamiento de la incertidumbre en la evaluación de riesgo de los ecosistemas se basa en gran medida en las experiencias de la Lista Roja de Especies Amenazadas de UICN (Newton, 2010; Regan \& Colyvan, 2000; Akcakaya et al., 2000).

\subsection{Documentación}

Todas las evaluaciones deben ir acompañadas de la documentación e información de apoyo, que deben ser sometidas a revisión por expertos apropiados (6. Revisión por expertos y publicación por expertos y publicación), y deben estar fácilmente disponibles una vez que se ha compeltado la evaluación (para ejemplos, ver el sitio web de la Lista Roja de Ecosistemas de UICN: www.iucnrle.org). Todos los campos requeridos en la base de datos en línea de la LRE también deben ser completados (ver el sitio web de la_Lista Roja de Ecosistemas de UICN). La documentación debe incluir las siguientes secciones:

1. Resumen. Un breve resumen ( 200 palabras) que describa la evaluación completa de forma resumida, incluyendo el área de evaluación, el ecosistema tipo focal y sus rasgos característicos, procesos de amenaza y resultado de la evaluación.

2. Descripción del ecosistema. Una descripción completa del ecosistema tipo, incluyendo los elementos listados en la Tabla 4.

3. Evaluación de riesgo. Esta sección debe incluir información específica de la aplicación y resultado de cada criterio, p. ej. inferencias, análisis estadísticos y análisis espaciales. También debe incluir una discusión de las suposiciones, limitaciones o data adicional requerida. En la Sección 5 están disponibles lineamientos adicionales.

4. Referencias. Debe proporcionarse una lista completa de referencias mostrando las fuentes de información usadas para la evaluación. 


\section{Criterios y umbrales}

El modelo de evaluación de riesgo de la Lista Roja de Ecosistemas de UICN (LRE) incluye cinco criterios para la evaluación de riesgo de colapso del ecosistema (Tabla 6). Esta sección esboza la teoría, los umbrales y subcriterios pertinentes para la aplicación de cada criterio. Una tabla resumen de las Categorías y Criterios de la Lista Roja de Ecosistemas de UICN actuales es proporcionada en el Apéndice 2.

Tabla 6. Propósitos de los criterios de la Lista Roja de Ecosistemas de UICN.

\begin{tabular}{|c|c|c|}
\hline & Criterio & Propósito \\
\hline $\mathbf{A}$ & $\begin{array}{l}\text { Disminución en la distribución } \\
\text { geográfica }\end{array}$ & $\begin{array}{l}\text { Identifica los ecosistemas que están sufriendo } \\
\text { disminuciones de área, con gran frecuencia } \\
\text { debido a amenazas que resultan en la pérdida y } \\
\text { fragmentación de los ecosistemas. }\end{array}$ \\
\hline B & Distribución geográfica restringida & $\begin{array}{l}\text { Identifica los ecosistemas con pequeñas } \\
\text { distribuciones que son susceptibles a amenazas y } \\
\text { catástrofes espacialmente explícitas. }\end{array}$ \\
\hline C & Degradación ambiental & $\begin{array}{l}\text { Identifica los ecosistemas que están sufriendo } \\
\text { degradación ambiental. }\end{array}$ \\
\hline D & $\begin{array}{l}\text { Interrupción de los procesos o } \\
\text { interacciones bióticas }\end{array}$ & $\begin{array}{l}\text { Identifica los ecosistemas que están sufriendo } \\
\text { pérdida o interrupción de los procesos e } \\
\text { interacciones bióticas clave. }\end{array}$ \\
\hline $\mathbf{E}$ & $\begin{array}{l}\text { Análisis cuantitativo que estima la } \\
\text { probabilidad de colapso del } \\
\text { ecosistema }\end{array}$ & $\begin{array}{l}\text { Permite una evaluación integrada de múltiples } \\
\text { amenazas, síntomas y sus interacciones. }\end{array}$ \\
\hline
\end{tabular}




\subsection{Criterio A. Disminución en la distribución geográfica}

\subsubsection{Teoría}

Una disminución en la distribución geográfica —definida como todas las ocurrencias espaciales de un ecosistema tipo-influye en su riesgo de colapso por: (i) la reducción de la habilidad de un ecosistema de mantener su biota nativa característica; y (ii) lo predispone a amenazas adicionales (Keith et al., 2013). La pérdida de biota nativa característica debido a la disminución en la distribución típicamente ocurre a través de una combinación de la reducción de capacidad de carga, diversidad del nicho, particiones espaciales de recursos y un incremento de la susceptibilidad a la competencia, depredación y amenazas (MacArthur \& Wilson, 1967; Shi et al., 2010; Harpole \& Tilman, 2007; Hanski, 1998; McKnight et al., 2007). La tasa de disminución de la distribución de un ecosistema indica su trayectoria hacia el colapso, ocurriendo el colapso del ecosistema típicamente cuando no permanece ninguna ocurrencia espacial del ecosistema tipo (la extensión de la distribución colapsa a cero).

\subsubsection{Umbrales y subcriterios}

Un ecosistema puede listarse bajo el criterio A si cumple con los umbrales para cualquiera de cuatro subcriterios ( $A 1, A 2 a, A 2 b$ o $A 3)$, cuantificado como una disminución en la distribución geográfica sobre los siguientes períodos de tiempo:

\begin{tabular}{|c|c|c|c|c|}
\hline Subcriterio & Período de tiempo & CR & EN & VU \\
\hline A1 & Pasado (durante los últimos 50 años) & $\geq 80 \%$ & $\geq 50 \%$ & $\geq 30 \%$ \\
\hline $\mathrm{A} 2 \mathrm{a}$ & Futuro (durante los próximos 50 años) & $\geq 80 \%$ & $\geq 50 \%$ & $\geq 30 \%$ \\
\hline$A 2 b$ & $\begin{array}{l}\text { Cualquier período de } 50 \text { años (incluyendo el } \\
\text { pasado, presente y futuro) }\end{array}$ & $\geq 80 \%$ & $\geq 50 \%$ & $\geq 30 \%$ \\
\hline A3 & Histórico (desde aproximadamente 1750) & $\geq 90 \%$ & $\geq 70 \%$ & $\geq 50 \%$ \\
\hline
\end{tabular}

\subsubsection{Aplicación}

\section{Requerimientos de datos}

La tasa de disminución en la distribución típicamente se estima a partir de conjuntos de datos de series de tiempo apropiados para el ecosistema tipo focal. Los mapas de ecosistemas - tales como aquellos derivados de clasificaciones de sensores remotos, modelos de distribución, observaciones de campo o datos históricos - son la fuente principal de datos para evaluar el criterio A. Cuando más de una fuente de datos está disponible, tales como diferentes mapas de vegetación o estimaciones producidas con diferentes métodos, los evaluadores deben primero evaluar críticamente la eficacia de las alternativas como representaciones de la distribución del ecosistema tipo. Si más de una fuente de datos es adecuada, los evaluadores deben calcular las estimaciones de cada fuente de datos, y explorar la sensibilidad del estatus de los ecosistemas a la incertidumbre de los datos (Sección 4.4.1 Tratamiento de la incertidumbre). La disminución neta en la distribución formará un intervalo de estimaciones generadas a partir de cada fuente de datos. 
Los sensores remotos son una fuente de datos central para el mapeo de distribuciones de muchos ecosistemas terrestres y marinos que tienen firmas interpretables en diferentes tipos de imágenes (p. ej. Fig. 8). Cuando no están disponibles datos regionales o locales, los datos globales, como los que están disponibles para los bosques (Hansen et al., 2013), manglares (Giri et al., 2011), y arrecifes coralinos (Andréfouët et al., 2006), pueden ser plantillas adecuadas sobre los cuales superponer clasificaciones adecuadas de los ecosistemas tipo.
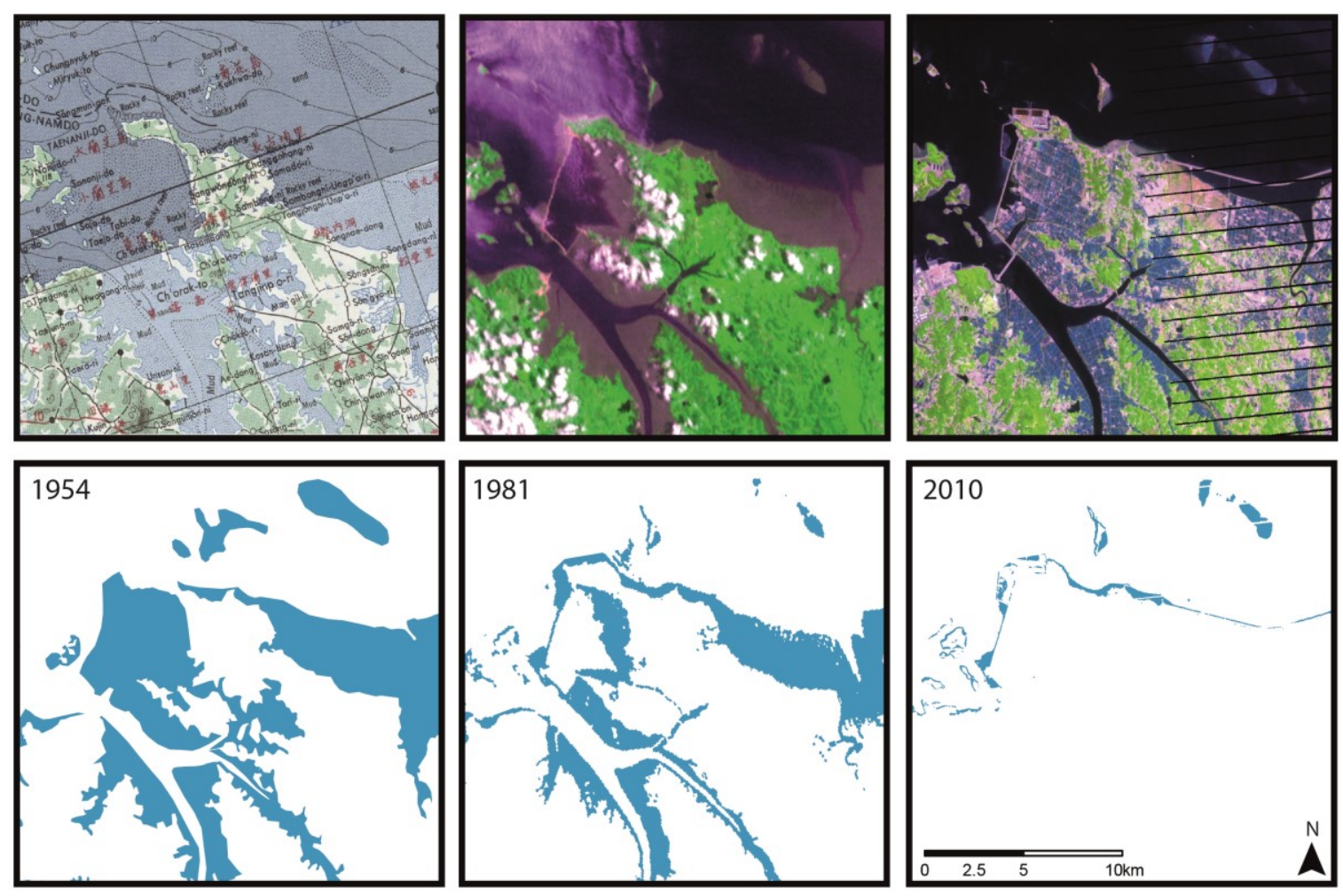

Figura 8. Los mapas de series de tiempo de la distribución de un ecosistema informan el riesgo de colapso del ecosistema. Aquí, los mapas topográficos históricos (1954) e imágenes de satélite del Archivo Landsat (1981, 2010) permitieron desarrollar una serie de tiempo normalizada del área del ecosistema de las llanuras intermareales del Mar Amarillo para la evaluación bajo el criterio A (Murray et al., 2014; Murray et al., 2015; Murray et al., 2012).

En algunos casos, se pueden utilizar indicadores espaciales de las distribuciones de los ecosistemas, tales como las observaciones de campo de ensambles de organismos, especies clave, clima, sustrato, topografía, batimetría, corrientes oceánicas, regímenes de inundación, acuíferos o alguna síntesis de éstos, que puedan ser justificados como representaciones válidas de la distribución de la biota del ecosistema o de su nicho espacial. Por ejemplo, los mapas de factores físicos tales como las características del fondo marino, las corrientes oceánicas, la temperatura del agua y la química del agua pueden ser apropiadas para los ecosistemas marinos. En algunos ecosistemas subterráneos, marinos y de agua dulce, las tendencias en la dimensión de profundidad pueden ser indicadores adecuados de la disminución en la distribución, con tal de que reflejen las tendencias en la capacidad de carga y la diversidad de nicho de la biota nativa característica (Keith et al., 2013). 
Los modelos de distribución espacial ofrecen la oportunidad de seleccionar y combinar formalmente el conjunto más adecuado de indicadores espaciales para predecir las distribuciones de los ecosistemas. Por ejemplo, Clark et al. (2015) usaron datos espaciales batimétricos y datos de la concentración de hielo marino obtenidos a partir de sensores remotos para modelar la distribución de las condiciones de luz adecuadas para las comunidades bentónicas marinas de invertebrados bajo el hielo de la Antártida. Los modelos son especialmente útiles para la predicción de series de tiempo de las distribuciones de los ecosistemas en el futuro para evaluar el criterio A2. Keith et al. (2014) modelaron la distribución de un ecosistema fangoso bajo futuros escenarios climáticos utilizando un mapa de la distribución actual del ecosistema basado en información de sensores remotos, en combinación con variables hidrológicas predictivas del clima, sustratos y del terreno. En ambos estudios, una comprensión mecanicista de la relación entre la ocurrencia del ecosistema y los factores ambientales limitantes fue fundamental para el desarrollo de un mapa adecuado del ecosistema.

\section{Métodos}

Para aplicar el criterio A, se requieren al menos dos estimaciones comparables de la distribución del ecosistema tipo en diferentes puntos en el tiempo. Está más allá del alcance de estas directrices el proporcionar información detallada sobre la adquisición, la clasificación y la exactitud de evaluación de los datos espaciales. Sin embargo, se supone que los datos espaciales utilizados para evaluaciones bajo el criterio A son adecuados para el propósito por ser: (i) comparables a través de períodos de tiempo (no sesgados); (ii) suficientemente precisos (Congalton \& Green, 2008); y (iii) de un tamaño de grano adecuado para el ecosistema tipo siendo evaluado. A pesar de que las evaluaciones se pueden completar con sólo dos puntos de datos (véase más adelante), se deben hacer esfuerzos para asegurar el poder apropiado en un modelo estadístico adecuado de los cambios del ecosistema y que todos las suposiciones del modelo sean abordadas en el análisis. Las buenas prácticas en el procesamiento y análisis de datos (Olofsson et al., 2014; Olofsson et al., 2013; Fuller et al., 2003) deben ser empleadas para minimizar el sesgo en las estimaciones del cambio de área a partir de un conjunto de datos espaciales de series de tiempo al evaluar el criterio $A$.

El subcriterio $A 1$ puede evaluarse directamente si se dispone de datos de hace 50 años y del presente. Sin embargo, es raro que los datos crudos estén disponibles para precisamente el período de tiempo requerido en una evaluación de la LRE. Más típicamente, los evaluadores deben utilizar métodos de interpolación, extrapolación, o predicción para calcular las estimaciones del cambio de distribución en los últimos 50 años (A1), los próximos 50 años (A2), y/o desde 1750 (A3). Esto implicará suposiciones sobre la naturaleza o el patrón de cambio, que deben ser explicadas y justificadas en la documentación. Para apoyar los cálculos, una herramienta de hoja de cálculo está disponible en el sitio web de la Lista Roja de Ecosistemas de UICN (www.iucnrle.org). Varias herramientas para ayudar en esta etapa están en desarrollo y estarán disponibles en el sitio web en el futuro. 


\section{Suposiciones}

Ya sea que las suposiciones sean hechas a partir de series temporales de imágenes de satélite o de otras fuentes de datos, dos aspectos importantes influirán fundamentalmente en las evaluaciones: (i) suposiciones acerca de la tasa de disminución; (ii) el número de puntos en las series de tiempo. Cuando la tasa de disminución se calcula a partir de dos observaciones (p. ej. mapas) sobre un período de tiempo específico, los evaluadores deben utilizar la información acerca de las causas y el contexto de la disminución para deducir la posible trayectoria (Fig. 9).

Aunque el criterio A se puede aplicar correctamente con sólo dos puntos de datos, contar con más datos permitirá un diagnóstico más seguro de la forma de la trayectoria, el ajuste de los modelos estadísticos alternativos, y por lo tanto, interpolaciones, extrapolaciones o predicciones más precisas. La selección de los modelos estadísticos candidatos siempre debe ser informada por las causas y el contexto de la disminución. Los evaluadores deben garantizar que los supuestos del modelo se cumplen adecuadamente. Al menos dos escenarios alternativos razonables deben ser explorados.
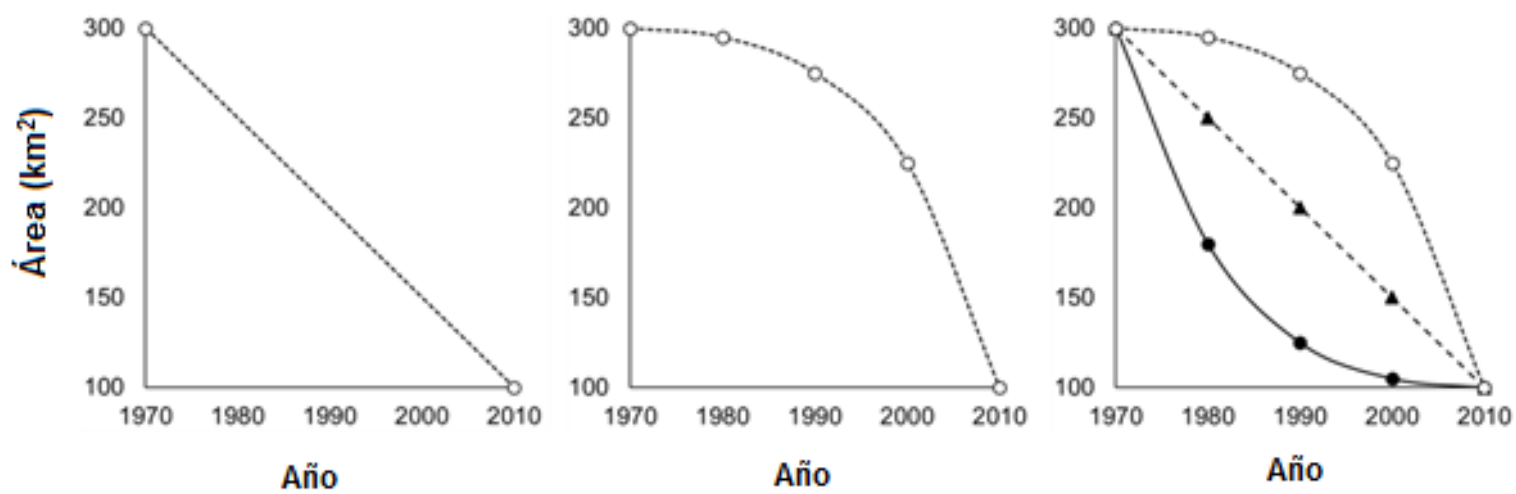

Figura 9. En esta figura, todas las trayectorias de tamaño de la distribución tienen los mismos puntos finales: $300 \mathrm{~km}^{2}$ en 1970 y $100 \mathrm{~km}^{2}$ en 2010. Una interpolación simple entre los dos extremos supone una disminución lineal (panel de la izquierda). La incorporación de estimaciones intermedias del tamaño de la distribución podría revelar que la disminución no es lineal (panel del medio). Diferentes ecosistemas tipo también podrían presentar trayectorias contrastantes con puntos finales idénticos: las proyecciones futuras de la distribución considerando estas trayectorias podría claramente ser diferente (panel de la derecha).

La Figura 10 ilustra dos escenarios alternativos de disminución para un ecosistema tipo modelo basado en el bosque de Coolibah - Boj negro, un ecosistema en una planicie de inundación semiárida en el este de Australia (Keith et al., 2009). En un escenario (PRD), la tasa de disminución es proporcional, por lo que una fracción constante de la distribución restante se pierde cada año. El área perdida se reduce con el tiempo (Fig. 10). En el otro escenario (ARD), un área constante se pierde cada año, produciendo un patrón lineal de disminución. Estos escenarios pueden ser modelados usando funciones exponenciales (PRD) y lineales (ARD), respectivamente. Los cambios predichos por estos modelos alternativos se vuelven más diferentes mientras son extrapolados más lejos en el futuro. En 
ausencia de cualquier otra información, el examen de las tasas de disminución proporcional (PRD) o absoluta (ARD) permite una evaluación del estatus del ecosistema bajo estos dos escenarios relativamente optimistas y pesimistas (Caja 9). Sin embargo, una serie temporal de observaciones más larga- junto con una comprensión de los conductores del cambio, el contexto normativo, la variabilidad regional en aptitud de la tierra, y la extensión de tenencias protegidas a través de la distribución del ecosistema- puede ayudar a seleccionar modelos más realistas. Estos modelos producirán límites más estrechos de la incertidumbre sobre el estimado del cambio en la distribución. Por ejemplo, ecosistemas en las primeras etapas de una explotación a gran escala pueden ser más propensos a exhibir patrones lineales de disminución (ARD) que aquellos en un estado avanzado de deterioro.

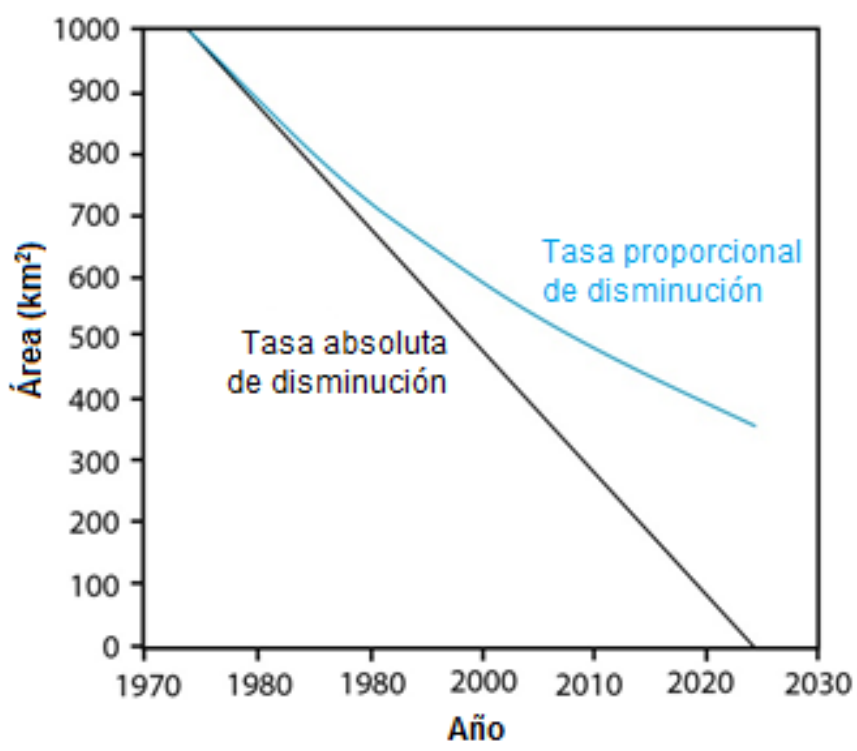

Figura 10. Escenarios alternativos para la disminución en la distribución de un ecosistema modelo (Keith et al., 2009; Keith et al., 2013). Esta figura muestra un ecosistema con un área inicial (1974) de $1.000 \mathrm{~km}^{2}$. Esta disminuyó a una tasa de $2 \%$ por año durante los 50 años siguientes, pero el resultado es sustancialmente diferente si la disminución es proporcional (PRD) o absoluta (ARD). En una PRD, la disminución es una fracción del área remanente del año anterior ( $0,02 \times$ área del año anterior), mientras que en una ARD el área sustraída cada año es una fracción constante del área del ecosistema al inicio de la disminución $(0,02 \times$ $\left.1000=20 \mathrm{~km}^{2} / a n ̃ o\right)$. Bajo un escenario de PRD, el ecosistema será considerado En Peligro bajo A2b (50\% de disminución para cualquier período de 50 años incluyendo el presente y el futuro), mientras que en el escenario ARD habría desaparecido para el 2024, y sería evaluado como Colapsado. 
Caja 9. Tasa de disminución proporcional y absoluta (criterio A)

La Sierra de Perijá es la cordillera montañosa que separa el noroeste de Venezuela del noreste de Colombia. Los bosques húmedos de Perijá del lado de Venezuela están amenazados por la expansión a gran escala de la agricultura comercial, principalmente de un tubérculo, la oreja de elefante con hoja en forma de flecha (Xanthosoma saggittifolium). Usando imágenes de satélite Landsat, se estimó que en 1986 los bosques húmedos de las cuencas de los ríos Guasare, Socuy y Cachirí ocupaban $328 \mathrm{~km}^{2}$, mientras que en el 2001 se habían reducido a $198 \mathrm{~km}^{2}$. Estos dos estimados permitieron una evaluación del estatus del ecosistema bajo el subcriterio $\mathrm{A} 2 \mathrm{~b}$, usando 1986-2001 como un primer estimado de la tasa de cambio observada en 15 años, y luego extrapolando las pérdidas proyectadas al 2036.

Diferentes suposiciones acerca de la tasa y tipo de disminución llevan a diferentes estimados de la extensión de estos bosques húmedos para el 2036. Los bosques en el 2001 ocupaban $198 \mathrm{~km}^{2}$ o el $60,4 \%$ de su área en 1986, entonces, la disminución es a una tasa media proporcional de $3,3 \%$ por año. El próximo paso es considerar cómo esta tasa puede cambiar sobre el tiempo para proyectar las pérdidas al 2036. La suposición de una tasa de disminución proporcional (PRD) entre 2001 y 2036 resulta en una disminución total del $81,5 \%$ entre 1986 y 2036 . Si se supone una tasa de disminución absoluta (ARD) se predice la disminución del 100\% para el 2024. Por lo que, bajo el criterio A2b una PRD conlleva a una clasificación de En Peligro Crítico ( $\geq 80 \%$ disminución sobre cualquier período de 50 años incluyendo el presente y futuro), mientras que una ARD lleva a una clasificación de por lo menos En Peligro Crítico ( $\geq 80 \%$ disminución sobre cualquier período de 50 años incluyendo el presente y futuro), aunque parece poco probable que el ecosistema colapse por completo si permanecen fragmentos del bosque en terreno montañoso menos accesible. En conclusión, el ecosistema es considerado En Peligro Crítico (CR) bajo el subcriterio A2b. Información sobre la forma más probable de la curva de disminución puede ayudar a determinar cuál de estas dos categorías posibles se debe informar como la mejor estimación

\section{Documentación}

Los evaluadores deben: (i) citar los repositorios de datos de mapas de series de tiempo de las distribuciones de los ecosistemas utilizados en la evaluación (ver el sitio web de la Lista Roja de Ecosistemas de UICN para una lista de los repositorios de datos espaciales preferidos: www.iucnrle.org); (ii) proporcionar referencias bibliográficas completas; (iii) justificar el por qué los datos espaciales utilizados son una representación adecuada de la distribución del ecosistema tipo focal; (iv) justificar las suposiciones y escenarios alternativos utilizados para interpolar, extrapolar o predecir cambios en la distribución de los datos disponibles; (v) explicar los métodos de cálculo, incluido el umbral del colapso supuesto. Además, se anima a los evaluadores a describir el origen de los datos espaciales (como el tipo de sensor satelital) y su resolución espacial (tamaño de grano), y hacer comentarios sobre la exactitud de todos los mapas clasificados. 


\subsection{Criterio B. Distribución geográfica restringida}

\subsubsection{Teoría}

El tamaño de la distribución geográfica de un ecosistema influye sobre su riesgo de colapso cuando es confrontado por una amenaza o catástrofe espacialmente explícita (Keith et al., 2013). En general, los ecosistemas que están ampliamente distribuidos o que existen a través de múltiples fragmentos independientes tienen menor riesgo de catástrofes, eventos de perturbación o cualquier otra amenaza que presente un grado de contagio espacial (p. ej. invasiones, contaminación, fuego, operaciones forestales y el cambio hidrológico o cambios climáticos regionales). La función principal del criterio B es identificar los ecosistemas cuya distribución es tan restringida que están en riesgo de colapso por la ocurrencia fortuita de un evento individual o de la interacción de unos pocos eventos amenazantes (Rodríguez et al., 2015). El criterio $B$ también incluye una aproximación para una estimación del hábitat ocupado por la biota componente, el cual está positivamente relacionado con la viabilidad de la población, independientemente de la exposición a eventos catastróficos.

\subsubsection{Umbrales y subcriterios}

Un ecosistema puede ser listado bajo el criterio B si cumple los umbrales para cualquiera de los tres subcriterios (B1, B2 y B3), los cuales indican una distribución geográfica restringida como sigue:

\begin{tabular}{|c|c|c|c|c|}
\hline Subcriterio & Medida de la distribución geográfica & $\mathrm{CR}$ & EN & VU \\
\hline \multirow[t]{2}{*}{ B1 } & $\begin{array}{l}\text { La extensión de un polígono convexo mínimo } \\
\left(\mathrm{km}^{2}\right) \text { que encierra todas las ocurrencias } \\
(\text { extensión de la presencia, EOO) es: } \\
\text { Y por los menos uno de los siguientes (a-c): } \\
\text { (a) Una disminución continua observada o } \\
\text { inferida en CUALQUIERA DE: } \\
\text { i. una medida de extensión espacial } \\
\text { apropiada para el ecosistema; O } \\
\text { ii. una medida de la calidad ambiental } \\
\text { apropiada para la biota nativa } \\
\text { característica del ecosistema; } 0 \\
\text { iii. una medida apropiada de la } \\
\text { interrupción de las interacciones } \\
\text { bióticas de la biota nativa característica } \\
\text { del ecosistema. } \\
\text { (b) Procesos de amenaza observados o } \\
\text { inferidos que es probable causen una } \\
\text { disminución continua en la distribución } \\
\text { geográfica, la calidad ambiental o las } \\
\text { interacciones bióticas dentro de los próximos } \\
20 \text { años. }\end{array}$ & $\leq 2,000$ & $\leq 20,000$ & $\leq 50,000$ \\
\hline & (c) El ecosistema existe en: & $\begin{array}{c}1 \\
\text { Localidad }\end{array}$ & $\begin{array}{c}\quad \leq 5 \\
\text { Localidades }\end{array}$ & $\begin{array}{l}\quad \leq 10 \\
\text { Localidades }\end{array}$ \\
\hline
\end{tabular}




\begin{tabular}{|lll|c|c|}
\hline Subcriterio & Medida de la distribución geográfica & CR & EN & VU \\
\hline B2 & $\begin{array}{l}\text { El número de celdas ocupadas dentro de una } \\
\text { cuadrícula de celdas de 10×10 km (área de } \\
\text { ocupación, AOO) es: } \\
\text { Y por lo menos uno de a-c arriba (igual a B1). }\end{array}$ & $\leq 2$ & $\leq 20$ & $\leq 50$ \\
\hline & $\begin{array}{l}\text { Un número de localidades muy pequeño (generalmente menor a 5) Y } \\
\text { propenso a los efectos de las actividades humanas o eventos } \\
\text { estocásticos dentro de un período de tiempo muy corto en un futuro } \\
\text { incierto, y por lo tanto capaz de colapsar o de convertirse En Peligro } \\
\text { B3 }\end{array}$ & VU \\
& $\begin{array}{l}\text { Crítico (CR) dentro de un período de tiempo muy corto (B3 sólo puede } \\
\text { conllevar a un listado de Vulnerable, VU). }\end{array}$ & \\
\hline
\end{tabular}

\subsubsection{Aplicación}

Requerimientos de datos

La distribución geográfica de un ecosistema tipo es evaluada bajo el criterio $B$ con dos métricas estandarizadas: la extensión de la presencia (EOO) y el área de ocupación (AOO) (Gaston \& Fuller, 2009; Keith et al., 2013). Además, la evaluación del criterio B requiere una evaluación cualitativa de si está ocurriendo una disminución en la extensión espacial o la calidad ambiental, o un incremento de la interrupción de las interacciones bióticas de forma continua, o si es probable que esto ocurra como resultado de amenazas. Por último, se requiere un estimado del número de localidades en las cuales ocurre un ecosistema. Por lo tanto, se requieren mapas precisos de la distribución actual del ecosistema, información sobre la dirección de las tendencias actuales y una comprensión de las amenazas que influyen en el ecosistema (Keith et al., 2013). Para más información sobre las fuentes de datos y los requisitos de los mapas de distribución para la aplicación en la LRE, consulte la Sección 5.1.3.

En algunos casos, los datos espaciales pueden ser insuficientes para estimar la EOO o el $\mathrm{AOO}$, pero hay evidencias de que un pequeño número de eventos amenazantes plausibles puede causar que un ecosistema pase a estar en Peligro Crítico o Colapsado en un futuro próximo. Tales ecosistemas pueden ser elegibles para ser listados como Vulnerable bajo el criterio B3 si ocupan unas pocas localidades en relación a la extensión de los eventos amenazantes. Se requieren mapas de distribución, registros de localidad o conocimiento experto para determinar el número de localidades en el que ocurre un ecosistema.

\section{Métodos}

\section{Evaluando las métricas espaciales para los criterios B1 y B2}

Las dos medidas estandarizadas de la distribución de los ecosistemas representan conceptualmente diferentes aspectos del tamaño del rango geográfico tanto para especies (Gaston, 1994; Gaston \& Fuller, 2009) como para ecosistemas (Rodríguez et al., 2015; Keith et al., 2013). La EOO (subcriterio B1) mide la dispersión del riesgo sobre un área contigua que encierra todas las ocurrencias utilizando un polígono convexo mínimo. En contraste, el AOO (subcriterio B2) mide la dispersión del riesgo entre los fragmentos ocupados a través de un recuento de las celdas de cuadrícula ocupadas (Keith et al., 2013). 
Garantizar la aplicación estandarizada de estos métodos es crítico para la medición objetiva del tamaño de una distribución espacial. Por lo tanto, los mismos protocolos de medición son apropiados para todas las unidades de evaluación, incluyendo ecosistemas tipo con dimensiones de profundidad o patrones de distribución particulares, tales como ecosistemas tipo con ocurrencias lineales. En ningún caso debe medirse el $\mathrm{AOO}$ o la $\mathrm{EOO}$ en formas que no cumplan con los métodos especificados a continuación:

1. Extensión de la presencia (EOO). La EOO de un ecosistema es medida a través de la determinación del área $\left(\mathrm{km}^{2}\right)$ de un polígono convexo mínimo - el polígono más pequeño que abarca todas las ocurrencias conocidas de un ecosistema focal en el que ningún ángulo interno es superior a 180 grados - ajustado a la distribución de un ecosistema. El polígono convexo mínimo (también conocido como casco convexo) no debe excluir ningún área, discontinuidad ni disyunción, independientemente de que el ecosistema puede ocurrir en esas áreas o no. Regiones tales como océanos (para ecosistemas terrestres), tierra (para ecosistemas costeros o marinos), o áreas fuera del área de estudio (tales como un país diferente) deben permanecer incluidas dentro del polígono convexo mínimo para asegurar que este método estandarizado sea comparable entre los ecosistemas tipo. Adicionalmente, estas características contribuyen a la dispersión de riesgos a lo largo de la distribución del ecosistema al hacer diferentes partes de su distribución más independientes espacialmente.

2. Área de ocupación (AOO). Las medidas del AOO son altamente sensibles al tamaño de grano (resolución de píxel) al cual la distribución es mapeada (Nicholson et al., 2009), por lo que todas las medidas del AOO de un ecosistema tipo deben ser estandarizadas a un grano espacial común. El AOO de un ecosistema en la LRE es determinado por el conteo del número de celdas ocupadas por el ecosistema dentro de una cuadrícula de celdas de $10 \times 10 \mathrm{~km}$. Este tamaño de grano relativamente grande es aplicado por tres razones: (i) los límites de los ecosistemas son inherentemente vagos (Regan et al., 2002), por lo que es más fácil determinar que una ocurrencia del ecosistema cae dentro de una celda de cuadrícula grande que dentro de una más pequeña; (ii) celdas más grandes pueden ser requeridas para diagnosticar la presencia de ecosistemas caracterizados por procesos que operan a escalas espaciales grandes, o que poseen rasgos diagnósticos que son escasos, crípticos, agrupados o móviles (p. ej. sistemas pelágicos o artesianos); (iii) celdas más grandes permiten la estimación del AOO incluso cuando los datos de distribución de alta resolución son limitados. Una cuadrícula global de celdas de $10 \times 10 \mathrm{~km}$ adecuada para este fin está disponible en el sitio web de la Lista Roja de Ecosistemas de UICN (www.iucnrle.org) tanto en formato raster como vectorial. Algunas distribuciones de ecosistemas comprenden una distribución muy sesgada de tamaños de fragmentos. En estos casos, un gran número de fragmentos pequeños aportan un efecto insignificante de dispersión de riesgos en comparación con los fragmentos más grandes, por lo que se puede aplicar una corrección al excluir del $\mathrm{AOO}$ las celdas de la cuadrícula que contienen fragmentos del ecosistema tipo que representan menos del $1 \%$ del área de la celda (es decir, $<1 \mathrm{~km}^{2}$ del ecosistema tipo focal, Caja 10). Están en marcha investigaciones para proporcionar orientación sobre cuándo aplicar esta corrección. 
Varias herramientas espaciales están en desarrollo para ayudar en la medición de la EOO y el AOO de un ecosistema tipo. Las mismas estarán disponibles en el sitio web de la Lista Roja de Ecosistemas de UICN (www.iucnrle.org).

\section{Evaluando los subcriterios B1 and B2}

Para ser elegible para ser listado bajo los subcriterios B1 o B2, un ecosistema debe cumplir los umbrales de la EOO o el AOO que delinean las categorías de amenaza, así como al menos uno de los tres subcriterios que se enfocan en las diversas formas de disminución.

Estos subcriterios distinguen los ecosistemas restringidos que presentan un riesgo apreciable de colapso de aquellos que persisten sobre largas escalas temporales dentro de pequeños rangos estables (Keith et al., 2013). Sólo se requiere evidencia cualitativa de disminución continua para invocar a los subcriterios, pero estándares relativamente altos de evidencias deben ser aplicados.

Los subcriterios B1a y B2a abordan la disminución continua en la distribución del ecosistema, el ambiente abiótico o los procesos bióticos. Para invocar este subcriterio, la disminución debe: (i) reducir la capacidad de un ecosistema para sostener su biota nativa característica; (ii) ser de una magnitud no-trivial; y (iii) ser más probable que no de continuar en el futuro (Tabla 3). Las reducciones episódicas o intermitentes califican como continuas, con tal de que sean recurrentes y no sean compensadas por incrementos de magnitud comparable. Las fases descendentes de los cambios cíclicos o de las fluctuaciones no pueden ser consideradas como disminuciones continuas. Estos requisitos implican la comprensión de las causas de la disminución para apoyar una inferencia correcta.

Los subcriterios $\mathrm{B} 1 \mathrm{~b}$ y $\mathrm{B} 2 \mathrm{~b}$ no requieren de pruebas de disminuciones pasadas o actuales, pero pueden ser invocados para disminuciones futuras inferidas por amenazas graves e inminentes. Para estos subcriterios, los evaluadores, deben: (i) identificar uno o más procesos de amenaza específicos; (ii) presentar evidencia convincente y ampliamente aceptada de que es muy probable (Tabla 3 ) que estas amenazas causen una disminución continua dentro de las próximas dos décadas. Estos requisitos implican una comprensión de cómo las amenazas afectan las características que definen el ecosistema y la sincronización de sus efectos. No se recomienda especular sobre amenazas genéricas con impactos o inicio inciertos. Las evidencias pertinentes incluyen las observaciones de amenazas similares en el pasado o en ecosistemas similares, así como el conocimiento acumulado sobre el comportamiento y la naturaleza de la amenaza en sí.

Los subcriterios B1c y B2c requieren un estimado del número de localidades que están ocupadas con relación a la extensión de posibles amenazas graves. Una localidad se define como un área distinta geográfica o ecológicamente en la que un único evento de amenaza puede afectar rápidamente todas las ocurrencias de un ecosistema. El tamaño de una localidad depende del área cubierta por el evento de amenaza y puede incluir parte de uno o varios fragmentos separados del ecosistema. Cuando un ecosistema tipo está afectado por más de un evento de amenaza, las localidades deben ser definidas tomando en cuenta la amenaza potencial más seria (UICN, 2012). Cuando un ecosistema tipo no está afectado por ningún evento de amenaza, el número de localidades será cero. La caja 11 contiene más orientación y ejemplos para apoyar la interpretación del concepto de localidad. 


\section{Evaluando el subcriterio B3}

El subcriterio B3 requiere sólo de información cualitativa sobre la distribución de un ecosistema y las amenazas a su persistencia. Para compensar por este tipo de evidencias (comparado con estimados cuantitativos para otros criterios), se requiere de un estándar más alto de evidencia cualitativa y la categoría más alta que puede ser invocada por el subcriterio B3 es Vulnerable. El subcriterio B3 comprende dos partes, ambas de las cuales deben cumplirse para que un ecosistema tipo califique para un estatus de Vulnerable. Primero, el ecosistema tipo debe tener una distribución muy restringida, generalmente menor a 5 localidades (Caja 11). Segundo, el ecosistema tipo debe estar enfrentando amenazas severas (actividades humanas o eventos estocásticos) dentro de un período de tiempo muy corto en un futuro incierto, y por lo tanto ser capaz de colapso o de pasar a estar En Peligro Crítico dentro de un período de tiempo muy corto. En otras palabras, el impacto de la amenaza es muy probable (Tabla 3 ) que se produzca en un futuro próximo y sus consecuencias sean severas. Los evaluadores tienen cierta flexibilidad para interpretar el "periodo de tiempo muy corto", pero esto generalmente significa dentro de las próximas dos décadas.

\section{Documentación}

Para cada evaluación de un ecosistema tipo, los asesores deben: (i) proporcionar los mapas actuales de las distribuciones de ecosistemas similares a los de la Caja 10 para mostrar cómo se determinaron la EOO, el AOO y el número de localidades; (ii) proporcionar referencias bibliográficas completas; (iii) justificar por qué los datos espaciales usados son una representación adecuada de la distribución del ecosistema tipo focal (si no se ha hecho ya para el criterio A); (iv) explicar por qué una corrección del AOO está justificada si es que se aplicó alguna; (v) justificar inferencias acerca de la disminución continua, y las amenazas que pueden conducir a la disminución continua dentro de los próximos 20 años; (vi) justificar las estimaciones del número de localidades a través de referencia a las amenazas más graves posibles y sus características espaciales (Caja 11). Al igual que con las evaluaciones derivadas del criterio $A$, se recomienda encarecidamente incluir la descripción de las fuente de datos espaciales (tales como tipo de sensor satelital), la exactitud de los datos mapeados y la resolución espacial (tamaño de grano) de todos los datos utilizados en la evaluación. Se fomenta la deposición de los datos espaciales del AOO y la EOO en un repositorio de datos apropiado, el cual debe estar referenciado en los documentos de la evaluación. 
Caja 10. La extensión de la presencia (EOO) y el área de ocupación (AOO) de un ecosistema (criterio B)
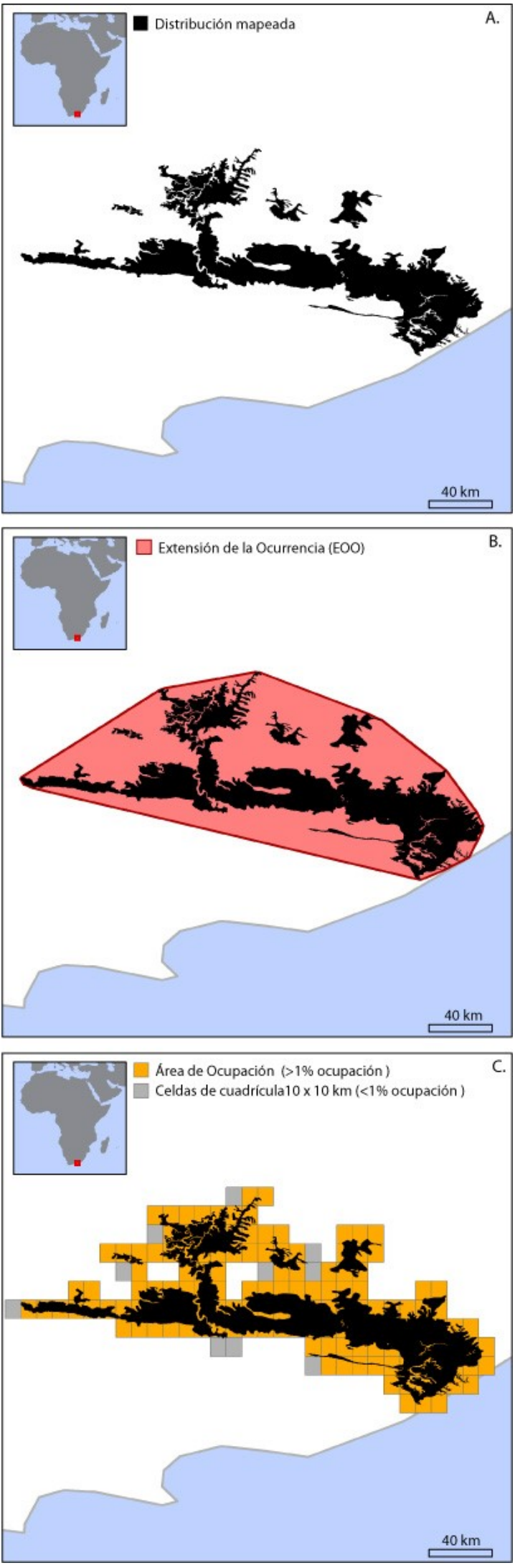

La distribución del Matorral Gran Pez, Sudáfrica (Mucina y Rutherford, 2006), es representa por un conjunto de datos raster con una resolución espacial de $30 \times 30 \mathrm{~m}$ (A). Tal como fue mapeada, el área del ecosistema tipo del Matorral Gran Pezl es 6.763,4 km².

Un polígono convexo mínimo -el polígono más pequeño que abarca todas las ocurrencias conocidas del ecosistema tipo en el que ningún ángulo interno supera los 180 grados- es aplicado para estimar la extensión de la presencia (EOO) para la evaluación bajo el subcriterio B1 (B). El área del polígono convexo mínimo es $18.359,2 \mathrm{~km}^{2}$, cumpliendo los requerimientos iniciales para ser clasificado como En Peligro bajo el criterio B1.

Para estimar el área de ocupación (AOO) para la evaluación bajo el subcriterio B2, se requiere el número de celdas ocupadas por el ecosistema tipo (C). La medición estandarizada del AOO asegura que los datos de distribución mapeados a distintas resoluciones son generalizados a una cuadrícula común de $10 \times 10 \mathrm{~km}$, lo que permite comparaciones consistentes entre los ecosistemas tipo. En primer lugar, una cuadrícula de $10 \times 10 \mathrm{~km}$ se aplica al ecosistema tipo, lo que indica que 155 celdas de cuadrículas de 10×10 $\mathrm{km}$ intersectan el mapa de distribución (mostrado en naranja y gris). En segundo lugar, cuando se excluye el número de celdas que contienen pedazos muy pequeños $\left(<1 \mathrm{~km}^{2}\right)$ que no contribuyen significantemente a la dispersión del riesgo (mostradas en gris), la medición del AOO es de 145 celdas de cuadrícula (mostrado en naranja). Esta $\mathrm{AOO}$ es mayor que los umbrales para la clasificación en una categoría amenazada bajo B2.

Finalmente, para poder ser listado en una categoría de amenaza bajo el criterio $\mathrm{B}$, se requiere también evidencia cualitativa de la disminución continua. En este caso, el ecosistema tipo del Matorral Gran Pez no cumple ninguno de los subcriterios adicionales, y es entonces asignado a una clasificación global de Preocupación Menor. 
Caja 11. Determinando el número de localidades (criterio B) (adaptado del Apéndice S2 en Keith et al., 2013)

Bosques de Coolibah - Boj negro del sudeste de Australia

En su estado maduro, el bosque de Coolibah - Boj negro tiene una estructura abierta con árboles muy dispersos, una cubierta variable de arbustos y un estrato herbáceo. La fauna de vertebrados característica incluye diversos ensambles de especies de aves de humedales y de bosques, muchos de los cuales dependen de los huecos de los árboles, de otras características de los árboles grandes o del agua estancada para la reproducción y forrajeo, (NSW Scientific Committee, 2004). Las posibles amenazas más graves son el desmonte de tierras y los cambios en los regímenes hídricos. Los patrones espaciales de desmonte de tierras muestran un alto grado de contagio, siendo el mejor predictor de los futuros desmontes la proximidad de un fragmento a parcelas de tierra que ya han sido despejadas de vegetación nativa. Una interpretación amplia de localidades bajo el subcriterio B3 identifica tres zonas jurisdiccionales con diferentes controles regulatorios de desmonte de tierras: la División Oeste de arrendamiento de Nueva Gales del Sur; la División Central de dominio absoluto de Nueva Gales del Sur; y Queensland; esto se traduce en un estimado de tres localidades definidos por el desmonte de tierras. Una interpretación más limitada de localidades basada en los vecindarios de contagio resultaría en un estimado de más de cinco. Pequeñas áreas protegidas están excluidas de estas localidades, ya que no están amenazadas por el desmonte de tierras. Estas áreas fueron evaluadas considerando la siguiente amenaza potencial más seria: los cambios en los regímenes hídricos. Como las áreas protegidas están localizadas en por lo menos dos sub-cuencas diferentes con diferentes infraestructuras de gestión de agua, hay por lo menos otras dos localidades. Por lo tanto, la interpretación más cautelosa produce una estimación de cinco localidades, aunque es probable que haya más. Basado en las actuales tasas de disminución debido al desmonte de tierras (subcriterio A1) y las tasas actuales de degradación ambiental debido a los cambios en el régimen hídrico (subcriterio $\mathrm{C} 1$ ), es poco probable que el ecosistema colapse o pase a estar en Peligro Crítico en el futuro próximo (cerca de 20 años). El ecosistema tipo, por lo tanto, no cumple con el subcriterio B3, por lo que el estado del ecosistema tipo es Preocupación Menor bajo este subcriterio.

\section{Fynbos de planicies arenosas del Cabo de Sudáfrica}

El Fynbos de planicies arenosas del Cabo es un denso matorral rico en especies, moderadamente alto, con arbustos emergentes dispersos (Rebelo et al., 2006). El ecosistema tipo es un ensamble de especies edáficamente determinado, restringido a arenas grises regis del Terciario, ácidas, profundas y ubicadas a bajas elevaciones (20-200 m) en terreno plano a ondulado. Los Fynbos de planicies arenosas del Cabo están restringidos a la provincia del Cabo Occidental de Sudáfrica, casi en su totalidad dentro de los límites de la Ciudad del Cabo. La amenaza más grave al ecosistema tipo es la destrucción del hábitat asociada con el desarrollo urbano (Rebelo et al., 2006; Wood et al., 1994). Las ocurrencias que están actualmente dentro de las reservas proclamadas están protegidas de esta amenaza, aunque estos rodales están amenazados por la invasión de plantas exóticas (Rebelo et al., 2006). Como toda la distribución del ecosistema tipo está dentro de la Ciudad del Cabo, la vegetación remanente sin declarar está sujeta a las mismas presiones de desarrollo, regímenes de regulación y planificación de las autoridades. Por lo tanto, la distribución se interpreta como dos localidades semi-independientes; una fuera de las áreas protegidas (amenazada por la destrucción del hábitat y las plantas invasoras) y una dentro de las áreas protegidas (amenazada por las plantas invasoras, pero no por la destrucción del hábitat). Dado el carácter severo e inmediato de las amenazas, el ecosistema tipo es propenso a los efectos de la actividad humana o eventos estocásticos tal que es capaz de colapsas o de pasar a estar en Peligro Crítico dentro de un período de tiempo muy corto. El estado del ecosistema tipo es entonces Vulnerable según el subcriterio B3. 


\subsection{Criterio C. Degradación ambiental}

\subsubsection{Teoría}

El modelo de riesgo de la LRE define dos criterios para evaluar las disminuciones en las funciones y procesos de los ecosistemas. Dos criterios son necesarios para evaluar la degradación abiótica (ambiental) y biótica debido a que las causas, efectos y mecanismos de la disminución de funcionalidad difieren fundamentalmente entre ellos (Keith et al., 2013). La degradación abiótica es el deterioro de los atributos físicos, no vivientes que cumplen un papel decisivo en los procesos y/o en la distribución de un ecosistema tipo. La degradación abiótica reduce la capacidad de un ecosistema de mantener su biota nativa característica. Por ejemplo, la disminución en los recursos limitantes (dimensión de nicho) reduce la diversidad de especies en un rango de ecosistemas terrestres, dulceacuícolas y marinos (Harpole \& Tilman, 2007).

\subsubsection{Umbrales y subcriterios}

Un ecosistema puede ser listado bajo el criterio $\mathrm{C}$ si cumple con los umbrales para cualquiera de los cuatro subcriterios ( $\mathrm{C} 1, \mathrm{C} 2 \mathrm{a}, \mathrm{C} 2 \mathrm{~b}$ o $\mathrm{C} 3$ ), los cuales expresan diferentes niveles de degradación ambiental sobre los siguientes períodos de tiempo:

\begin{tabular}{|c|c|c|c|c|c|}
\hline Subcriterio & \multicolumn{2}{|l|}{ Período de tiempo } & \multicolumn{3}{|c|}{ Severidad relativa (\%) } \\
\hline \multirow{4}{*}{ C1 } & \multirow{4}{*}{$\begin{array}{l}\text { Los últimos } 50 \text { años, basado en el cambio en } \\
\text { una variable abiótica que afecta una fracción } \\
\text { de la extensión del ecosistema y con } \\
\text { severidad relativa, como se indica en la } \\
\text { siguiente tabla: }\end{array}$} & $\begin{array}{c}\text { Extensión } \\
(\%)\end{array}$ & $\geq 80$ & $\geq 50$ & $\geq 30$ \\
\hline & & $\geq 80$ & CR & EN & VU \\
\hline & & $\geq 50$ & EN & VU & \\
\hline & & $\geq 30$ & VU & & \\
\hline \multirow[b]{5}{*}{$\mathrm{C} 2$} & \multirow{4}{*}{$\begin{array}{l}\text { C2a. Los próximos } 50 \text { años, basado en el } \\
\text { cambio en una variable abiótica que afecta } \\
\text { una fracción de la extensión del ecosistema y } \\
\text { con severidad relativa, como se indica en la } \\
\text { siguiente tabla; } 0\end{array}$} & $\begin{array}{c}\text { Extensión } \\
(\%)\end{array}$ & $\geq 80$ & $\geq 50$ & $\geq 30$ \\
\hline & & $\geq 80$ & CR & EN & VU \\
\hline & & $\geq 50$ & EN & VU & \\
\hline & & $\geq 30$ & VU & & \\
\hline & $\begin{array}{l}\text { C2b. Cualquier período de } 50 \text { años, } \\
\text { incluyendo pasado, presente y futuro, basado } \\
\text { en el cambio en una variable abiótica que } \\
\text { afecta una fracción de la extensión del } \\
\text { ecosistema y con severidad relativa, como se } \\
\text { indica en la siguiente tabla: }\end{array}$ & & & & \\
\hline \multirow{4}{*}{ C3 } & \multirow{4}{*}{$\begin{array}{l}\text { Desde } 1750 \text {, basado en el cambio en una } \\
\text { variable abiótica que afecta una fracción de la } \\
\text { extensión del ecosistema y con severidad } \\
\text { relativa, como se indica en la siguiente tabla: }\end{array}$} & $\begin{array}{c}\text { Extensión } \\
(\%)\end{array}$ & $\geq 90$ & $\geq 70$ & $\geq 50$ \\
\hline & & $\geq 90$ & $\mathrm{CR}$ & EN & VU \\
\hline & & $\geq 70$ & EN & VU & \\
\hline & & $\geq 50$ & VU & & \\
\hline
\end{tabular}




\subsubsection{Aplicación}

Requerimientos de datos

Para evaluar el criterio $C$ es necesario seleccionar las variables abióticas adecuadas que representen los rasgos característicos del ecosistema tipo. Esta elección está basada en un número de consideraciones:

1. Debe haber evidencia convincente de una relación causal entre el proceso de degradación ambiental y la pérdida de biota nativa característica. Por ejemplo, una evaluación de la degradación de humedales basado en el cambio en la calidad del agua requeriría pruebas de que la disminución en la calidad del agua está asociada con la pérdida de la biota de los humedales, ya sea mediante la observación directa o inferencia a partir de ecosistemas tipo comparables. Un modelo conceptual desarrollado cuidadosamente puede destacar los procesos clave y las transiciones ecológicas entre los estados sano y colapsado para ser evaluado con el criterio $C$ (Sección 4.2.3).

2. La evaluación de la degradación abiótica requiere de variables escalares adecuadas para la estimación de la severidad de la degradación, así como variables espaciales adecuadas para la estimación de la extensión de la degradación. Las características del ecosistema y sus amenazas determinarán qué variables son relevantes. Las variables con relaciones causa-efecto directas y claras y la mayor sensibilidad a la pérdida de biota nativa característica serán las más adecuadas.

3. La elección de una variable que represente la degradación abiótica debería permitir inferencias directas sobre los valores umbrales de la variable que define el colapso del ecosistema (Fig. 3).

4. Es poco probable que la aplicación de índices genéricos a través de ecosistemas funcionalmente contrastantes evalúe con precisión la degradación si los procesos clave difieren entre estos ecosistemas. La elección de las variables abióticas deberá apoyarse en la ecología de un ecosistema particular (Tabla 7). Si están disponibles variables alternativas que representan diferentes procesos de degradación, deben ser examinadas independientemente y la que produzca la mayor tasa de disminución deberá ser utilizada para evaluar el estatus, o los resultados deben contribuir a una estimación acotada del estatus.

5. La agregación de múltiples variables en un solo índice para la evaluación según el criterio $C$ puede ser problemático y no es recomendada. La agregación se basa en supuestos estadísticos que pueden ser injustificados, especialmente en ecosistemas con datos escasos. La agregación también puede confundir a los diferentes mecanismos de degradación del medio ambiente, volviendo el índice menos sensible que las variables individuales debido a los efectos de promediar. Por lo tanto, los evaluadores deben evitar la agregación de las variables cuando no están seguros acerca de la dinámica de los ecosistemas y las suposiciones que subyacen la agregación. En estos casos, se debe hacer el mejor esfuerzo para seleccionar una variable que sea relevante a los procesos del ecosistema y sensible a la degradación ambiental. El uso de índices agregados debe ser soportado por la 
evaluación crítica de las suposiciones ecológicas y matemáticas. Debe demostrarse un vínculo claro entre el cambio en el valor del índice y la proximidad al colapso.

6. Si la interacción entre dos o más variables se considera importante, es preferible desarrollar reglas sólidas y basadas en expertos para definir estados que son una combinación de las variables, en lugar de utilizar un índice. Por ejemplo, un ecosistema tipo muy degradado podría requerir que dos variables hayan cruzado un umbral determinado o que estén entre dos valores particulares, mientras que una degradación moderada podría requerir que cualquiera de las dos variables haya cruzado el umbral o que ambas estén entre un conjunto diferente de valores. El uso de un método basado en reglas requiere que el evaluador diga explícitamente y entienda cómo las variables pueden ser combinadas. En muchos índices estas relaciones están sumergidas, son pobremente entendidas, y tienen efectos imprevistos en los valores del índice.

7. La estimación de la extensión de la degradación abiótica puede basarse en estimaciones derivadas de expertos, de inferencias o de datos espaciales. Por ejemplo, para evaluar la severidad relativa de la degradación ambiental en toda la zona de los pantanos, marismas y lagos de la cuenca Murray-Darling se combinaron datos sobre los niveles de extracción de agua y del área superficial para cada humedal (Keith et al., 2013).

Tabla 7. Ejemplos de variables potencialmente adecuadas para la evaluar la severidad de la degradación ambiental bajo el criterio $\mathrm{C}$.

\begin{tabular}{|c|c|}
\hline Degradación ambiental & Variables \\
\hline $\begin{array}{l}\text { Desertificación de } \\
\text { pastizales }\end{array}$ & $\begin{array}{l}\text { Cobertura proporcional de suelo desnudo, densidad del suelo, } \\
\text { índices de compactación del suelo, índices de cambio basados en } \\
\text { sensores remotos (Zhao et al., 2005; Ludwig et al., 2007). }\end{array}$ \\
\hline $\begin{array}{l}\text { Eutrofización de los suelos, } \\
\text { corrientes de agua dulce o } \\
\text { lagos }\end{array}$ & $\begin{array}{l}\text { Niveles de nitrógeno disuelto o en el suelo, fósforo, cationes, } \\
\text { oxígeno, turbidez, bioensayo (Carpenter, 2003). }\end{array}$ \\
\hline $\begin{array}{l}\text { De-humidificación de } \\
\text { bosques nublados }\end{array}$ & Cobertura de nubes, altitud de nubes (Pounds et al., 1999). \\
\hline $\begin{array}{l}\text { Deforestación por lluvia } \\
\text { ácida }\end{array}$ & Química del agua de lluvia (Likens, 1992). \\
\hline $\begin{array}{l}\text { Homogenización de micro } \\
\text { hábitats }\end{array}$ & $\begin{array}{l}\text { Diversidad de rasgos de micro-terrenos, variación espacial en la } \\
\text { profundidad y duración de inundación (Cabezas et al., 2009). }\end{array}$ \\
\hline $\begin{array}{l}\text { Cambios del régimen } \\
\text { hídrico o hidroperíodo }\end{array}$ & $\begin{array}{l}\text { Monitoreo en campo del flujo volumétrico de las corrientes, o } \\
\text { profundidad de la mesa de agua piezométrica; uso de sensores } \\
\text { remotos para estimar la extensión espacial de la superficie de agua, } \\
\text { frecuencia y profundidad de inundación (Mac Nally et al., 2011). }\end{array}$ \\
\hline $\begin{array}{l}\text { Salinización de suelos o } \\
\text { humedales }\end{array}$ & $\begin{array}{l}\text { Monitoreo de campo de lasalinidad de los suelos o aguas } \\
\text { subterráneas, uso de sensores remotos para estimar el albedo de } \\
\text { la superficie terrestre (Metternicht \& Zinck, 2003). }\end{array}$ \\
\hline
\end{tabular}




\begin{tabular}{|c|c|}
\hline Degradación ambiental & Variables \\
\hline $\begin{array}{l}\text { Sedimentación de } \\
\text { corrientes, arrecifes } \\
\text { coralinos }\end{array}$ & $\begin{array}{l}\text { Tasas de acumulación de sedimentos, carga de sedimentos en } \\
\text { corrientes, descarga, turbidez de la columna de agua, frecuencia a } \\
\text { intensidad de las firmas espectrales de las columnas de sedimentos } \\
\text { (Rogers, 1990). }\end{array}$ \\
\hline $\begin{array}{l}\text { Simplificación estructural } \\
\text { de los ecosistemas } \\
\text { marinos bentónicos }\end{array}$ & $\begin{array}{l}\text { Micro-relieve, abundancia de sedimentos bentónicos, frecuencia de } \\
\text { la pesca de arrastre y patrón espacial (Watling \& Norse, 1998). }\end{array}$ \\
\hline Aumento del nivel del mar & $\begin{array}{l}\text { Monitoreo acústico del nivel del mar, extensión de inundación por } \\
\text { mareas (Hannah \& Bell, 2012). }\end{array}$ \\
\hline $\begin{array}{l}\text { Regresión de las masas de } \\
\text { hielo }\end{array}$ & $\begin{array}{l}\text { Extensión de las masas de hielo estimada con sensores remotos } \\
\text { (Hong \& Shin, 2010). }\end{array}$ \\
\hline
\end{tabular}

\section{Métodos}

El concepto clave para evaluar la disminución funcional de cualquiera de las variables abióticas o bióticas es la severidad relativa. La severidad relativa es esencial para la comparación de riesgos entre ecosistemas sometidos a diferentes tipos de degradación. La severidad relativa describe el cambio proporcional observado en una variable ambiental escalada entre dos valores: una que describe el estado inicial del sistema $(0 \%)$, y otra que describe el estado colapsado (100\%). Por lo tanto, si un ecosistema tipo sufre una degradación con una severidad relativa de $50 \%$ sobre el período de tiempo de una evaluación, esto implica que se ha transformado hasta mitad de camino hacia un estado colapsado. La información sobre la severidad relativa es combinada con información sobre la proporción del ecosistema que se ve afectada (extensión) para determinar la categoría de riesgo bajo el criterio C. Los evaluadores pueden o bien estimar el grado de degradación que excede un nivel umbral de severidad o estimar la severidad promedio de la degradación a través de toda la distribución del ecosistema (100\% de extensión; Fig. 11).

Los ecosistemas son listados como CR si el cambio ambiental es extremadamente grave ( $\geq 80 \%$ severidad relativa) como extenso (sobre $\geq 80 \%$ de la distribución). Los ecosistemas pueden ser elegibles para ser listados en categorías de menor amenaza si son sometidos a degradaciones muy severas pero localizadas, o a degradaciones menos severas en áreas extensas (Fig. 11). Los ecosistemas que no cumplan con los umbrales para la categoría de Vulnerable pero estén cercanos a ellos pueden ser asignados a la categoría de Casi Amenazado. Por ejemplo, un ecosistema que ha sufrido $>80 \%$ de disminución de la calidad ambiental a lo largo del $20-30 \%$ de su distribución, o $>30 \%$ de disminución sobre $70-80 \%$ de su distribución puede calificar como Casi Amenazado.

En el caso más simple, la severidad relativa puede calcularse por medio de la estandarización del rango de valores crudos de la variable abiótica entre su valor inicial y su valor de colapso. Los evaluadores deben: (i) estimar el valor de la variable abiótica en el estado inicial (al principio de la evaluación del período de tiempo); (ii) estimar el valor esperado en el estado colapsado; (iii) medir o estimar el valor presente o futuro de la 
variable (es decir, al final de la evaluación del período de tiempo). Tenga en cuenta que la severidad relativa calculada puede ser negativa si la condición del ecosistema ha mejorado.

Las siguientes ecuaciones re-escalan una variable abiótica a un cambio proporcional hacia el colapso de forma adecuada para evaluar el criterio C:

Severidad relativa $(\%)=($ Disminución observada o predicha $/$ Disminución máxima $) \times 100$ donde

Disminución observada o predicha $=$ Valor inicial - Valor presente o futuro y

$$
\text { Disminución máxima }=\text { Valor inicial }- \text { Valor de colapso }
$$

A continuación, los evaluadores determinan la extensión de la degradación como una proporción de la distribución total del ecosistema. Con estas dos cantidades los evaluadores asignan una categoría de riesgo utilizando los umbrales descritos.
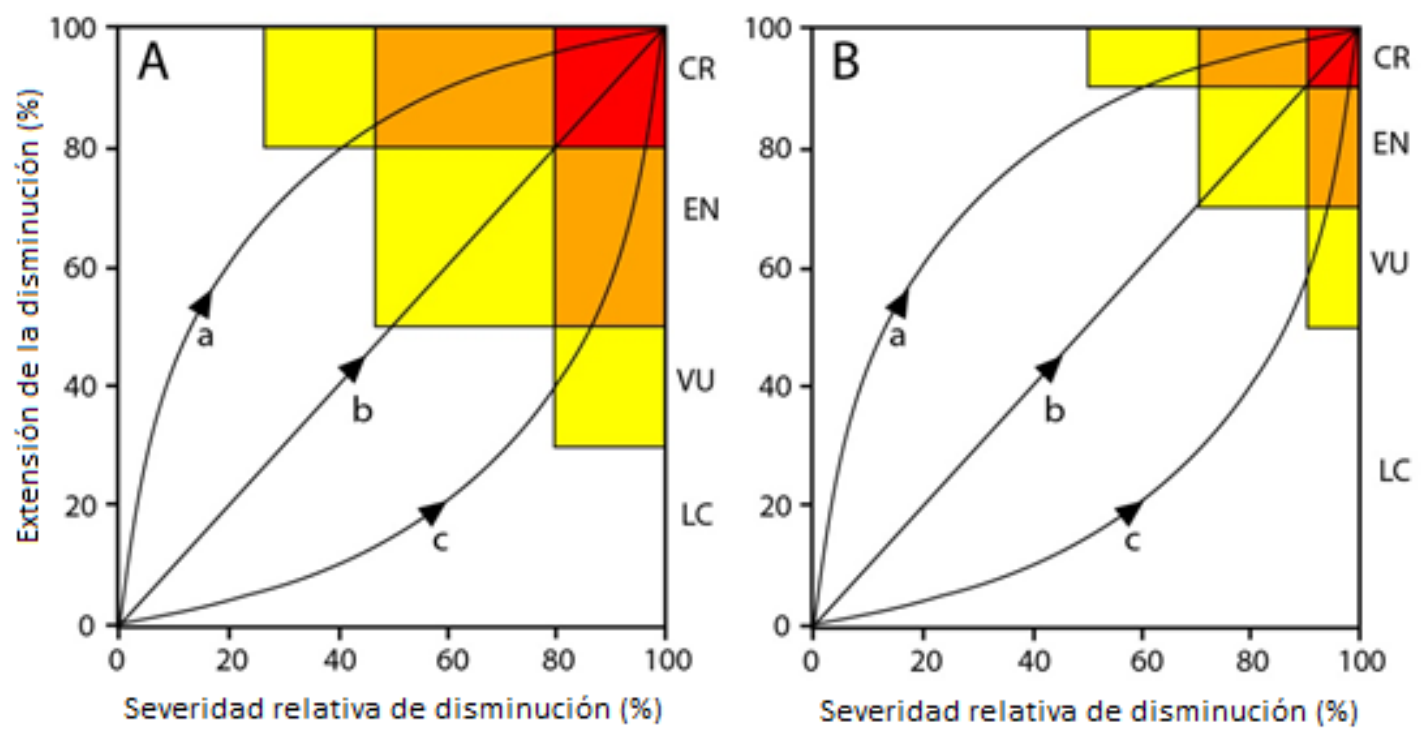

Figura 11. Vías contrastantes de degradación ambiental o biótica y sus correspondientes clasificaciones de riesgo bajo los criterios C1, C2, D1, D2 (A) o C3, D3 (B): (a) degradación inicial generalizada y relativamente benigna, que aumenta en severidad, (b) la severidad $u$ extensión de la degradación aumentan a tasas similares, (c) degradación localizada pero severa, que luego aumenta en extensión. 

al., 2013)

La inundación es un proceso ecológico clave que sustenta los Bosques de Gonakier de la llanura de inundación del río Senegal en Senegal-Mauritania (Keith et al., 2013). Debido a que las inundaciones sólo se producen durante los meses de la estación húmeda, se asumió que la altura máxima anual del río es un buen indicador de la capacidad de inundación del río cada año. Se disponía de datos de la altura del río para 100 años entre 1904-2003. Para evaluar el criterio C, se utilizó la altura máxima promedio del río en cuatro estaciones de medición como un indicador de la degradación ambiental. El caudal del río se redujo drásticamente, llegando a un mínimo durante las décadas de 1970 y 1980. Es muy poco probable que ocurrieran inundaciones de $2.500 \mathrm{~m}^{3} / \mathrm{s}$, las cuales son necesarias para la inundación de la llanura, según los registros del caudal del río entre 1986-1989. Entre mediados de 1970 y mediados de 1980 se observaron tasas extremas de mortalidad de árboles, correspondiendo a las más bajas alturas máximas del río $(473 \pm 27 \mathrm{~cm})$ observadas durante los 100 años de registro.

Basado en estas observaciones, el umbral de colapso fue definido como una caída de la altura promedio máxima del río por debajo de $450-500 \mathrm{~cm}$ para un período de 50 años, causando amplia mortalidad de los árboles. Para calcular la severidad relativa de la degración hidrológica, la serie de tiempo fue dividida en el período de referencia (1904-1953) y el período presente (19542003). Debido a que el umbral de colapso es un intervalo, la severidad relativa fue estimada para los límites superiores e inferiores del intervalo.

Para el límite inferior $(450 \mathrm{~mm})$, la severidad relativa es:

(Disminución observada $/($ Disminución máxima) $\times 100=(712-619) /(712-450) \times 100=35 \%$

Para el límite superior $(500 \mathrm{~mm})$, la severidad relativa es

(Disminución observada $/($ Disminución máxima $) \times 100=(712-619) /(712-500) \times 100=44 \%$

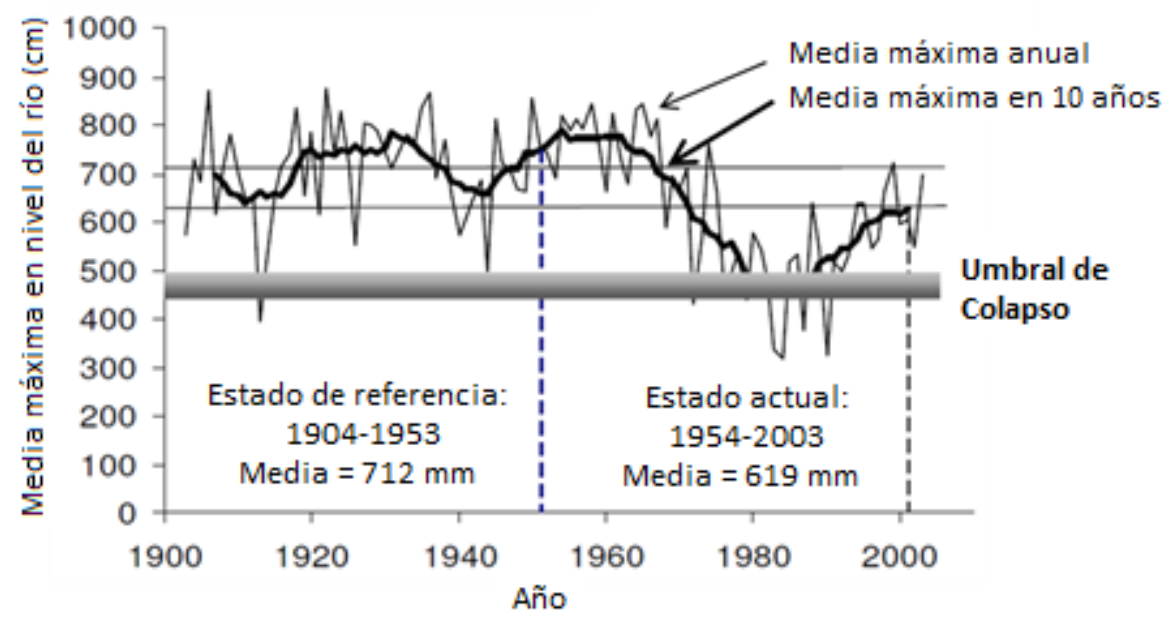

Figura 12. Altura del río en el bosque de Gonakier.

Dado que la degradación hidrológica afecta a todo el ecosistema, se supuso que la extensión de la amenaza fue $>80 \%$, lo que conduce a la conclusión de que el ecosistema es Vulnerable de acuerdo al Criterio C1 (degradación con severidad relativa $\geq 30 \%$ sobre una extensión $\geq 80 \%$ en los últimos 50 años). 


\section{Suposiciones}

La determinación de los valores inicial y colapsado de la variable abiótica se basa en suposiciones acerca de los estados colapsados del ecosistema. Esta incertidumbre en el punto de colapso se puede representar con umbrales acotados de los valores de la variable. El cálculo de la severidad relativa puede repetirse con ambos valores, proporcionando un estimado inferior y superior de la categoría de riesgo (Caja 12). Del mismo modo, la incertidumbre en la extensión de la degradación se puede evaluar con el uso de estimados superiores e inferiores. El uso de valores acotados resulta en una estimación de la extensión y severidad de la degradación abiótica a la vez que expresa claramente la incertidumbre.

De forma similar a la disminución de la extensión requerida para la evaluación bajo el criterio $\mathrm{A}$, la aplicación del criterio $\mathrm{C}$ asume una forma funcional de disminución. El caso más simple ilustrado arriba se aplica cuando existe una relación lineal entre la variable de evaluación y la trayectoria hacia un estado colapsado. Otros escenarios son posibles, por ejemplo, cuando el colapso procede más lentamente o más rápidamente que lo indicado por los cambios en la variable de evaluación. En tales casos, debe utilizarse una transformación adecuada de la variable de evaluación para el cálculo de la severidad relativa.

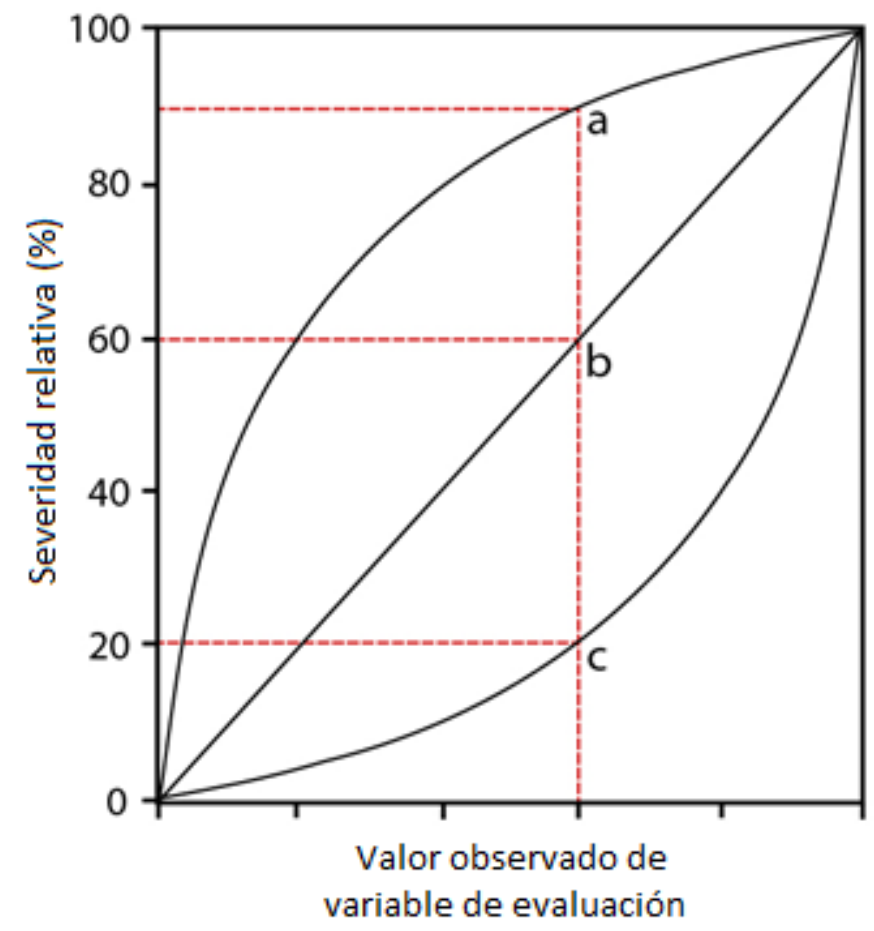

Figura 13. Un valor observado para una variable utilizada para evaluar la degradación puede ser mapeado con diferentes valores de severidad relativa dependiendo de la forma funcional considerada. La línea roja indica un valor observado que puede ser asignado a una severidad relativa de $20 \%, 60 \%$, o $90 \%$ dependiendo de la forma funcional. Esto corresponde a una categoría de riesgo de LC, EN, o CR si la degradación ocurre sobre $\geq 80 \%$ del ecosistema tipo. 
Los datos de series temporales pueden ayudar a determinar si la degradación es constante, acelerada, o desacelerada. Los evaluadores deben evaluar si los datos disponibles son suficientemente representativos como para caracterizar la forma de la curva de degradación de la variable abiótica, idealmente a través de métodos estadísticos apropiados (Di Fonzo et al., 2013; Connors et al., 2014). Cuando no se disponga de datos de series de tiempo, puede ser posible inferir cambios en la degradación mediante deducciones de expertos o por sustituciones espacio-por-tiempo con sitios de referencia apropiados (Pickett, 1989). Para superar la incertidumbre debido a estas suposiciones, los análisis de sensibilidad que incluyan estimados producidos a partir de múltiples formas de la curva de degradación pueden proporcionar una estimación acotada para el resultado de la evaluación de riesgo.

\section{Documentación}

Los evaluadores deben documentar: (i) la selección de la variable abiótica con respecto al modelo conceptual de la dinámica del ecosistema; (ii) la fijación de un umbral de colapso acotado para la variable abiótica; (iii) el cálculo de la severidad relativa; (iv) la estimación de la extensión de la degradación; ( $v$ ) suposiciones y análisis de sensibilidad adecuados ( $p$. ej. respecto a la definición de colapso o la forma de la curva de degradación); (vi) las categorías de riesgo finales y límites factibles. La variación temporal en la degradación se muestra mejor en un gráfico que represente cambios en la variable a través del tiempo, e incluya cualquier interpolación o extrapolación para coincidir con el período de tiempo relevante. 


\subsection{Criterio D. Interrupción de los procesos e interacciones bióticas}

\subsubsection{Teoría}

La persistencia de la biota dentro de los ecosistemas depende de los procesos y las interacciones bióticas. Esto incluye: procesos competitivos, de depredación, de facilitación, mutualistas, tróficos y patógenos; enlaces móviles (p. ej. migración estacional); y especies invasoras. La pérdida de biodiversidad disminuye la capacidad de los ecosistemas para captar recursos, producir biomasa, descomponer la materia orgánica y reciclar carbono, agua y nutrientes, y también disminuye la estabilidad de estas funciones a través del tiempo (Cardinale et al., 2012). La identidad de los organismos dentro de un sistema controla su funcionamiento dado que los taxones clave hacen contribuciones desproporcionadas a las funciones del ecosistema. La diversidad de organismos también es importante, debido a que la partición de nicho y las interacciones positivas entre especies promueven contribuciones complementarias a las funciones del ecosistema.

Las interacciones de retroalimentación son cruciales para que un ecosistema tipo absorba los cambios ambientales, mientras mantiene la biota y los procesos característicos. Por el contrario, las interrupciones significativas a los procesos y las interacciones bióticas pueden causar el colapso, cambios de régimen y re-organización en ecosistemas emergentes (Thébault \& Loreau, 2005). La interrupción de las interacciones a través de cascadas tróficas es una de las cinco principales amenazas para la biodiversidad (Diamond, 1989), aunque las interacciones no tróficas también juegan papeles importantes (Fontaine et al., 2005; Goudard \& Loreau, 2008). Ciertos ecosistemas tipo pueden ser especialmente sensibles a la interrupción de los procesos y las interacciones bióticas, tales como sistemas con una fuerte regulación trófica de arriba a abajo, con muchas interacciones mutualistas o de facilitación que dependen fuertemente de enlaces móviles, y donde operan retroalimentaciones positivas entre la biota y los regímenes de perturbación.

\subsubsection{Umbrales y subcriterios}

Un ecosistema puede ser listado bajo el criterio $D$ si cumple los umbrales para cualquiera de los cuatro subcriterios (D1, D2a, D2b o D3), los cuales expresan diferentes niveles de interrupción biótica sobre los siguientes períodos de tiempo: 


\begin{tabular}{|c|c|c|c|c|c|}
\hline Subcriterio & \multicolumn{2}{|l|}{ Período de tiempo } & \multicolumn{3}{|c|}{ Severidad relativa (\%) } \\
\hline \multirow{4}{*}{ D1 } & \multirow{4}{*}{$\begin{array}{l}\text { Los últimos } 50 \text { años, basado en el cambio en } \\
\text { una variable biótica que afecta una fracción } \\
\text { de la extensión del ecosistema y con } \\
\text { severidad relativa, como se indica en la } \\
\text { siguiente tabla: }\end{array}$} & $\begin{array}{c}\text { Extensión } \\
(\%)\end{array}$ & $\geq 80$ & $\geq 50$ & $\geq 30$ \\
\hline & & $\geq 80$ & CR & EN & VU \\
\hline & & $\geq 50$ & EN & VU & \\
\hline & & $\geq 30$ & VU & & \\
\hline \multirow[b]{5}{*}{$\mathrm{D} 2$} & \multirow{4}{*}{$\begin{array}{l}\text { D2a. Los próximos } 50 \text { años, basado en el } \\
\text { cambio en una variable biótica que afecta } \\
\text { una fracción de la extensión del ecosistema y } \\
\text { con severidad relativa, como se indica en la } \\
\text { siguiente tabla; } 0\end{array}$} & $\begin{array}{c}\text { Extensión } \\
(\%)\end{array}$ & $\geq 80$ & $\geq 50$ & $\geq 30$ \\
\hline & & $\geq 80$ & CR & EN & VU \\
\hline & & $\geq 50$ & EN & VU & \\
\hline & & $\geq 30$ & VU & & \\
\hline & $\begin{array}{l}\text { D2b. Cualquier período de } 50 \text { años, } \\
\text { incluyendo pasado, presente y futuro, } \\
\text { basado en un cambio en una variable biótica } \\
\text { que afecta una fracción de la extensión del } \\
\text { ecosistema y con severidad relativa, como se } \\
\text { indica en la siguiente tabla: }\end{array}$ & & & & \\
\hline \multirow{4}{*}{ D3 } & \multirow{4}{*}{$\begin{array}{l}\text { Desde } 1750 \text {, basado en el cambio en una } \\
\text { variable biótica que afecta una fracción de la } \\
\text { extensión del ecosistema y con severidad } \\
\text { relativa, como se indica en la siguiente tabla: }\end{array}$} & $\begin{array}{c}\text { Extensión } \\
(\%)\end{array}$ & $\geq 90$ & $\geq 70$ & $\geq 50$ \\
\hline & & $\geq 90$ & CR & EN & $\mathrm{VU}$ \\
\hline & & $\geq 70$ & EN & VU & \\
\hline & & $\geq 50$ & VU & & \\
\hline
\end{tabular}

\subsubsection{Aplicación}

\section{Requerimientos de datos}

La evaluación del criterio $D$ enfrenta los mismos requisitos de datos del criterio $C$, excepto que se utilizan variables bióticas adecuadas. Los modelos conceptuales proporcionan un marco útil para la selección de variables bióticas vinculadas a los procesos clave del ecosistema. Un amplio conjunto de variables son potencialmente útiles para la cuantificación de los procesos bióticos y la degradación de su funcionalidad asociada. Esto incluye cambios en la riqueza de especies, composición y dominancia; la abundancia relativa de los tipos de especies funcionales, gremios o especies exóticas; medidas de diversidad de las interacciones; cambios en la identidad y frecuencia del movimiento de las especies; medidas de diversidad y complejidad estructural de nicho (Tabla 8).

Tabla 8. Ejemplos de variables bióticas potencialmente adecuadas para evaluar la severidad de la interrupción de las interacciones bióticas bajo el criterio $\mathrm{D}$.

\begin{tabular}{|c|c|c|}
\hline Variable & $\begin{array}{l}\text { Papel en la resiliencia y } \\
\text { funcionamiento de los ecosistemas }\end{array}$ & Ejemplo \\
\hline $\begin{array}{l}\text { Riqueza de especies } \\
\text { (número de especies dentro } \\
\text { de un grupo taxonómico por } \\
\text { unidad de área). }\end{array}$ & $\begin{array}{l}\text { Los procesos ecológicos } \\
\text { disminuyen a un ritmo acelerado } \\
\text { con la pérdida de especies } \\
\text { (Cardinale et al., 2011). La riqueza } \\
\text { de especies se relaciona } \\
\text { indirectamente con el }\end{array}$ & $\begin{array}{l}\text { Respuesta de la diversidad y } \\
\text { abundancia relativa de } \\
\text { especies gramíneas ante } \\
\text { distintos niveles de pastoreo } \\
\text { en pastizales (Walker et al., } \\
\text { 1999). }\end{array}$ \\
\hline
\end{tabular}




\begin{tabular}{|c|c|c|}
\hline Variable & $\begin{array}{l}\text { Papel en la resiliencia y } \\
\text { funcionamiento de los ecosistemas }\end{array}$ & Ejemplo \\
\hline & $\begin{array}{l}\text { funcionamiento y resiliencia del } \\
\text { ecosistema a través de sus } \\
\text { correlaciones con la diversidad } \\
\text { funcional, redundancia y } \\
\text { complementariedad. }\end{array}$ & \\
\hline $\begin{array}{l}\text { Composición y dominancia } \\
\text { de especies. }\end{array}$ & $\begin{array}{l}\text { Cambios en la dominancia y } \\
\text { estructura de la comunidad son } \\
\text { síntomas de cambio en el } \\
\text { comportamiento e identidad del } \\
\text { ecosistema. }\end{array}$ & $\begin{array}{l}\text { Cambios en la dieta de los } \\
\text { predadores tope (ballenas } \\
\text { asesinas) debido a los efectos } \\
\text { de la sobrepesca sobre las } \\
\text { focas, causó la disminución de } \\
\text { leones marinos y redujo la } \\
\text { depredación de los erizos que } \\
\text { se alimentan de algas, } \\
\text { causando que sus poblaciones } \\
\text { explotaran con un } \\
\text { consecuente colapso de las } \\
\text { algas gigantes, los dominantes } \\
\text { estructurales del bentos (Estes } \\
\text { et al., 2009) (Caja 13). }\end{array}$ \\
\hline $\begin{array}{l}\text { Abundancia de especies } \\
\text { clave (ingenieros de } \\
\text { ecosistema, predadores y } \\
\text { herbívoros clave, } \\
\text { competidores dominantes, } \\
\text { dominantes estructurales, } \\
\text { especies invasoras } \\
\text { transformadoras). }\end{array}$ & $\begin{array}{l}\text { La invasión de ciertas especies } \\
\text { foráneas puede alterar el } \\
\text { comportamiento e identidad del } \\
\text { ecosistema, y convertir el hábitat } \\
\text { en inadecuado para la persistencia } \\
\text { de parte de la biota nativa. Las } \\
\text { especies foráneas transformadoras } \\
\text { se distinguen de invasiones } \\
\text { benignas que no tienen mayor } \\
\text { influencia en la funcionalidad y } \\
\text { dinámica del ecosistema. }\end{array}$ & $\begin{array}{l}\text { La invasión de las hormigas } \\
\text { locas simplifica la estructura } \\
\text { del bosque, reduce la } \\
\text { diversidad de fauna y los } \\
\text { ingenieros nativos del } \\
\text { ecosistema (Green et al., } \\
\text { 2011). La invasión de } \\
\text { matorrales y praderas áridas } \\
\text { de Australia por Cenchrus } \\
\text { ciliaris los hace más } \\
\text { propensos a incendios y } \\
\text { menos favorables para la } \\
\text { persistencia de las especies } \\
\text { de plantas nativas (Clarke et } \\
\text { al., 2005; Miller et al., 2010). }\end{array}$ \\
\hline $\begin{array}{l}\text { Diversidad funcional } \\
\text { (número y equidad de } \\
\text { tipos). }\end{array}$ & $\begin{array}{l}\text { La alta diversidad de tipos de } \\
\text { especies funcionales (p. ej. tipos } \\
\text { de uso de recursos, tipos de } \\
\text { respuestas a disturbios) promueve } \\
\text { la coexistencia a través de la } \\
\text { repartición de recursos, } \\
\text { diversificación de nichos y } \\
\text { mutualismos (Allen et al., 2005). } \\
\text { Mecanismos similares a la } \\
\text { complementariedad funcional. }\end{array}$ & $\begin{array}{l}\text { La alta diversidad de recursos } \\
\text { derivados de las plantas } \\
\text { sustenta la composición, } \\
\text { diversidad y funcionalidad de } \\
\text { la biota del suel (Eisenhauer et } \\
\text { al., 2011). Los regímenes de } \\
\text { fuego promueven la } \\
\text { coexistencia de múltiples tipos } \\
\text { funcionales de plantas (Keith } \\
\text { et al., 2007). }\end{array}$ \\
\hline $\begin{array}{l}\text { Redundancia funcional } \\
\text { (número de taxones por } \\
\text { tipo; redundancia dentro y } \\
\text { entre escalas; ver Allen et } \\
\text { al., 2005). }\end{array}$ & $\begin{array}{l}\text { Especies menores funcionalmente } \\
\text { equivalentes pueden sustituir por la } \\
\text { pérdida o reducción de las } \\
\text { dominantes si muchas especies } \\
\text { desempeñan roles funcionales } \\
\text { similares (redundancia funcional). } \\
\text { Una baja riqueza de especies } \\
\text { puede estar asociada con una baja } \\
\text { resiliencia y altos riesgos para el } \\
\text { funcionamiento del ecosistema } \\
\text { bajo el cambio ambiental (Allen et } \\
\text { al., 2005; Walker et al., 1999). }\end{array}$ & $\begin{array}{l}\text { Respuesta de las } \\
\text { comunidades de aves a } \\
\text { distintos niveles de intensidad } \\
\text { de uso de la tierra (Fischer et } \\
\text { al., 2007). }\end{array}$ \\
\hline Complementariedad & La complementariedad funcional & La alta complementariedad \\
\hline
\end{tabular}




\begin{tabular}{|c|c|c|}
\hline Variable & $\begin{array}{l}\text { Papel en la resiliencia y } \\
\text { funcionamiento de los ecosistemas }\end{array}$ & Ejemplo \\
\hline $\begin{array}{l}\text { funcional (disparidad entre } \\
\text { tipos o especies). }\end{array}$ & $\begin{array}{l}\text { entre especies (p. ej. en uso de } \\
\text { recursos, tamaño del cuerpo, } \\
\text { estatura, estatus trófico, fenología) } \\
\text { mejora la coexistencia a través de } \\
\text { la repartición de nichos y el } \\
\text { mantenimiento de los procesos del } \\
\text { ecosistema (Cardinale et al., 2007). }\end{array}$ & $\begin{array}{l}\text { funcional tanto dentro de los } \\
\text { ensambles de plantas como } \\
\text { de polinizadores promueve el } \\
\text { reclutamiento de comunidades } \\
\text { de plantas más diversas } \\
\text { (Fontaine et al., 2005). }\end{array}$ \\
\hline $\begin{array}{l}\text { Diversidad de interacción } \\
\text { (frecuencias y dominancia } \\
\text { de interacciones, } \\
\text { propiedades de las matrices } \\
\text { de redes). }\end{array}$ & $\begin{array}{l}\text { Las interacciones dan forma a la } \\
\text { organización de los ecosistemas, } \\
\text { median en la evolución y } \\
\text { persistencia de las especies } \\
\text { participantes e influyen sobre las } \\
\text { funciones del ecosistema, p. ej., } \\
\text { productividad (Thompson, 1997). }\end{array}$ & $\begin{array}{l}\text { El pastoreo excesivo reduce la } \\
\text { diversidad de las interacciones } \\
\text { de polinización (Vázquez \& } \\
\text { Simberloff, 2003). }\end{array}$ \\
\hline $\begin{array}{l}\text { Diversidad trófica (número } \\
\text { de niveles tróficos, } \\
\text { interacciones dentro de } \\
\text { niveles, estructura de la } \\
\text { cadena alimentaria). }\end{array}$ & $\begin{array}{l}\text { Los efectos compensatorios de la } \\
\text { depredación y competencia por los } \\
\text { recursos mantienen la coexistencia } \\
\text { de los competidores inferiores y las } \\
\text { presas. La pérdida o reducción de } \\
\text { algunas interacciones (p. ej. por } \\
\text { sobreexplotación de depredadores } \\
\text { tope) pueden precipitar cascadas } \\
\text { tróficas vía la eliminación } \\
\text { competitiva o la sobreabundancia } \\
\text { de predadores generalistas. }\end{array}$ & $\begin{array}{l}\text { Ensambles diversos de } \\
\text { carnívoros (i.e., variados } \\
\text { rasgos de comportamiento y } \\
\text { densidades) promueven la } \\
\text { coexistencia de especies de } \\
\text { plantas (Calcagno et al., } \\
\text { 2011), la disminución de la } \\
\text { presa principal precipita } \\
\text { cambios de dieta y de fase } \\
\text { (Springer et al., 2003). }\end{array}$ \\
\hline $\begin{array}{l}\text { Flujo espacial de } \\
\text { organismos (tasa, } \\
\text { sincronización, frecuencia y } \\
\text { duración de los } \\
\text { movimientos de especies } \\
\text { entre ecosistemas). }\end{array}$ & $\begin{array}{l}\text { Los intercambios espaciales entre } \\
\text { los sistemas locales en paisajes } \\
\text { heterogéneos proporcionan un } \\
\text { "seguro" espacial para la función } \\
\text { del ecosistema (Loreau et al., } \\
\text { 2003). Los intercambios pueden } \\
\text { implicar recursos, genes o la } \\
\text { participación en los procesos } \\
\text { (Lundberg \& Moberg, 2003). }\end{array}$ & $\begin{array}{l}\text { Peces herbívoros e } \\
\text { invertebrados migran hacia los } \\
\text { arrecifes desde los lechos de } \\
\text { algas marinas y manglares, } \\
\text { reduciendo la abundancia de } \\
\text { algas en los arrecifes y } \\
\text { manteniendo los sustratos } \\
\text { adecuados para el } \\
\text { establecimiento de larvas de } \\
\text { coral después de la } \\
\text { perturbación (Moberg \& Folke, } \\
\text { 1999). }\end{array}$ \\
\hline $\begin{array}{l}\text { Complejidad estructural (p. } \\
\text { ej. índices de complejidad, } \\
\text { número y cobertura de los } \\
\text { estratos verticales en } \\
\text { bosques, arrecifes, índices } \\
\text { de sensores remotos). }\end{array}$ & $\begin{array}{l}\text { La arquitectura simplificada reduce } \\
\text { la diversidad de nichos, } \\
\text { proporcionando ambientes } \\
\text { adecuados para menos especies, } \\
\text { mayor exposición a los } \\
\text { depredadores y mayor } \\
\text { competencia por los recursos } \\
\text { (debido a la disminución en la } \\
\text { partición). }\end{array}$ & $\begin{array}{l}\text { Arrecifes coralinos } \\
\text { estructuralmente complejos } \\
\text { sustentan la mayor diversidad } \\
\text { de peces (Arias-González et } \\
\text { al., 2012), bosques } \\
\text { estructuralmente complejos } \\
\text { sustentan una mayor } \\
\text { diversidad de aves (Huth \& } \\
\text { Possingham, 2011). }\end{array}$ \\
\hline
\end{tabular}

\section{Métodos}

La evaluación del criterio $D$ sigue el mismo procedimiento que para el criterio $C$, pero se enfoca en variables bióticas en lugar de las variables abióticas. De nuevo, la severidad relativa es calculada por medio de la estandarización del rango de valores crudos de la variable biótica entre su valor inicial y su valor de colapso (Sección 2). Los evaluadores deben: (i) estimar el valor de la variable biótica en el estado inicial; (ii) estimar el valor 
esperado en el estado en el estado colapsado; (iii) medir o estimar el valor presente o futuro de la variable. Estas tres cantidades son usadas para re-escalar la variable biótica a un cambio proporcional hacia el colapso (Sección 5.3.3). A continuación, los evaluadores deben determinar la extensión de la perturbación como una proporción de la distribución total del ecosistema. Con estas dos cantidades los evaluadores proceden a asignar una categoría de riesgo utilizando los umbrales descritos. Del mismo modo que en el criterio C, no se recomienda el uso de índices genéricos (Sección 5.3.3).

\section{Suposiciones}

Las suposiciones en la aplicación del criterio $D$ son similares a las suposiciones para el criterio C. De nuevo, la determinación de un valor inicial y uno colapsado para la variable biótica se basa en suposiciones acerca de los estados inicial y colapsado del ecosistema (Sección 2.2). Al igual que en la aplicación del criterio A y $C$, la aplicación del criterio $D$ se basa en una suposición sobre la forma funcional de la disminución. En todos los casos, las decisiones tomadas en relación con supuestos deben ser discutidas de manera explícita en la documentación.

\section{Documentación}

Los asesores deben documentar: (i) la selección de la variable biótica con respecto al modelo conceptual de las dinámicas del ecosistema; (ii) la fijación de un umbral de colapso acotado para la variable biótica; (iii) el cálculo de la severidad relativa; (iv) la estimación de la extensión de la perturbación; ( $v$ ) supuestos y análisis de sensibilidad apropiados (en cuanto a la definición de colapso o de la forma supuesta de la curva de disminución); (vi) las categorías de riesgo finales y límites factibles. La variación temporal en la degradación biótica se muestra mejor en un gráfico que represente cambios en la variable a través del tiempo, e incluya cualquier interpolación o extrapolación para coincidir con el correspondiente el período de tiempo relevante (Caja 13).

Caja 13. Evaluando la interrupción de los procesos bióticos (criterio D)

Los bosques de algas marinas gigantes de Alaska son ensambles estructural y funcionalmente diversos, que se caracterizan por las especies de algas pardas del Orden Laminariales. Estos crean una arquitectura de bosques en capas compleja y dinámica de hasta $15 \mathrm{~m}$ de altura que proporcionan sustrato, refugio y recursos de forrajeo para un diverso ensamble de fauna de invertebrados epibentónicos herbívoros y depredadores vertebrados pelágicos.

La interrupción más grave de las interacciones bióticas ocurre a través de cascadas tróficas que involucran a las nutrias marinas, sus depredadores (ballenas asesinas) y sus presas (erizos, que consumen algas). Dado que la densidad de algas es inversamente proporcional a la densidad de erizos, y que los cambios de fase entre los bosques y baldíos de erizos están relacionados con un umbral de abundancia de nutrias (Estes et al., 2010), cualquiera de estas variables es potencialmente adecuada para evaluar el criterio $D$. Aunque se dispone de datos sobre los cambios poblacionales de ballenas grandes y pinnípedos (presas alternativas para las ballenas asesinas), éstos no son usados porque: (i) están disponibles datos sobre variables de respuesta más próximas; (ii) la relación causal que une las grandes ballenas y pinnípedos con la abundancia de nutrias vía la depredación de orcas es menos cierta que el vínculo entre nutrias, erizos y algas. 
Estaban disponibles datos de muestreos de densidades de estípite de algas para el período entre 1987 y 2000 a partir de siete islas (Estes et al., 2009). Se supuso que las siete islas, dispersas en toda la cadena Aleutiana, eran representativas de la distribución completa del ecosistema. El colapso del ecosistema ocurre cuando la densidad de algas es cercana a cero en todos los sitios, lo cual es consistente con el reemplazo de algas por baldíos de erizo a largo de la distribución.

Las tasas de cambio en la densidad de algas marinas fueron calculadas para cada isla asumiendo un modelo exponencial. Un promedio ponderado de todos los sitios indicó que las densidades de algas marinas disminuyeron en promedio en un 49,2\% entre 1987 y 2000.

Suponiendo que un cierto descenso ocurrió antes de 1987 o después de 2000, los datos sugieren que la disminución de la densidad de algas en los últimos 50 años fue de al menos $50 \%$ a lo largo de la extensión total del ecosistema.

Datos de reconocimiento aéreo de la nutria de mar estaban disponibles para 55 islas a lo largo de la cadena Aleutiana entre 1959 y 2000 (Doroff et al., 2003). El colapso del ecosistema ocurre cuando las poblaciones de nutria lleguen a cero en todos los sitios. La población total se estimó en 55.000-74.000 previo a la reducción ocurrida a mediados de 1980. Para el año 2000 había un total de 3.924-13.580 animales basado en la extrapolación del reconocimiento aéreo (Doroff et al., 2003). Los límites inferiores y superiores de la disminución de la población de nutria son:

$$
\begin{aligned}
& 100 \times(55000-13580) / 55000=75,3 \% \\
& \text { and } 100 \times(74000-3924) / 74000=94,7 \%
\end{aligned}
$$

La evidencia de las tendencias en la densidad de algas y avistamientos de nutria marina sugieren una disminución de la función biótica de $50-95 \%$ de severidad relativa en el $100 \%$ de la extensión del ecosistema. El límite superior de este rango puede sobrestimar la severidad de la disminución debido a que: (i) los muestreos pueden haber subestimado la población debido a problemas de detección (Doroff et al., 2003); (ii) los cálculos suponen que las poblaciones de nutria y de algas no se han recuperado desde el año 2000 , a pesar de que existe evidencia cualitativa de que ha ocurrido una cierta recuperación. El estatus más probable del ecosistema bajo el criterio D1 es En Peligro, aunque un estado de En Peligro Crítico es posible. Actualmente no hay proyecciones disponibles para cualquiera de las variables bióticas. El estatus del ecosistema es Datos Insuficientes bajo el criterio D2.

La población de nutrias en 1750 fue similar o ligeramente mayor que en su punto más alto a mediados de la década de 1980 (Doroff et al., 2003). Basado en esta suposición, la disminución de las poblaciones de nutria a lo largo de la distribución del bosque de algas fue de 75-95\% desde 1750. El estatus del ecosistema tipo bajo el criterio D3 es entonces En Peligro (rango plausible En Peligro - En Peligro Crítico). De este modo, el ecosistema tipo de los bosques de algas marinas gigantes de Alaska es listado como En Peligro (rango plausible En Peligro - En Peligro Crítico). 


\subsection{Criterio E. Análisis cuantitativo de riesgo}

\subsubsection{Teoría}

El criterio $\mathrm{E}$ tiene dos propósitos. En primer lugar, se puede utilizar para listar un ecosistema tipo mediante la aplicación de modelos que integren múltiples mecanismos de disminución y sus interacciones en la evaluación del riesgo (como se describe abajo). En segundo lugar, proporciona un ancla para la evaluación de riesgos y un marco general para el resto de los criterios, como lo hace su análogo en los criterios de la Lista Roja para las especies. El criterio E especifica el nivel de riesgo que corresponde a cada categoría de amenaza, mediante la definición de la probabilidad de colapso y el período de tiempo especificado para ecosistemas tipo En Peligro Crítico (CR), En Peligro (EN) y Vulnerable (VU).

\subsubsection{Umbrales}

Un ecosistema puede ser listado bajo el Criterio E si cumple con los umbrales para el criterio, un análisis cuantitativo que estima que la probabilidad de colapso del ecosistema sea:

\begin{tabular}{|l|l|}
\hline CR & $\geq 50 \%$ dentro de 50 años \\
\hline EN & $\geq 20 \%$ dentro de 50 años \\
\hline VU & $\geq 10 \%$ dentro de 100 años \\
\hline
\end{tabular}

\subsubsection{Aplicación}

La probabilidad de colapso del ecosistema puede ser estimada con modelos estocásticos de simulación que incorporan los procesos claves del ecosistema. Los modelos deben:

1. Producir estimaciones de una variable del ecosistema para los cuales se ha estimado un umbral de colapso.

2. Producir estimaciones cuantitativas de los riesgos de colapso del ecosistema sobre un período de tiempo de 50-100 años.

3. Incorporar la estocasticidad en los procesos clave que determinan las propiedades del ecosistema.

4. Ser aplicado con escenarios que representen escenarios futuros plausibles de las dinámicas del ecosistema.

Una amplia gama de modelos pueden ser usados para aplicar el criterio E. Proporcionamos recomendaciones generales para la aplicación del criterio $E$ en la forma de nueve pasos para asegurar que los modelos se basan en suposiciones sólidas, científicamente creíbles y transparentes (Fig. 14). 


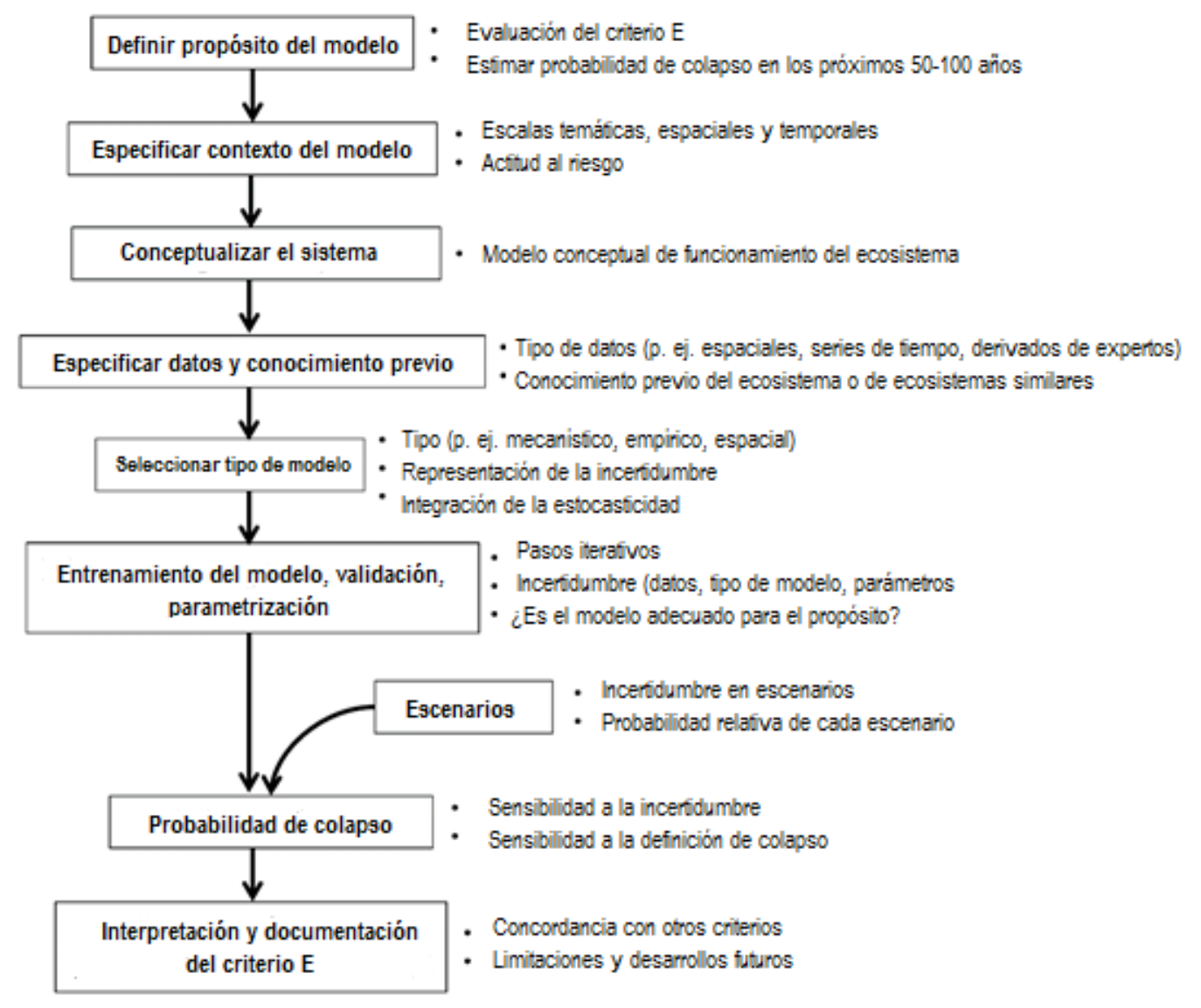

Figura 14. Nuevo pasos para aplicar el criterio E.

1. Definir el propósito del modelo

Los modelos para el criterio $\mathrm{E}$ deben proporcionar una predicción adecuada del riesgo de colapso sobre un período de 50-100 años. Si el modelo usado para el criterio E está siendo adaptado de un modelo con objetivos diferentes (p. ej. proporcionar orientación para la gestión y toma de decisiones), puede ser necesario modificar sus objetivos e implementación. Aunque otros objetivos pueden ser importantes en la construcción del modelo, los modelos utilizados para el criterio $\mathrm{E}$ serán revisados con base en la calidad de sus predicciones para los propósitos de evaluación de la LRE.

\section{Especificar el contexto de modelado}

Los ecosistemas son inherentemente dependientes de la escala, por lo que las escalas temáticas, espaciales y temporales de los procesos del ecosistema pueden afectar a la construcción de los modelos y sus predicciones. El definir adecuadamente los límites del ecosistema bajo evaluación es crucial - las presiones externas y las salidas externas deben se claramente etiquetadas como tales. El modelo debe apuntar a representar espacialmente todas las ocurrencias del ecosistema; si no, se deben hacer inferencias adecuadas para evaluar la representatividad de las predicciones finales. El período de tiempo para las predicciones del criterio $E$ es 50-100 años, el cual es más largo que para los otros criterios (A2a, A2b, C2a, C2b, D2a, D2b) y por lo tanto pueden requerir un entendimiento diferente de las amenazas futuras. 
El modelado puede implicar decisiones que dependen de la actitud ante el riesgo del evaluador, i.e. los costos relativos de subestimar o sobrestimar el riesgo de colapso. En general se recomienda una actitud ante el riego de precaución, pero realista, a la hora de aplicar el criterio E. Tales decisiones deben documentarse a fondo dentro de la documentación del criterio E, y si es posible, apoyarse en medidas cuantitativas de la aversión al riesgo.

\section{Conceptualizar el sistema}

Los modelos para el criterio $E$ deben basarse en una comprensión sólida de la dinámica y la función de los ecosistemas, respaldados por datos e inferencias relevantes de ecosistemas similares. Los modelos conceptuales pueden ayudar a identificar los procesos y las variables clave del ecosistema que indican el colapso. El modelo conceptual puede representar las relaciones causa-efecto o transiciones entre los estados de referencia y colapsado del ecosistema. El modelo conceptual utilizado para el criterio $\mathrm{E}$ puede diferir del modelo conceptual general usado en la descripción del ecosistema (Sección 6.2.3), ya que puede representar relaciones más complejas e incluir variables medibles. Decidir el nivel de abstracción apropiado para los procesos clave es un componente fundamental de la conceptualización y debe considerar el propósito del modelo, contexto, resolución requerida del resultado y el esfuerzo necesario para la construcción del modelo. Un componente crítico de la evaluación bajo el criterio $\mathrm{E}$ es la definición explícita de colapso y la forma en que se relaciona con el modelo conceptual de las dinámicas del ecosistema y las variables medidas (Sección 3.2).

\section{Especificar los datos y el conocimiento previo}

La aplicación del criterio $\mathrm{E}$ requiere que los niveles de las variables clave de los ecosistemas sean predichas sobre períodos de tiempo específicos. Estas variables pueden representar la distribución espacial (como en los criterios A y B), el ambiente abiótico (criterio $\mathrm{C}$ ), y/o las interacciones bióticas (criterio $\mathrm{D}$ ). Las variables adecuadas pueden ser seleccionadas siguiendo los procesos descritos en las secciones de Aplicación correspondientes a cada criterio. Los datos pueden ser medidas cuantitativas (p. ej. datos espaciales, series de tiempo) o derivados de expertos. En esta etapa el grado de agregación espacial y temporal de los datos y las predicciones pueden ser revisadas, para hacer coincidir las dinámicas del ecosistema con el contexto de modelado. Por ejemplo, puede ser apropiado agregar datos diarios o mensuales a series de tiempo anuales. En situaciones de escasez de datos, puede ser posible inferir los procesos y datos a partir de ecosistemas similares (Maxwell et al., 2015). Esto debe estar claramente indicado y discutido dentro de la documentación del modelo.

\section{Seleccionar el tipo de modelo}

Una amplia gama de modelos de simulación de las dinámicas de los ecosistemas permiten estimar directamente la probabilidad de colapso del ecosistema. La selección del modelo apropiado dependerá de: (i) la dinámica del ecosistema; (ii) la disponibilidad de datos; (iii) la representación de la incertidumbre; y (iv) la integración de la estocasticidad. Algunos modelos pueden ser más apropiados para representar ecosistemas específicos y sus dinámicas ( $p$. ej. modelos hidrológicos para los 
humedales, modelos de vegetación global para los bosques). El tipo de datos de entrada también puede limitar la elección del modelo (p. ej. algunos tipos de modelo pueden ser incapaces de manejar los datos faltantes o los datos derivados por expertos). Los modelos deben ser elegidos o adaptados de manera que se pueda llevar a cabo un análisis de incertidumbre y sensibilidad apropiado. Idealmente, la incertidumbre del modelo debe abordarse mediante la aplicación de varios modelos que representen interpretaciones alternativas de la dinámica del ecosistema. Por último, las dinámicas del ecosistema dependen de procesos estocásticos, por lo que los modelos deben ser elegidos o adaptados a fin de integrar la estocasticidad (ver caso de estudio de la Laguna de Coorong en el Apéndice S2 en Keith et al., 2013).

Los tipos de modelos que podrían utilizarse para la aplicación del criterio $\mathrm{E}$ incluyen:

- modelos de estado y transición (Lester and Fairweather, 2009, Rumpff et al., 2011, Maxwell et al., 2015).

- modelos de balance de masa (p. ej. Ecopath, Modelos de Complejidad Intermedia) (Christensen y Walters, 2004, Plagányi et al., 2014).

- parcelas de bifurcación (Holdo et al., 2013).

- teoría de redes (p. ej. Análisis de Viabilidad de la Comunidad) (de Visser et al., 2011).

- modelos dinámicos de la vegetación global (Scholze et al., 2006).

- modelos dinámicos de distribución de especies y población (Midgley et al., 2010, Keith et al., 2008).

- modelos espaciales (p. ej. autómata celular) (Soares-Filho et al., 2002).

- modelos generales de ecosistemas (p. ej. el modelo de Madingley) (Harfoot et al., 2014).

6. Entrenamiento, parametrización y validación del modelo

Los modelos deben seguir las mejores prácticas recomendadas para cada tipo de modelo, y deben ser apropiadamente entrenados, parametrizados y/o validados. Por ejemplo, el modelo de estado-y-transición derivado de datos de la laguna Coorong fue validado a través de múltiples vías, por lo que ni los estados ni las transiciones se determinaron a priori (Lester \& Fairweather, 2011). Para algunos modelos la validación completa puede no ser posible; en estos casos el comportamiento del modelo puede evaluarse con indicadores de comportamiento pertinentes, p. ej. la reproducción satisfactoria del comportamiento observado, la ausencia de correlación en los residuales del modelo (Jakeman et al., 2006). El entrenamiento, la parametrización y la validación del modelo pueden ocurrir en etapas iterativas que deberán ser documentadas a fondo. Puede ser apropiado evaluar los efectos de la incertidumbre de los datos, de los parámetros y del modelo a través de análisis de sensibilidad. En general, los evaluadores deben demostrar que el modelo es adecuado para el propósito de su aplicación en el criterio $\mathrm{E}$.

7. Escenarios

Los escenarios futuros que representa amenazas plausibles y cambios en las dinámicas del ecosistema deben ser identificados. Es importante reconocer que los conceptos y datos que soportan los escenarios pueden estar sujetos a altos niveles 
de incertidumbre, cuyos efectos pueden ser difíciles de seguir en modelos grandes (p. ej. proyecciones de cambio climático; Kujala et al., 2013). A menudo, no se conoce la probabilidad relativa de cada escenario futuro (Peterson et al., 2003), por lo que la probabilidad final del colapso se puede expresar como un rango de valores más que como una sola estimación.

8. Probabilidad de colapso

El estimado de la probabilidad de colapso puede ser un único valor, pero en la mayoría de los casos puede ser expresado como un rango de valores que representan la incertidumbre en la construcción del modelo. Los análisis de sensibilidad de la probabilidad de colapso pueden hacerse en relación a: (i) incertidumbre de los datos, modelos y parámetros; (ii) incertidumbre de los escenarios; y (iii) otras formas de incertidumbre que puedan afectar los resultados del modelo, p. ej. la elección de las variables para evaluar el colapso del ecosistema. Un análisis de sensibilidad del umbral de colapso debe llevarse a cabo en todos los modelos, ya que el resultado final para el criterio $E$ puede ser particularmente sensible a la definición del colapso. En simulaciones del bosque de fresno de montaña (Burns et al., 2015), por ejemplo, el umbral de colapso tendría que disminuir de un promedio de un árbol con hueco por hectárea a 0,7 para cambiar el resultado de la evaluación de riesgo.

9. Interpretación y documentación

El criterio E proporciona un marco general para la aplicación de los otros criterios, e incluye dinámicas del ecosistema que no pueden ser capturadas por los otros criterios. Por consiguiente, puede ser útil comparar los resultados para el criterio $\mathrm{E}$ con los resultados de los otros criterios y proporcionar una visión de las posibles razones para las diferencias en los resultados de evaluación. Se requiere un mayor nivel de documentación para el criterio $\mathrm{E}$ que para los otros criterios, dado el carácter científico de la modelización y los efectos de la incertidumbre. Se recomienda que los evaluadores publiquen sus modelos en la literatura revisada por pares y coloquen sus materiales (datos, código) en repositorios de datos para permitir el pleno escrutinio de los modelos y sus resultados. Dentro de la revisión por pares de la LRE, expertos en evaluación de riesgos y modelado revisarán los modelos en función de criterios estrictos y pueden solicitar análisis adicionales.

Actualmente están en desarrollo lineamientos y ejemplos específicos de la aplicación del criterio $E$, los cuales se pondrán a disposición en el sitio web de la Lista Roja de Ecosistemas de UICN (www.iucnrle.org). 
Caja 14. Desarrollando un modelo cuantitativo de la dinámica de los ecosistemas (criterio E)

La probabilidad de colapso del ecosistema ha sido estimada para la laguna Coorong de Australia del Sur, a través de la adaptación de un modelo de estado-y-transición derivado empíricamente (Apéndice S2 en Keith et al., 2013; Lester \& Fairweather, 2011). El colapso del ecosistema ocurre cuando la mitad de los años modelados ocurren ya sea en los estados degradados del ecosistema o en un período de recuperación siguiendo la ocurrencia de estados degradados.

La evaluación cuantitativa de la probabilidad de colapso del ecosistema en el Coorong se llevó a cabo con una cadena de modelos (Lester \& Fairweather, 2011). Simulaciones a escala reducida de varios modelos climáticos globales fueron aplicadas a los modelos hidrológicos de la cuenca de Murray-Darling para estimar una serie temporal de los flujos. Seis escenarios fueron investigados para cuantificar la probabilidad de un colapso ecológico en el Coorong basado en tres proyecciones climáticas para el 2030 y dos niveles de extracción (i.e., con y sin la infraestructura y la extracción actual). Todos los escenarios fueron corridos para un período de 114 años (Lester \& Fairweather, 2009). Dado que cada escenario debe ser interpretado como 114 años de posible variabilidad debido a las fluctuaciones climáticas, la proporción de los años que ocurren en estados degradados o de recuperación proporciona una evaluación de la estocasticidad dentro del sistema.

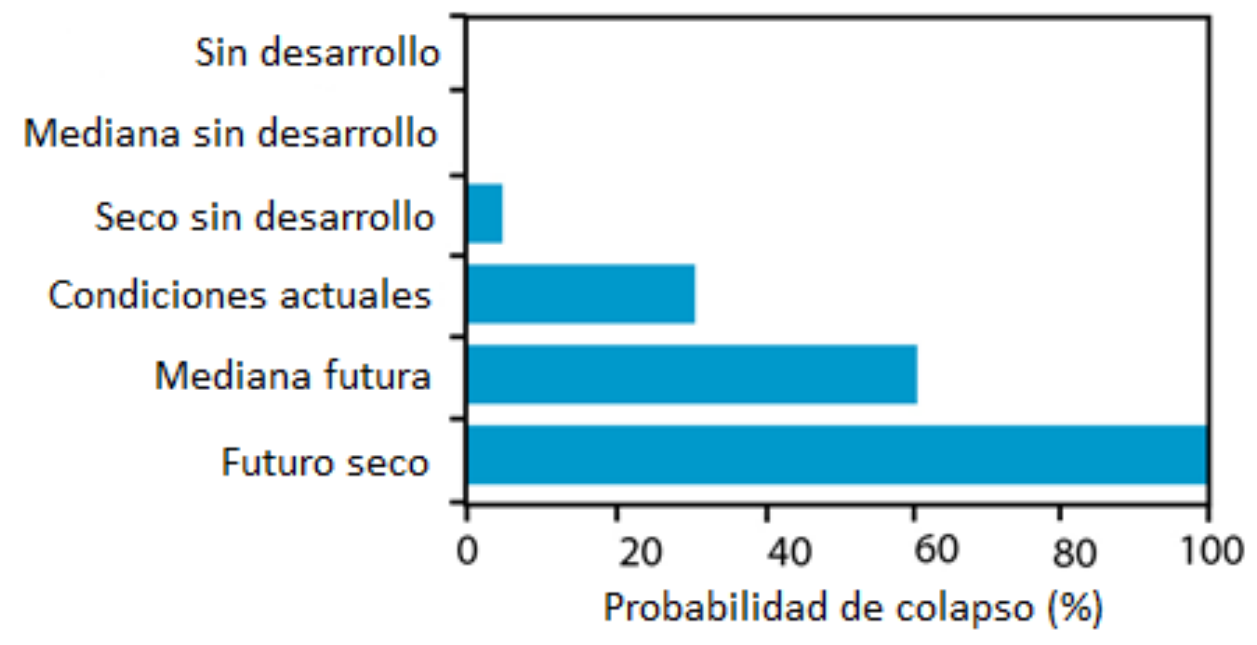

Figura 15. Probabilidad de colapso de la laguna Coorong bajo seis escenarios de cambio climático y extracción de agua. Los tres escenarios climáticos son: secuencia histórica desde 1895; la proyección futura de clima medio basada en tres escenarios de cambio climático a partir de 15 modelos climáticos globales; y una proyección futura de clima seco basado en el percentil 10 de los mismos modelos.

De los seis escenarios investigados, se produjo colapso ecológico en cuatro. La extracción de agua no cesará en la cuenca de Murray-Darling, por lo que los escenarios "sin desarrollo" pueden ser descontados del cálculo global de riesgo de colapso. La probabilidad de colapso ecológico varía de $30 \%$ a $100 \%$ a través de tres escenarios que representan los niveles actuales de desarrollo. La laguna Coorong es entonces listada como En Peligro Crítico (rango plausible En Peligro - En Peligro Crítico) bajo el criterio E. 


\section{Revisión por expertos y publicación}

El Comité para Estándares Científicos de la Lista Roja de Ecosistemas de UICN coordinará la revisión por pares independientes de las evaluaciones de riesgo para la Lista Roja de Ecosistemas mundial de UICN. Las revisiones de las evaluaciones sub-globales serán responsabilidad de los gerentes de proyecto, a los cuales se les alienta a buscar asesoría del Comité para Estándares Científicos. Las evaluaciones serán revisadas por los menos por dos expertos: uno con experticia en la ecología del ecosistema tipo bajo evaluación y otro que esté familiarizado con las Categorías y Criterios de la Lista Roja de Ecosistemas de UICN.

Los criterios de revisión incluyen:

1. Si el ecosistema tipo es consistente con la definición conceptual de un ecosistema, y por lo tanto una unidad válida para la evaluación usando los criterios de la Lista Roja de Ecosistemas de UICN.

2. Si la documentación incluye o hace referencia a una descripción adecuada del ecosistema tipo. Esto incluye las referencias cruzadas con clasificaciones relevantes, un recuento de los procesos ecológicos y amenazas clave, un modelo conceptual gráfico, y una evaluación cuantitativa de cada criterio para el cual existen datos.

3. Si todos los datos accesibles e información relevante para la evaluación del ecosistema tipo según la Lista Roja de Ecosistemas de la UICN han sido considerados.

4. Si la calidad de los datos subyacentes ha sido evaluada y se considera adecuada.

5. Si las definiciones y conceptos establecidos en las directrices han sido correctamente interpretados y aplicados.

6. Si los métodos y cálculos han sido aplicados de forma válida, y si hay métodos alternativos más adecuados.

7. Si los estimados de las variables en el pasado, presente, futuro, y para los estados colapsados están completos y basados en evidencias.

8. Si las inferencias relacionadas con los criterios de la Lista Roja de Ecosistemas de UICN están justificados y son comunicados de forma transparente.

9. Si las incertidumbres han sido incorporadas adecuadamente en la evaluación. 


\section{Referencias}

Akcakaya, H.R., Ferson, S., Burgman, M.A., Keith, D.A., Mace, G.M. y Todd, C.R. (2000). 'Making Consistent UICN Classifications under Uncertainty'. Conservation Biology 14:1001-1013.

Aladin, N. \& Plotnikov, I. (1993). 'Large saline lakes of former USSR: a summary review'. Hydrobiologia 267:1-12.

Alevizon, W.S. (2010). Introduction To Caribbean Coral Reefs. Gainsville, USA: William Alevizon.

Allen, C., Gunderson, L. y Johnson, A.R. (2005). 'The Use of Discontinuities and Functional Groups to Assess Relative Resilience in Complex Systems'. Ecosystems 8: 958966.

Allen, T.F. y Hoekstra, T.W. (1990). 'The confusion between scale-defined levels and conventional levels of organization in ecology'. Journal of Vegetation Science 1:5-12.

Andréfouët, S., Muller-Karger, F.E., Robinson, J.A., Kranenburg, C.J., Torres-Pulliza, D., Spraggins, S.A. y Murch, B. (2006). 'Global assessment of modern coral reef extent and diversity for regional science and management applications: a view from space'. In: Suzuki, Y., Nakamori, T., Hidaka, M., Kayanne, H., Casareto, B., Nadaoka, K., Yamano, H. and Tsuchiya, M. (eds.) Proceedings of 10th International Coral Reef Symposium, Okinawa, Japan, 28 June-2 July 2004, pp. 1732-1745. Tokyo, Japan: Japanese Coral Reef Society.

Arias-González, J.E., Acosta-González, G., Membrillo, N., Garza-Pérez, J.R. y CastroPérez, J.M. (2012). 'Predicting spatially explicit coral reef fish abundance, richness and Shannon-Weaver index from habitat characteristics'. Biodiversity and Conservation 21:115-130.

Aronson, R.B. y Blake, D.B. (2001). 'Global climate change and the origin of modern benthic communities in Antarctica'. American Zoologist 41:27-39.

Auld, T.D. y Hutton, I. (2004). 'Conservation issues for the vascular flora of Lord Howe Island'. Cunninghamia 8:490-500.

Auld, T.D. y Leishman, M.R. (2015). 'Ecosystem risk assessment for GnaLREd Mossy Cloud Forest, Lord Howe Island, Australia'. Austral Ecology 40:364-372.

Barrett, S. y Yates, C.J. (2015). 'Risks to a mountain summit ecosystem with endemic biota in southwestern Australia'. Austral Ecology 40:423-432.

Beck, M.W., Brumbaugh, R.D., Airoldi, L., Carranza, A., Coen, L.D., Crawford, C., Defeo, O., Edgar, G.J., Hancock, B., Kay, M.C., Lenihan, H.S., Luckenbach, M.W., Toropova, C. L., Zhang, G. y Guo, X. (2011). 'Oyster Reefs at Risk and Recommendations for Conservation, Restoration, and Management'. BioScience 61:107-116.

Blab, J., Riecken, U. y Ssymank, A. (1995). 'Proposal on a criteria system for a National Red Data Book of Biotopes'. Landscape Ecology 10:41-50.

Burns, E.L., Lindenmayer, D.B., Stein, J., Blanchard, W., McBurney, L., Blair, D. y Banks, S.C. (2015). 'Ecosystem assessment of mountain ash forest in the Central Highlands of Victoria, south-eastern Australia'. Austral Ecology 40:386-399. 
Cabezas, A., Comín, F.A., Beguería, S. y Trabucchi, M. (2009). 'Hydrologic and landscape changes in the Middle Ebro River (NE Spain): implications for restoration and management'. Hydrology and Earth Systems Science 13:273-284.

Calcagno, V., Sun, C., Schmitz, O.J. y Loreau, M. (2011). 'Keystone Predation and Plant Species Coexistence: The Role of Carnivore Hunting Mode'. The American Naturalist 177(1):E1-E13.

Cardinale, B.J., Duffy, J.E., Gonzalez, A., Hooper, D.U., Perrings, C., Venail, P., Narwani, A., Mace, G.M., Tilman, D., Wardle, D.A., Kinzig, A.P., Daily, G.C., Loreau, M., Grace, J.B., Larigauderie, A., Srivastava, D.S. y Naeem, S. (2012). 'Biodiversity loss and its impact on humanity'. Nature 486:59-67.

Cardinale, B.J., Matulich, K.L., Hooper, D.U., Byrnes, J.E., Duffy, E., Gamfeldt, L., Balvanera, P., O'Connor, M.I. y Gonzalez, A. (2011). 'The functional role of producer diversity in ecosystems'. American Journal of Botany 98:572-592.

Cardinale, B.J., Wright, J.P., Cadotte, M.W., Carroll, I.T., Hector, A., Srivastava, D.S., Loreau, M. y Weis, J.J. (2007). 'Impacts of plant diversity on biomass production increase through time because of species complementarity'. Proceedings of the National Academy of Sciences 104:18123-18128.

Carpenter, S.R. (2003). Regime Shifts in Lake Ecosystems: Patterns and Variation. Excellence in Ecology Series, Volume 15. Olderdorf/Luhe, Germany: International Ecology Institute.

Carpenter, S.R. and Turner, M.G. (2001). 'Hares y Tortoises: Interactions of Fast and Slow Variables in Ecosystems'. Ecosystems 3:495-497.

Catling, P.M. y Brownell, V.R. (1995). 'A review of the alvars of the Great Lakes region: distribution, floristic composition, biogeography and protection'. Canadian Field Naturalist 109:143-171.

Chapelle, G. and Peck, L.S. (1999). 'Polar gigantism dictated by oxygen availability'. Nature 399:114-115.

Christensen, V. y Walters, C.J. (2004). 'Ecopath with Ecosim: methods, capabilities and limitations'. Ecological modelling 172:109-139.

Clark, G.F., Raymond, B., Riddle, M.J., Stark, J.S. y Johnston, E.L. (2015). 'Vulnerability of Antarctic shallow invertebrate-dominated ecosystems'. Austral Ecology 40:482-491.

Clarke, P.J., Latz, P.K. y Albrecht, D.E. (2005). 'Long-term changes in semi-arid vegetation: Invasion of an exotic perennial grass has larger effects than rainfall variability'. Journal of Vegetation Science 16:237-248.

Commonwealth of Australia (2000). Environment Protection and Biodiversity Conservation Regulations, REG 7.02 Criteria for listing threatened ecological communities. Commonwealth of Australia, Canberra, ACT.

Congalton, R.G. y Green, K. (2008). Assessing the Accuracy of Remotely Sensed Data: Principles and Practices, $2^{\text {nd }}$ Edition. Boca Raton, Florida, USA: CRC Press/Taylor \& Francis Group.

Connors, B.M., Cooper, A.B., Peterman, R.M. y Dulvy, N.K. (2014). 'The false classification of extinction risk in noisy environments'. Proceedings of the Royal Society $B$ 281:20132935.

Council of the European Commission (1992). 'Council directive 92/43/EEC of 21 May 1992 on the conservation of natural habitats and of wild fauna and flora'. Official Journal of the European Communities, Series L 206:7-49. 
Crespin, S.J. y Simonetti, J.A. (2015). 'Predicting colapso del ecosistema: Spatial factors that influence risks to tropical ecosystems'. Austral Ecology 40:492-501.

Dayton, P. (1979). 'Observations of growth, dispersal and population dynamics of some sponges in McMurdo Sound, Antarctica'. In: Levi, C. and Boury-Esnault, N. (eds.) Biologie des Spongiares (Sponge Biology). Colloques Internationaux du Centre National de la Reserch Scientifique 291:271-282.

Dayton, P.K. (1990). 'Polar benthos'. In: W.O. Smith (ed.) Polar oceanography, pp. 631-685. London: Academic Press.

de Visser, S.N., Freymann, B.P. y Olff, H. (2011). 'The serengeti food web: empirical quantification and analysis of topological changes under increasing human impact'. Journal of Animal Ecology 80:484-494.

DEC (2007). Definitions, categories and criteria for threatened and priority ecological communities. Perth: Department of Environment and Conservation (DEC), Government of Western Australia.

DECC (2007). Lord Howe Island Biodiversity Management Plan. Sydney: Department of Environment and Climate Change (DECC), NSW.

Di Fonzo, M., Collen, B. y Mace, G.M. (2013). 'A new method for identifying rapid decline dynamics in wild vertebrate populations'. Ecology and Evolution 3:2378-2391.

Diamond, J. (2007). ‘Easter Island revisited’. Science 317:1692-1694.

Diamond, J.M. (1989). 'The present, past and future of human-caused extinctions'. Philosophical Transactions of the Royal Society of London B 325:469-477.

Domning, D. (1972). 'Steller's sea cow and the origin of North Pacific aboriginal whaling'. Syesis 5:187-189.

Doroff, A.M., Estes, J.A., Tinker, M.T., Burn, D.M. y Evans, T.J. (2003). 'Sea otter population declines in the Aleutian archipelago'. Journal of Mammalogy 84:55-64.

Driver, A., Sink, K.J., Nel, J.N., Holness, S., Van Niekerk, L., Daniels, F., Jonas, Z., Majiedt, P.A., Harris, L. y Maze, K. (2012). National Biodiversity Assessment 2011: An assessment of South Africa's biodiversity and ecosystems. Synthesis Report'. Pretoria: South African National Biodiversity Institute and Department of Environmental Affairs.

Earl, J. (2003). The Distribution and Impacts of Lippia (Phyla canescens) in the Murray Darling System. Guyra: Murray Darling Basin Lippia Working Group.

Eisenhauer, N., Milcu, A., Sabais, A.C.W., Bessler, H., Brenner, J., Engels, C., Klarner, B., Maraun, M., Partsch, S., Roscher, C., Schonert, F., Temperton, V.M., Thomisch, K., Weigelt, A., Weisser, W.W. y Scheu, S. (2011). 'Plant Diversity Surpasses Plant Functional Groups and Plant Productivity as Driver of Soil Biota in the Long Term'. PLOS ONE 6:e16055.

Elith, J., Burgman, M.A. y Regan, H.M. (2002). 'Mapping epistemic uncertainties and vague concepts in predictions of species distribution'. Ecological Modelling 157:313-329.

Essl, F. y Egger, G. (2010). Lebensraumvielfalt in Österreich - Gefährdung und Handlungsbedarf. Zusammenschau der Roten Liste gefährdeter Biotoptypen Österreichs. Klagenfurt: Naturwissenschaftlicher Verein für Kärnten und Umweltbundesamt $\mathrm{GmbH}$.

Estes, J.A., Doak, D., Springer, A. y Williams, T. (2009). 'Causes and consequences of marine mammal population declines in southwest Alaska: a food-web perspective'. Philosophical Transactions of the Royal Society B 364:1647-1658. 
Estes, J.A., Terborgh, J., Brashares, J.S., Power, M.E., Berger, J., Bond, W.J., Carpenter, S. R., Essington, T.E., Holt, R.D. y Jackson, J.B. (2011). 'Trophic downgrading of planet Earth'. Science 333:301-306.

Estes, J.A., Tinker, M. y Bodkin, J.L. (2010). 'Using ecological function to develop recovery criteria for depleted species: sea otters and kelp forests in the Aleutian archipelago'. Conservation Biology 24:852-860.

Faber-Langendoen, D., Keeler-Wolf, T., Meidinger, D., Tart, D., Hoagland, B., Josse, C., Navarro, G., Ponomarenko, S., Saucier, J.-P., Weakley, A. y Comer, P. (2014). 'EcoVeg: a new approach to vegetation description and classification'. Ecological Monographs 84:533-561.

Fischer, J., Lindenmayer, D.B., Blomberg, S.P., Montague-Drake, R., Felton, A. y Stein, J.A. (2007). 'Functional Richness and Relative Resilience of Bird Communities in Regions with Different Land Use Intensities'. Ecosystems 10:964-974.

Folke, C., Carpenter, S., Walker, B., Scheffer, M., Elmqvist, T., Gunderson, L. y Holling, C.S. (2004). 'Regime shifts, resilience, and biodiversity in ecosystem management'. Annual Review of Ecology, Evolution, and Systematics 35:557-581.

Fontaine, C., Dajoz, I., Meriguet, J. y Loreau, M. (2005). 'Functional diversity of plantpollinator interaction webs enhances the persistence of plant communities'. PLoS Biol 4(1), e1. [doi:10.1371/journal.pbio.0040001]

Foody, G.M. (2011). 'Impacts Of Imperfect Reference Data On The Apparent Accuracy Of Species Presence-Absence Models And Their Predictions'. Global Ecology And Biogeography 20(3):498-508.

Fuller, R.M., Smith, G.M. y Devereux, B.J. (2003). 'The characterisation and measurement of land cover change through remote sensing: problems in operational applications?'. International Journal of Applied Earth Observation and Geoinformation 4:243-253.

Gaston, K.J. (1994). Rarity. London, UK: Chapman and Hall.

Gaston, K.J. y Fuller, R.A. (2008). 'Commonness, population depletion and conservation biology'. Trends in Ecology \& Evolution 23:14-19.

Gaston, K.J. y Fuller, R.A. (2009). 'The sizes of species' geographic ranges'. Journal of Applied Ecology 46:1-9.

Gili, J.-M., Arntz, W.E., Palanques, A., Orejas, C., Clarke, A., Dayton, P.K., Isla, E., Teixidó, N., Rossi, S. y López-González, P.J. (2006). 'A unique assemblage of epibenthic sessile suspension feeders with archaic features in the high-Antarctic'. Deep Sea Research Part II: Topical Studies in Oceanography 53:1029-1052.

Giri, C., Ochieng, E., Tieszen, L., Zhu, Z., Singh, A., Loveland, T., Masek, J. y Duke, N. (2011). 'Status and distribution of mangrove forests of the world using earth observation satellite data'. Global Ecology and Biogeography 20:154-159.

Goudard, A. y Loreau, M. (2008). 'Nontrophic interactions, biodiversity, and ecosystem functioning: an interaction web model'. The American Naturalist 171:91-106.

Government of Manitoba (2014). The En Peligro Species and Ecosystems Act. $<$ https://web2.gov.mb.ca/laws/statutes/ccsm/e111e.php?ccsm=e111>. Accessed 15 November 2015.

Grebmeier, J.M., Overland, J.E., Moore, S.E., FaLREy, E.V., Carmack, E.C., Cooper, L.W., Frey, K.E., Helle, J.H., McLaughlin, F.A. y McNutt, S.L. (2006). 'A major ecosystem shift in the northern Bering Sea'. Science 311:1461-1464. 
Green, P.T., O'Dowd, D.J., Abbott, K.L., Jeffery, M., Retallick, K. y Mac Nally, R. (2011). 'Invasional meltdown: Invader-invader mutualism facilitates a secondary invasion'. Ecology 92:1758-1768.

Gregr, E.J., Ahrens, A.L. y Perry, R.I. (2012). 'Reconciling classifications of ecologically and biologically significant areas in the world's oceans'. Marine Policy 36:716-726.

Hannah, J. y Bell, R.G. (2012). 'Regional sea level trends in New Zealand'. Journal of Geophysical Research: Oceans 117:C01004.

Hansen, M.C., Potapov, P.V., Moore, R., Hancher, M., Turubanova, S.A., Tyukavina, A., Thau, D., Stehman, S.V., Goetz, S.J., Loveland, T.R., Kommareddy, A., Egorov, A., Chini, L., Justice, C.O. y Townshend, J.R.G. (2013). 'High-Resolution Global Maps of 21st-Century Forest Cover Change'. Science 342:850-853.

Hanski, I. (1998). 'Metapopulation dynamics'. Nature 396:41-49.

Harfoot, M.B.J., Newbold, T., Tittensor, D.P., Emmott, S., Hutton, J., Lyutsarev, V., Smith, M.J., SchaLREmann, J.P.W. y Purves, D.W. (2014). 'Emergent Global Patterns of Ecosystem Structure and Function from a Mechanistic General Ecosystem Model'. PLoS Biol 12:e1001841.

Harpole, W.S. y Tilman, D. (2007). 'Grassland species loss resulting from reduced niche dimension'. Nature 446:791-793.

Hartley, S. y Kunin, W.E. (2003). 'Scale dependency of rarity, extinction risk, and conservation priority'. Conservation Biology 17:1559-1570.

Healy, T., Wang, Y. y Healy, J. (eds.) (2002). Muddy Coasts of the World: Processes, Deposits, and Function, Amsterdam, The Netherlands: Elsevier Science.

Hermoso, V., Januchowski-Hartley, S.R. \& Pressey, R.L. (2013). 'When the suit does not fit biodiversity: loose surrogates compromise the achievement of conservation goals'. Biological Conservation 159:197-205.

Hobbs, R.J., Arico, S., Aronson, J., Baron, J.S., Bridgewater, P., Cramer, V.A., Epstein, P.R., Ewel, J.J., Klink, C.A., Lugo, A.E., Norton, D., Ojima, D., Richardson, D.M., Sanderson, E.W., Valladares, F., Vilà, M., Zamora, R. y Zobel, M. (2006). 'Novel ecosystems: theoretical and management aspects of the new ecological world order'. Global Ecology and Biogeography 15:1-7.

Holdaway, R.J., Wiser, S.K. y Williams, P.A. (2012). 'Status assessment of New Zealand's naturally uncommon ecosystems'. Conservation Biology 26:619-629.

Holdo, R.M., Holt, R.D. y Fryxell, J.M. (2013). 'Herbivore-vegetation feedbacks can expand the range of savanna persistence: insights from a simple theoretical model'. Oikos 122:441-453.

Hong, S. y Shin, I. (2010). 'Global Trends of Sea Ice: Small-Scale Roughness and Refractive Index'. Journal of Climate 23:4669-4676.

Huth, N. y Possingham, H.P. (2011). 'Basic ecological theory can inform habitat restoration for woodland birds'. Journal of Applied Ecology 48:293-300.

UICN (2001). UICN Red List Categories and Criteria: Version 3.1, Gland, Switzerland and Cambridge, UK: Comisión de Supervivencia de Especies de UICN.

UICN (2012). UICN Red List Categories and Criteria: Version 3.1. Second edition. Gland, Switzerland and Cambridge, UK: UICN.

UICN (2015). The UICN Red List of Threatened Species. Version 2015-4. $<$ www.iucnredlist.org >. Accessed 19 November 2015. 
UICN Standards and Petitions Subcommittee (2014). Guidelines for Using the UICN Red List Categories and Criteria. Version 11. Prepared by the Standards and Petitions Subcommittee. <www.iucnredlist.org/documents/RedListGuidelines.pdf>

Jakeman, A.J., Letcher, R.A. y Norton, J.P. (2006). 'Ten iterative steps in development and evaluation of environmental models'. Environmental Modelling \& Software 21:602614.

Jarvis, A. y Mulligan, M. (2011). 'The climate of cloud forests'. Hydrological Processes 25:327-343.

Kauffman, A. y Gupta, M.M. (1991). Introduction to fuzzy arithmetic: theory and application. New York: VanNostrand Reinhold.

Keith, D. y Myerscough, P. (1993). 'Floristics and soil relations of upland swamp vegetation near Sydney'. Australian Journal of Ecology 18:325-344.

Keith, D.A. (2009). 'The interpretation, assessment and conservation of ecological communities'. Ecological Management \& Restoration 10:S3-S15.

Keith, D.A. (2015). 'Assessing and managing risks to ecosystem biodiversity'. Austral Ecology 40:337-346.

Keith, D.A., Akçakaya, H.R., Thuiller, W., Midgley, G.F., Pearson, R.G., Phillips, S.J., Regan, H.M., Araújo, M.B. y Rebelo, T.G. (2008). 'Predicting extinction risks under climate change: coupling stochastic population models with dynamic bioclimatic habitat models'. Biology Letters 4:560-563.

Keith, D.A., Elith, J. y Simpson, C.C. (2014). 'Predicting distribution changes of a mire ecosystem under future climates'. Diversity and Distributions 20:440-454.

Keith, D.A., Holman, L., Rodoreda, S., Lemmon, J. and Bedward, M. (2007). 'Plant functional types can predict decade-scale changes in fire-prone vegetation'. Journal of Ecology 95:1324-1337.

Keith, D.A., Orscheg, C., Simpson, C.C., Clarke, P.J., Hughes, L., Kennelly, S.J., Major, R.E., Soderquist, T.R., Wilson, A.L. y Bedward, M. (2009). 'A new approach and case study for estimating extent and rates of habitat loss for ecological communities'. Biological Conservation 142:1469-1479.

Keith, D.A., Rodríguez, J.P., Brooks, T.M., Burgman, M.A., Barrow, E.G., Bland, L., Comer, P.J., Franklin, J., Link, J., McCarthy, M.A., Miller, R.M., Murray, N.J., Nel, J., Nicholson, E., Oliveira-Miranda, M.A., Regan, T.J., Rodríguez-Clark, K.M., Rouget, M. y Spalding, M.D. (2015). 'The Lista Roja de Ecosistemas de UICN: Motivations, Challenges, and Applications'. Conservation Letters 8:214-226.

Keith, D.A., Rodríguez, J.P., Rodríguez-Clark, K.M., Nicholson, E., Aapala, K., Alonso, A., Asmussen, M., Bachman, S., Basset, A., Barrow, E.G., Benson, J.S., Bishop, M.J., Bonifacio, R., Brooks, T.M., Burgman, M.A., Comer, P., Comín, F.A., Essl, F., FaberLangendoen, D., Fairweather, P.G., Holdaway, R.J., Jennings, M., Kingsford, R.T., Lester, R.E., Nally, R.M., McCarthy, M.A., Moat, J., Oliveira-Miranda, M.A., Pisanu, P., Poulin, B., Regan, T.J., Riecken, U., Spalding, M.D. y Zambrano-Martínez, S. (2013). 'Scientific Foundations for an Lista Roja de Ecosistemas de UICN'. PLoS ONE 8(5):e62111.

Kingsford, R. y Johnson, W. (1998). 'Impact of water diversions on colonially-nesting waterbirds in the Macquarie Marshes of arid Australia'. Colonial Waterbirds 21(2):159-170. 
Kingsford, R.T. y Auld, K.M. (2005). 'Waterbird breeding and environmental flow management in the Macquarie Marshes, arid Australia'. River Research and Applications 21:187-200.

Kingsford, R.T. y Thomas, R.F. (1995). 'The Macquarie Marshes in arid Australia and their waterbirds: a 50-year history of decline'. Environmental Management 19:867-878.

Kirby, M.X. (2004). 'Fishing down the coast: Historical expansion and collapse of oyster fisheries along continental margins'. Proceedings of the National Academy of Sciences of the United States of America 101:13096-13099.

Kontula, T. y Raunio, A. (2009). 'New method and criteria for national assessments of threatened habitat types'. Biodiversity and Conservation 18:3861-3876.

Kujala, H., Moilanen, A., Araújo, M.B. y Cabeza, M. (2013). 'Conservation planning with uncertain climate change projections'. PloS ONE 8:e53315.

Lehmann, C.E.R., Anderson, T.M., Sankaran, M., Higgins, S.I., Archibald, S., Hoffmann, W.A., Hanan, N.P., Williams, R.J., Fensham, R.J., Felfili, J., Hutley, L.B., Ratnam, J., San Jose, J., Montes, R., Franklin, D., Russell-Smith, J., Ryan, C.M., Durigan, G., Hiernaux, P., Haidar, R., Bowman, D.M.J.S. y Bond, W.J. (2014). 'Savanna vegetation-fire-climate relationships differ among continents'. Science 343:548-552.

Lester, R.E. y Fairweather, P.G. (2009). 'Modelling future conditions in the degraded semiarid estuary of Australia's largest river using ecosystem states'. Estuarine, Coastal and Shelf Science 85:1-11.

Lester, R.E. y Fairweather, P.G. (2011). 'Ecosystem states: Creating a data-derived, ecosystem-scale ecological response model that is explicit in space and time'. Ecological Modelling 222:2690-2703.

Likens, G.E. (1992). The Ecosystem Approach: Its Use and Abuse. Excellence in Ecology Series, Volume 3. Olderdorf/Luhe, Germany: Ecology Institute

Lindenmayer, D. (2009). Forest pattern and ecological process: a synthesis of 25 years of research. Melbourne, Australia: CSIRO Publishing.

Lindgaard, A. y Henriksen, S. (eds.) (2011). The 2011 Norwegian Red List for Ecosystems and Habitat Types. Trondheim: Norwegian Biodiversity Information Centre.

Loreau, M., Mouquet, N. y Gonzalez, A. (2003). 'Biodiversity as spatial insurance in heterogeneous landscapes'. Proceedings of the National Academy of Sciences 100:12765-12770.

Ludwig, J.A., Bastin, G.N., Chewings, V.H., Eager, R.W. y Liedloff, A.C. (2007). 'Leakiness: A new index for monitoring the health of arid and semiarid landscapes using remotely sensed vegetation cover and elevation data'. Ecological Indicators 7:442-454.

Lundberg, J. y Moberg, F. (2003). 'Mobile Link Organisms and Ecosystem Functioning: Implications for Ecosystem Resilience and Management'. Ecosystems 6:87-98.

Mac Nally, R., Cunningham, S.C., Baker, P.J., Horner, G.J. y Thomson, J.R. (2011). 'Dynamics of Murray-Darling floodplain forests under multiple stressors: The past, present, and future of an Australian icon'. Water Resources Research 47:W00G05.

MacArthur, R.H. y Wilson, E.O. (1967). The theory of island biogeography. Princeton, New Jersey: Princeton University Press.

Mace, G.M., Collar, N.J., Gaston, K.J., Hilton-Taylor, C., Akcakaya, H.R., Leader-Williams, N., Milner-Gulland, E.J. y Stuart, S.N. (2008). 'Quantification of extinction risk: UICN's system for classifying threatened species'. Conservation Biology 22:1424-42. 
MacKinnon, J., Verkuil, Y.I. \& Murray, N.J. (2012). UICN situation analysis on East and Southeast Asian intertidal habitats, with particular reference to the Yellow Sea (including the Bohai Sea). Occasional Paper of the Comisión de Supervivencia de Especies de UICN No. 47. Gland, Switzerland and Cambridge, UK: UICN.

Mastrandrea, M.D., Field, C.B., Stocker, T.F., Edenhofer, O., Ebi, K.L., Frame, D.J., Held, H., Kriegler, E., Mach, K.J. y Matschoss, P.R. (2010). Guidance Note for Lead Authors of the IPCC Fifth Assessment Report on Consistent Treatment of Uncertainties. Intergovernmental Panel on Climate Change (IPCC).

Maxwell, P.S., Pitt, K.A., Olds, A.D., Rissik, D. y Connolly, R.M. (2015). 'Identifying habitats at risk: simple models can reveal complex ecosystem dynamics'. Ecological Applications 25:573-587.

McClintock, J.B., Amsler, C.D., Baker, B.J. y Van Soest, R.W. (2005). 'Ecology of Antarctic marine sponges: an overview'. Integrative and Comparative Biology 45:359-368.

McKnight, M.W., White, P.S., McDonald, R.I., Lamoreux, J.F., Sechrest, W., Ridgely, R.S. y Stuart, S.N. (2007). 'Putting beta-diversity on the map: broad-scale congruence and coincidence in the extremes'. PLoS Biol 5:e272.

Metternicht, G.I. y Zinck, J.A. (2003). 'Remote sensing of soil salinity: potentials and constraints'. Remote Sensing of Environment 85:1-20.

Meyer, J. (2011). 'Montane cloud forests on remote islands of Oceania: the example of French Polynesia (South Pacific Ocean)'. In: Bruijnzeel, L.A., Scatena, F.N. and Hamilton, L.S. (eds).Tropical Montane Cloud Forests: Science for Conservation and Management, pp. 121-129. Cambridge, UK: Cambridge University Press.

Micklin, P. y Aladin, N.V. (2008). 'Reclaiming the Aral Sea'. Scientific American 298:64-71.

Midgley, G.F., Davies, I.D., Albert, C.H., Altwegg, R., Hannah, L., Hughes, G.O., O'Halloran, L.R., Seo, C., Thorne, J.H. y Thuiller, W. (2010). 'BioMove-an integrated platform simulating the dynamic response of species to environmental change'. Ecography 33:612-616.

Miller, G., Friedel, M., Adam, P. y Chewings, V. (2010). 'Ecological impacts of buffel grass (Cenchrus ciliaris L.) invasion in central Australia - does field evidence support a fireinvasion feedback?'. The Rangeland Journal 32:353-365.

Moberg, F. y Folke, C. (1999). 'Ecological goods and services of coral reef ecosystems'. Ecological Economics 29:215-233.

Mucina, L. y Rutherford, M.C. (eds.) (2006). The Vegetation of South Africa, Lesotho and Swaziland. Strelitzia 19. Pretoria: South African National Biodiversity Institute.

Mueller-Dombois, D. y Fosberg, F.R. (1998). Vegetation of the Tropical Pacific Islands. New York: Springer-Verlag.

Murray, N.J., Clemens, R.S., Phinn, S.R., Possingham, H.P. y Fuller, R.A. (2014). 'Tracking the rapid loss of tidal wetlands in the Yellow Sea'. Frontiers in Ecology and the Environment 12:267-272.

Murray, N.J. y Fuller, R.A. (2015). 'Protecting stopover habitat for migratory shorebirds in East Asia'. Journal of Ornithology 156:217-225.

Murray, N.J., Ma, Z. y Fuller, R.A. (2015). 'Tidal flats of the Yellow Sea: A review of ecosystem status and anthropogenic threats'. Austral Ecology 40:472-481.

Murray, N.J., Phinn, S.R., Clemens, R.S., Roelfsema, C.M. y Fuller, R.A. (2012). 'Continental Scale Mapping of Tidal Flats across East Asia Using the Landsat Archive'. Remote Sensing 4:3417-3426. 
Newton, A.C. (2010). 'Use of a Bayesian network for Red Listing under uncertainty'. Environmental Modelling \& Software 25:15-23.

Nicholson, E., Keith, D.A. y Wilcove, D.S. (2009). 'Assessing the threat status of ecological communities'. Conservation Biology 23:259-274.

Nicholson, E., Regan, T.J., Auld, T.D., Burns, E.L., Chisholm, L.A., English, V., Harris, S., Harrison, P., Kingsford, R.T., Leishman, M.R., Metcalfe, D.J., Pisanu, P., Watson, C.J., White, M., White, M.D., Williams, R.J., Wilson, B. y Keith, D.A. (2015). 'Towards consistency, rigour and compatibility of risk assessments for ecosystems and ecological communities'. Austral Ecology 40:347-363.

NSW Scientific Committee (2004). Coolibah - Black Box Woodland of the northern riverine plains in the Darling Riverine Plains and Brigalow Belt South bioregions - En Peligro ecological community listing. Final Determination. Sydney: NSW Scientific Committee.

Olofsson, P., Foody, G.M., Herold, M., Stehman, S.V., Woodcock, C.E. y Wulder, M.A. (2014). 'Good practices for estimating area and assessing accuracy of land change'. Remote Sensing of Environment 148:42-57.

Olofsson, P., Foody, G.M., Stehman, S.V. y Woodcock, C.E. (2013). 'Making better use of accuracy data in land change studies: Estimating accuracy and area and quantifying uncertainty using stratified estimation'. Remote Sensing of Environment 129:122131.

Payet, K., Rouget, M., Esler, K.J., Reyers, B., Rebelo, T., Thompson, M.W. y Vlok, J.H. (2013). 'Effect of Land Cover and Ecosystem Mapping on Ecosystem-Risk Assessment in the Little Karoo, South Africa'. Conservation Biology 27:531-541.

Peterson, G.D., Cumming, G.S. y Carpenter, S.R. (2003). 'Scenario planning: a tool for conservation in an uncertain world'. Conservation Biology 17:358-366.

Pickett, S.T.A. (1989). 'Space-for-time substitution as an alternative to long-term studies'. In: Likens, G.E. (ed.) Long-term Studies in Ecology: Approaches and Alternatives, pp.110-135. New York: Springer-Verlag.

Pickett, S.T.A. y Cadenasso, M.L. (1995). 'Landscape ecology: spatial heterogeneity in ecological systems'. Science 269:331-334.

Plagányi, É.E., Punt, A.E., Hillary, R., Morello, E.B., Thébaud, O., Hutton, T., Pillans, R.D., Thorson, J.T., Fulton, E.A. y Smith, A.D. (2014). 'Multispecies fisheries management and conservation: tactical applications using models of intermediate complexity'. Fish and Fisheries 15:1-22.

Pounds, J.A., Fogden, M.P.L. y Campbell, J.H. (1999). 'Biological response to climate change on a tropical mountain'. Nature 398:611-615.

Precautionary Principle Project (2005). Guidelines for Applying the Precautionary Principle to Biodiversity Conservation and Natural Resource Management. Cambridge, UK: The Precautionary Principle Project - a joint initiative of Fauna \& Flora International, UICN, ResourceAfrica and TRAFFIC.

Rebelo, A.G., Boucher, C., Helme, N., Mucina, L., Rutherford, M.C. (2006). 'Fynbos biome'. In: Mucina, L. y Rutherford, M.C. (eds.) The Vegetation of South Africa, Lesotho and Swaziland. Strelitzia 19, pp.52-219. Pretoria: South African National Biodiversity Institute.

Regan, H.M. y Colyvan, M. (2000). ‘Fuzzy Sets and Threatened Species Classification'. Conservation Biology 14:1197-1199. 
Regan, H.M., Colyvan, M. y Burgman, M.A. (2002). 'A taxonomy and treatment of uncertainty for ecology and conservation biology'. Ecological Applications 12:618628.

Reid, M., Ogden, R. y Thoms, M. (2011). 'The influence of flood frequency, geomorphic setting and grazing on plant communities and plant biomass on a large dryland floodplain'. Journal of Arid Environments 75:815-826.

Reisewitz, S.E., Estes, J.A. y Simenstad, C.A. (2006). 'Indirect food web interactions: sea otters and kelp forest fishes in the Aleutian archipelago'. Oecologia 146:623-631.

Republic of South Africa (2004). 'National Environmental Management: Biodiversity Act, 2004'. Government Gazette Republic of South Africa Cape Town 467:1-84

Reschke, C., Reid, R., Jones, J., Feeney, T., y Potter, H. (1999). Conserving Great Lakes Alvars. Chicago, USA: The Nature Conservancy.

Riecken, U., Finck, P., Raths, U., Schröder, E. y Ssymank, A. (2009). German Red Data Book on En Peligro habitats (short version, July 2009). Bonn-Bad Godesberg, Germany: German Federal Agency for Nature Conservation (BfN).

Riecken, U., Heinzel, K., Schlumprecht, H., Boedeker, D. y für Naturschutz, B. (2006). Rote Liste der gefährdeten Biotoptypen Deutschlands: zweite fortgeschriebene Fassung 2006. Bonn, Germany: Bundesamt für Naturschutz.

Robertson, A.I. y Rowling, R.W. (2000). 'Effects of livestock on riparian zone vegetation in an Australian dryland river'. Regulated Rivers: Research \& Management 16:527541.

Rodríguez, J.P., Keith, D.A., Rodríguez-Clark, K.M., Murray, N.J., Nicholson, E., Regan, T.J., Miller, R.M., Barrow, E.G., Bland, L.M., Boe, K., Brooks, T.M., Oliveira-Miranda, M.A., Spalding, M. y Wit, P. (2015). 'A practical guide to the application of the Lista Roja de Ecosistemas de UICN criteria'. Philosophical Transactions of the Royal Society B 370: 20140003.

Rodríguez, J.P., Rodríguez-Clark, K.M., Baillie, J.E.M., Ash, N., Benson, J., Boucher, T., Brown, C., Burgess, N.D., Collen, B., Jennings, M., Keith, D.A., Nicholson, E., Revenga, C., Reyers, B., Rouget, M., Smith, T., Spalding, M., Taber, A., Walpole, M., Zager, I. y Zamin, T. (2011). 'Establishing UICN Red List Criteria for Threatened Ecosystems'. Conservation Biology 25:21-29.

Rodríguez, J.P., Rodríguez-Clark, K.M., Keith, D.A., Barrow, E.G., Benson, J., Nicholson, E. y Wit, P. (2012a). 'Lista Roja de Ecosistemas de UICN'. S.A.P.I.EN.S [Online] 5.2 <http://sapiens.revues.org/1286>.

Rodríguez, J.P., Rodríguez-Clark, K.M., Keith, D.A., Barrow, E.G., Comer, P. y OliveiraMiranda, M.A. (2012b). 'From Alaska to Patagonia: the UICN Red List of the continental ecosystems of the Americas'. Oryx 46:170-171.

Rodríguez, J.P., Rojas-Suárez, F. y Giraldo Hernández, D. (eds.) (2010). Libro Rojo de los Ecosistemas Terrestres de Venezuela. Caracas, Venezuela: Provita, Shell Venezuela y Lenovo (Venezuela).

Rogers, C.S. (1990). 'Responses of coral reef s and reef organisms to sedimentation'. Marine Ecology Progress Series 62:185-202.

Rumpff, L., Duncan, D., Vesk, P., Keith, D. y Wintle, B. (2011). 'State-and-transition modelling for adaptive management of native woodlands'. Biological Conservation 144:1224-1236. 
Salafsky, N., Salzer, D., Stattersfield, A.J., Hilton-Taylor, C., Neugarten, R., Butchart, S.H.M., Collen, B., Cox, N., Master, L.L., O'Connor, S. y Wilkie, D. (2008). 'A standard lexicon for biodiversity conservation: Unified classifications of threats and actions'. Conservation Biology 22:897-911.

Scheffer, M., Carpenter, S.R., Foley, J., Folke, C. y Walker, B.H. (2001). 'Catastrophic shifts in ecosystems'. Nature 413:591-596.

Scholze, M., Knorr, W., Arnell, N.W. y Prentice, I.C. (2006). 'A climate-change risk analysis for world ecosystems'. Proceedings of the National Academy of Sciences 103:13116-13120.

Shi, J., Ma, K., Wang, J., Zhao, J. y He, K. (2010). 'Vascular plant species richness on wetland remnants is determined by both area and habitat heterogeneity'. Biodiversity and Conservation 19:1279-1295.

Simmons, C.L., Auld, T.D., Hutton, I., Baker, W. J. y Shapcott, A. (2012). 'Will climate change, genetic and demographic variation or rat predation pose the greatest risk for persistence of an altitudinally distributed island endemic?'. Biology 1:736-765.

Soares-Filho, B.S., Coutinho Cerqueira, G. y Lopes Pennachin, C. (2002). 'DINAMICA-a stochastic cellular automata model designed to simulate the landscape dynamics in an Amazonian colonization frontier'. Ecological Modelling 154:217-235.

Spalding, M.D., Fox, H.E., Halpern, B.S., McManus, M.A., Molnar, J., Allen, G.R., Davidson, N., Jorge, Z.A., Lombana, A.L., Lourie, S.A., Martin, K.D., McManus, E., Recchia, C.A. y Robertson, J. (2007). 'Marine ecoregions of the world: A bioregionalization of coastal and shelf areas'. BioScience 57:573-583.

Springer, A.M., Estes, J.A., van Vliet, G.B., Williams, T.M., Doak, D.F., Danner, E.M., Forney, K.A. y Pfister, B. (2003). 'Sequential megafaunal collapse in the North Pacific Ocean: An ongoing legacy of industrial whaling?'. PNAS 100:12223-12228.

Steneck, R. y Watling, L. (1982). 'Feeding capabilities and limitation of herbivorous molluscs: a functional group approach'. Marine Biology 68:299-319.

Steneck, R.S., Graham, M.H., Bourque, B.J., Corbett, D., Erlandson, J.M., Estes, J.A. y Tegner, M.J. (2002). 'Kelp forest ecosystems: biodiversity, stability, resilience and future'. Environmental Conservation 29:436-459.

Tansley, A.G. (1935). 'The use and abuse of vegetational concepts and terms'. Ecology 16:284-307.

Taylor, B. y Ganf, G.G. (2005). 'Comparative ecology of two co-occurring floodplain plants: the native Sporobolus mitchellii and the exotic Phyla canescens'. Marine and Freshwater Research 56:431-440.

Thébault, E. y Loreau, M. (2005). 'Trophic Interactions and the Relationship between Species Diversity and Ecosystem Stability'. The American Naturalist 166:E95-E114.

Thompson, J.N. (1997). Conserving Interaction Biodiversity. In: Pickett, S.T.A., Ostfeld, R.S., Shachak, M. and Likens, G.E. (eds.) The Ecological Basis of Conservation, pp.285293. Springer US.

Thoms, M. y Sheldon, F. (2000). 'Water resource development and hydrological change in a large dryland river: the Barwon-Darling River, Australia'. Journal of Hydrology 228:10-21.

Thoms, M.C. (2003). Floodplain-river ecosystems: lateral connections and the implications of human interference. Geomorphology, 56, 335-349. 
UNEP (2001). Partow, H. The Mesopotamian marshlands: demise of an ecosystem. Early Warning and Assessment Technical Report, UNEP/DEWA/TR.01-3 Rev. 1. Division of Early Warning and Assessment. Nairobi, Kenya: United Nations Environment Programme.

Vázquez, D.P. y Simberloff, D. (2003). 'Changes in interaction biodiversity induced by an introduced ungulate'. Ecology Letters 6:1077-1083.

Walker, B., Kinzig, A. y Langridge, J. (1999). 'Plant Attribute Diversity, Resilience, and Ecosystem Function: The Nature and Significance of Dominant and Minor Species'. Ecosystems 2:95-113.

Wang, Y. y Zhu, D. (1994). 'Tidal flats in China'. Oceanology of China Seas 2:445-456.

Wang, Y.P., Gao, S., Jia, J., Thompson, C.E.L., Gao, J. y Yang, Y. (2012). 'Sediment transport over an accretional intertidal flat with influences of reclamation, Jiangsu coast, China'. Marine Geology 291-294:147-161.

Watling, L. y Norse, E.A. (1998). 'Disturbance of the seabed by mobile fishing gear: a comparison to forest clearcutting'. Conservation Biology 12:1180-1197.

Wiens, J.A. (1989). 'Spatial scaling in ecology'. Functional Ecology 3:385-397.

Wood, J., Low, A.B., Donaldson, J.S. y Rebelo, A.G. (1994). 'Threats to plant species diversity through urbanization and habitat fragmentation in the Cape Metropolitan Area, South Africa'. In: Huntley, B.J. (ed.) Botanical Diversity in Southern Africa. Strelitzia 1, pp.259-274. Pretoria: South African National Biodiversity Institute.

Zhao, H.L., Zhao, X.Y., Zhou, R.L., Zhang, T.H. y Drake, S. (2005). 'Desertification processes due to heavy grazing in sandy rangeland, Inner Mongolia'. Journal of Arid Environments 62:309-319. 


\section{Apéndice 1. Lista de contribuyentes}

\begin{tabular}{|c|c|c|}
\hline Nombre & Organización & País \\
\hline Kaisu Aapala & Finnish Environment Institute & Finlandia \\
\hline Alfonso Alonso & Smithsonian Conservation Biology Institute & Estados Unidos \\
\hline Marianne Asmüssen & $\begin{array}{l}\text { Instituto Venezolano de Investigaciones } \\
\text { Científicas }\end{array}$ & Venezuela \\
\hline Steven Bachman & Royal Botanic Gardens, Kew & Reino Unido \\
\hline Jonathan Baillie & Zoological Society of London & Reino Unido \\
\hline Edmund G. Barrow & UICN & Kenia / Irlanda \\
\hline Alberto Bassett & University of Lecce & Italia \\
\hline John Benson & Royal Botanic Gardens and Domain Trust & Australia \\
\hline Melanie J. Bishop & Macquarie University & Australia \\
\hline Lucie M. Bland & University of Melbourne & Australia \\
\hline Kaia Boe & UICN & Suiza \\
\hline Ronald Bonifacio & $\begin{array}{l}\text { South Australian Department of Environment } \\
\text { and Natural Resources }\end{array}$ & Australia \\
\hline Tim Boucher & The Nature Conservancy & Estados Unidos \\
\hline Thomas M. Brooks & UICN & Suiza \\
\hline Claire Brown & UNEP-WCMC & Reino Unido \\
\hline Neil Burgess & UNEP-WCMC & Reino Unido \\
\hline Mark A. Burgman & University of Melbourne & Australia \\
\hline Ben Collen & Zoological Society of London & Reino Unido \\
\hline Patrick Comer & NatureServe & Estados Unidos \\
\hline Francisco A. Comín & Pyrenean Institute of Ecology-CSIC & España \\
\hline Franz Essl & Environment Agency & Austria \\
\hline Don Faber-Langendoen & NatureServe & Estados Unidos \\
\hline Peter G. Fairweather & Flinders University & Australia \\
\hline Ariany García Rawlins & Provita & Venezuela \\
\hline Robert J. Holdaway & Landcare Research & Nueva Zelandia \\
\hline Michael Jennings & University of Idaho & Estados Unidos \\
\hline David A. Keith & University of New South Wales & Australia \\
\hline Richard T. Kingsford & University of New South Wales & Australia \\
\hline Tytti Kontula & Finnish Environment Institute & Finlandia \\
\hline Rebecca E. Lester & Deakin University & Australia \\
\hline Ralph Mac Nally & Monash University & Australia \\
\hline Michael A. McCarthy & University of Melbourne & Australia \\
\hline Rebecca M. Miller & UICN & Reino Unido \\
\hline Justin Moat & Royal Botanic Gardens, Kew & Reino Unido \\
\hline
\end{tabular}




\begin{tabular}{|c|c|c|}
\hline Nombre & Organización & País \\
\hline Nicholas J. Murray & University of New South Wales & Australia \\
\hline Emily Nicholson & Deakin University & Australia \\
\hline $\begin{array}{l}\text { María A. (Tina) Oliveira- } \\
\text { Miranda }\end{array}$ & Provita & Venezuela \\
\hline Phil Pisanu & $\begin{array}{l}\text { South Australian Department of Environment } \\
\text { and Natural Resources }\end{array}$ & Australia \\
\hline Brigitte Poulin & Tour du Valat Research Center & Francia \\
\hline Tracey J. Regan & Arthur Rylah Institute & Australia \\
\hline Belinda Reyers & Council for Scientific and Industrial Research & Sudáfrica \\
\hline Uwe Riecken & $\begin{array}{l}\text { German Federal Agency for Nature } \\
\text { Conservation }\end{array}$ & Alemania \\
\hline Jon Paul Rodríguez & $\begin{array}{l}\text { Instituto Venezolano de Investigaciones } \\
\text { Científicas }\end{array}$ & Venezuela \\
\hline $\begin{array}{l}\text { Kathryn M. Rodríguez- } \\
\text { Clark }\end{array}$ & $\begin{array}{l}\text { Instituto Venezolano de Investigaciones } \\
\text { Científicas }\end{array}$ & Venezuela \\
\hline Mark D. Spalding & $\begin{array}{l}\text { The Nature Conservancy and University of } \\
\text { Cambridge }\end{array}$ & Reino Unido \\
\hline Andrew Taber & The Wildlife Trust & Estados Unidos \\
\hline Irene Zager & Provita & Venezuela \\
\hline $\begin{array}{l}\text { Sergio Zambrano- } \\
\text { Martínez }\end{array}$ & $\begin{array}{l}\text { Instituto Venezolano de Investigaciones } \\
\text { Científicas }\end{array}$ & Venezuela \\
\hline Carlos Zambrana-Torrelio & EcoHealth Alliance & Estados Unidos \\
\hline Tara Zamin & Monash University & Australia \\
\hline
\end{tabular}




\section{Apéndice 2. Criterios de la Lista Roja de Ecosistemas de UICN, Versión 2.1}

A. Disminución en la Distribución geográfica sobre CUALQUIERA de los siguientes períodos de tiempo:

\begin{tabular}{|c|c|c|c|c|}
\hline & A1. los últimos 50 años & $\begin{array}{c}\text { A2a. los próximos } 50 \\
\text { años }\end{array}$ & $\begin{array}{c}\text { A2b. cualquier período } \\
\text { de } 50 \text { años incluyendo } \\
\text { el pasado, presente y } \\
\text { futuro }\end{array}$ & A3. desde 1750 \\
\hline CR & $\geq 80 \%$ & $\geq 80 \%$ & $\geq 80 \%$ & $\geq 90 \%$ \\
\hline EN & $\geq 50 \%$ & $\geq 50 \%$ & $\geq 50 \%$ & $\geq 70 \%$ \\
\hline VU & $\geq 30 \%$ & $\geq 30 \%$ & $\geq 30 \%$ & $\geq 50 \%$ \\
\hline
\end{tabular}

B. Distribución geográfica restringida indicada por CUALQUIERA DE B1, B2 o B3:

B1. La extensión de un polígono convexo mínimo que encierra todas la ocurrencias (extensión de la presencia, EOO) no es mayor que :

\begin{tabular}{|c|c|c|c|}
\hline CR & $2,000 \mathrm{~km}^{2}$ & $\begin{array}{c}Y \text { al menos } \\
\text { una de las } \\
\text { siguientes } \\
\text { (a-c): }\end{array}$ & $\begin{array}{l}\text { (a) Una disminución continua observada o inferida en CUALQUIERA DE: } \\
\text { i. una medida de la extensión especial apropiada para el ecosistema; O } \\
\text { ii. una medida de la calidad ambiental apropiada para la biota nativa } \\
\text { característica del ecosistema; O } \\
\text { iii. una medida apropiada de la interrupción de las interacciones bióticas de la } \\
\text { biota nativa característica del ecosistema } \\
\text { (b) Procesos de amenaza observados o inferidos que es probable causen } \\
\text { disminuciones continuas en la distribución geográfica, la calidad ambiental o las } \\
\text { interacciones bióticas dentro de los próximos } 20 \text { años. } \\
\text { (c) El ecosistema existe en } 1 \text { Localidad }\end{array}$ \\
\hline EN & $20,000 \mathrm{~km}^{2}$ & $\begin{array}{c}Y \text { al menos } \\
\text { una de las } \\
\text { siguientes } \\
\text { (a-c): }\end{array}$ & $\begin{array}{l}\text { (a) Una disminución continua observada o inferida en CUALQUIERA DE: } \\
\text { i. una medida de la extensión especial apropiada para el ecosistema; O } \\
\text { ii. una medida de la calidad ambiental apropiada para la biota nativa } \\
\text { característica del ecosistema; } 0 \\
\text { iii. una medida apropiada de la interrupción de las interacciones bióticas de la } \\
\text { biota nativa característica del ecosistema } \\
\text { (b) Procesos de amenaza observados o inferidos que es probable causen } \\
\text { disminuciones continuas en la distribución geográfica, la calidad ambiental o las } \\
\text { interacciones bióticas dentro de los próximos } 20 \text { años. } \\
\text { (c) El ecosistema existe en } \leqq 5 \text { Localidades }\end{array}$ \\
\hline VU & $50,000 \mathrm{~km}^{2}$ & $\begin{array}{c}\text { Y al menos } \\
\text { una de las } \\
\text { siguientes } \\
\text { (a-c): }\end{array}$ & $\begin{array}{l}\text { (a) Una disminución continua observada o inferida en CUALQUIERA DE: } \\
\text { i. una medida de la extensión especial apropiada para el ecosistema; O } \\
\text { ii. una medida de la calidad ambiental apropiada para la biota nativa } \\
\text { característica del ecosistema; O } \\
\text { iii. una medida apropiada de la interrupción de las interacciones bióticas de la } \\
\text { biota nativa característica del ecosistema } \\
\text { (b) Procesos de amenaza observados o inferidos que es probable causen } \\
\text { disminuciones continuas en la distribución geográfica, la calidad ambiental o las } \\
\text { interacciones bióticas dentro de los próximos } 20 \text { años. } \\
\text { (c) El ecosistema existe en } \leqq 10 \text { Localidades }\end{array}$ \\
\hline
\end{tabular}


B2. El número de celdas ocupadas dentro de una cuadrícula de celdas de 10×10 km (área de ocupación, AOO) no es mayor que:

\begin{tabular}{|c|c|c|c|}
\hline CR & 2 & $\begin{array}{c}\text { Y al menos } \\
\text { una de las } \\
\text { siguientes } \\
\quad(a-c):\end{array}$ & $\begin{array}{l}\text { (a) Una disminución continua observada o inferida en CUALQUIERA DE: } \\
\text { i. una medida de la extensión especial apropiada para el ecosistema; O } \\
\text { ii. una medida de la calidad ambiental apropiada para la biota nativa } \\
\text { característica del ecosistema; O } \\
\text { iii. una medida apropiada de la interrupción de las interacciones bióticas de la } \\
\text { biota nativa característica del ecosistema. } \\
\text { (b) Procesos de amenaza observados o inferidos que es probable causen } \\
\text { disminuciones continuas en la distribución geográfica, la calidad ambiental o las } \\
\text { interacciones bióticas dentro de los próximos } 20 \text { años. } \\
\text { (c) El ecosistema existe en } 1 \text { Localidad }\end{array}$ \\
\hline EN & 20 & $\begin{array}{c}\text { Y al menos } \\
\text { una de las } \\
\text { siguientes } \\
\quad(a-c):\end{array}$ & $\begin{array}{l}\text { (a) Una disminución continua observada o inferida en CUALQUIERA DE: } \\
\text { i. una medida de la extensión especial apropiada para el ecosistema; O } \\
\text { ii. una medida de la calidad ambiental apropiada para la biota nativa } \\
\text { característica del ecosistema; } 0 \\
\text { iii. una medida apropiada de la interrupción de las interacciones bióticas de la } \\
\text { biota nativa característica del ecosistema. } \\
\text { (b) Procesos de amenaza observados o inferidos que es probable causen } \\
\text { disminuciones continuas en la distribución geográfica, la calidad ambiental o las } \\
\text { interacciones bióticas dentro de los próximos } 20 \text { años. } \\
\text { (c) El ecosistema existe en } \leqq 5 \text { Localidades }\end{array}$ \\
\hline VU & 50 & $\begin{array}{c}\text { Y al menos } \\
\text { una de las } \\
\text { siguientes } \\
\quad(a-c):\end{array}$ & $\begin{array}{l}\text { (a) Una disminución continua observada o inferida en ANY OF: } \\
\text { i. una medida de la extensión especial apropiada para el ecosistema; OR } \\
\text { ii. una medida de la calidad ambiental apropiada para la biota nativa } \\
\text { característica del ecosistema; OR } \\
\text { iii. una medida apropiada de la interrupción de las interacciones bióticas de la } \\
\text { biota nativa característica del ecosistema. } \\
\text { (b) Procesos de amenaza observados o inferidos que es probable causen } \\
\text { disminuciones continuas en la distribución geográfica, la calidad ambiental o las } \\
\text { interacciones bióticas dentro de los próximos } 20 \text { años. } \\
\text { (c) El ecosistema existe en } \leqq 10 \text { Localidades }\end{array}$ \\
\hline
\end{tabular}

B3. El número de localidades es:

VU estocásticos dentro de un período de tiempo muy corto en un futuro incierto, y por lo tanto capaz de colapsar o de convertirse En Peligro Crítico dentro de un período de tiempo muy corto (B3 sólo puede conllevar a un listado VU).

C. Degradación ambiental sobre CUALQUIERA de los siguientes períodos de tiempo:

C1. Los últimos 50 años, basado en el cambio en una variable abiótica que afecta una fracción de la extensión del ecosistema y con severidad relativa, como se indica en la siguiente Tabla:
Severidad relativa $(\%)$

Extensión
$\quad(\%)$
$\geq 80$
$\geq 50$
$\geq 30$

C2a. Los próximos 50 años, basado en el cambio en una variable
abiótica que afecta una fracción de la extensión del ecosistema y con
severidad relativa, como se indica en la siguiente Tabla; 0

C2b. Cualquier período de 50 años, incluyendo pasado, presente y futuro, basado en el cambio en una variable abiótica que afecta una fracción de la extensión del ecosistema y con severidad relativa, como se indica en la siguiente Tabla:

C3. Desde 1750, basado en el cambio en una variable abiótica que afecta una fracción de la extensión del ecosistema y con severidad relativa, como se indica en la siguiente Tabla:

\begin{tabular}{|c|c|c|c|}
\hline \multirow[b]{2}{*}{$\begin{array}{c}\text { Extensión } \\
(\%)\end{array}$} & \multicolumn{3}{|c|}{ Severidad relativa (\%) } \\
\hline & $\geq 80$ & $\geq 50$ & $\geq 30$ \\
\hline$\geq 80$ & CR & EN & VU \\
\hline$\geq 50$ & EN & VU & \\
\hline \multirow[t]{2}{*}{$\geq 30$} & VU & & \\
\hline & \multicolumn{3}{|c|}{ Severidad relativa (\%) } \\
\hline $\begin{array}{c}\text { Extensión } \\
(\%)\end{array}$ & $\geq 90$ & $\geq 70$ & $\geq 50$ \\
\hline$\geq 90$ & CR & EN & VU \\
\hline$\geq 70$ & EN & VU & \\
\hline$\geq 50$ & vu & & \\
\hline
\end{tabular}


D. Interrupción de los procesos o interacciones bióticas sobre CUALQUIERA de los siguientes períodos de tiempo:

\begin{tabular}{|c|c|c|c|c|}
\hline \multirow{5}{*}{$\begin{array}{l}\text { D1. Los últimos } 50 \text { años, basado en el cambio en una variable biótica } \\
\text { que afecta una fracción de la extensión del ecosistema y con severidad } \\
\text { relativa, como se indica en la siguiente Tabla: }\end{array}$} & \multirow{3}{*}{$\begin{array}{c}\text { Extensión } \\
>80\end{array}$} & \multicolumn{3}{|c|}{ Severidad relativa $(\%)$} \\
\hline & & $\geq 80$ & $\geq 50$ & $\geq 30$ \\
\hline & & CR & EN & Vu \\
\hline & $\geq 50$ & EN & vu & \\
\hline & $\geq 30$ & Vu & & \\
\hline \multirow{2}{*}{$\begin{array}{l}\text { D2a. Los próximos } 50 \text { años, basado en el cambio en una variable biótica } \\
\text { que afecta una fracción de la extensión del ecosistema y con severidad } \\
\text { relativa, como se indica en la siguiente Tabla; } \mathbf{O}\end{array}$} & & \multicolumn{3}{|c|}{ Severidad relativa $(\%)$} \\
\hline & Extensión & $\geq 80$ & $\geq 50$ & $\geq 30$ \\
\hline \multirow{3}{*}{$\begin{array}{l}\text { D2b. Cualquier período de } 50 \text { años, incluyendo pasado, presente y } \\
\text { futuro, basado en el cambio en una variable biótica que afecta una } \\
\text { fracción de la extensión del ecosistema y con severidad relativa, como } \\
\text { se indica en la siguiente Tabla: }\end{array}$} & $\geq 80$ & CR & EN & VU \\
\hline & $\geq 50$ & EN & Vu & \\
\hline & $\geq 30$ & VU & & \\
\hline \multirow{5}{*}{$\begin{array}{l}\text { D3. Desde } 1750 \text {, basado en el cambio en una variable biótica que afecta } \\
\text { una fracción de la extensión del ecosistema y con severidad relativa, } \\
\text { como se indica en la siguiente Tabla: }\end{array}$} & & \multicolumn{3}{|c|}{ Severidad relativa $(\%)$} \\
\hline & Extensión & $\geq 90$ & $\geq 70$ & $\geq 50$ \\
\hline & $\geq 90$ & CR & EN & VU \\
\hline & $\geq 70$ & EN & Vu & \\
\hline & $\geq 50$ & VU & & \\
\hline
\end{tabular}

E. Un análisis cuantitativo que estima que la probabilidad de colapso del ecosistema sea:

\begin{tabular}{|l|l|}
\hline CR & $\geq 50 \%$ dentro de 50 años \\
\hline EN & $\geq 20 \%$ dentro de 50 años \\
\hline VU & $\geq 10 \%$ dentro de 100 años \\
\hline
\end{tabular}




\section{Apéndice 3. Códigos de colores}

\begin{tabular}{llrll} 
& & \multicolumn{3}{c}{ Código de color RGB } \\
\cline { 3 - 5 } Categoría & Color & R & G & B \\
\hline CO & Negro & 0 & 0 & 0 \\
CR & Rojo & 255 & 0 & 0 \\
EN & Anaranjado & 255 & 165 & 0 \\
VU & Amarillo & 255 & 255 & 0 \\
NT & Verde-Amarillo & 173 & 255 & 47 \\
LC & Verde & 0 & 128 & 0 \\
DD & Gris & 128 & 128 & 128 \\
NE & Blanco & 255 & 255 & 255 \\
\hline
\end{tabular}

